\title{
SEASONAL AND ANATOMICAL VARIATION IN COMPACT BONE REMODELING IN THE ADULT SHEEP
}

\author{
A Thesis \\ presented to \\ the Faculty of California Polytechnic State University \\ San Luis Obispo
}

\author{
In Partial Fulfillment \\ of the requirements for the Degree \\ Master of Science in Biomedical Engineering \\ by \\ Joseph Calcagno
}

December 2011 


\section{(C) 2011 \\ Joseph Calcagno \\ ALL RIGHTS RESERVED}




\section{COMMITTEE MEMBERSHIP}

TITLE:

AUTHOR:

DATE SUBMITTED:

COMMITTEE CHAIR: Dr. Scott Hazelwood SHEEP

Joseph Calcagno

December 2011
SEASONAL AND ANATOMICAL VARIATION IN COMPACT BONE REMODELING IN THE ADULT

COMMITTEE MEMBER: Dr. Lanny Griffin

COMMITTEE MEMBER: Dr. Clifford Les 


\section{ABSTRACT \\ SEASONAL AND ANATOMICAL VARIATION IN COMPACT BONE REMODELING IN THE ADULT SHEEP \\ Joseph Calcagno}

In order to determine whether ovine compact bone is suitable for study of osteoporosis, the remodeling parameters of the untreated animal must be fully characterized. Ovine compact bone is an attractive large animal model due to its similarities in size and bone remodeling to humans. However hormonal, exercise, and dietary changes due to seasonal changes can cause treatment effects to be hidden or superimposed on existing changes in the bone. In order to determine if any seasonal or anatomical variation occurred in the compact bone remodeling, 28 skeletally mature Columbia-Rambouillet cross ewes underwent a sham ovariectomy, OVX, as part of a larger study. The animals were divided into 4 seasonal groups (autumn, winter, spring, and summer) of 7 sheep. Each group underwent surgery and was sacrificed 12 months post-op in their respective seasons. The radii and ulnae were harvested and processed for analysis. Each radius/ulna was divided into 6 anatomical locations (craniolateral, cranial, craniomedial, caudolateral, caudal, and caudomedial). Histomorphometric analysis of the bone volume to tissue volume ratio, the percent of tissue and material remodeling, the mean secondary osteonal radius, and the number of cement line interfaces were quantified. Quantitative microdensitometry analysis was performed to determine the density of each region with respect to an aluminum standard. 2-way repeated measures ANOVAs were performed to 
determine seasonal and anatomical differences as well as a possible interaction between season and anatomical sectors. Significant seasonal and anatomical differences as well as seasonality within sectors were observed in the remodeling parameters. With the seasonal and anatomical changes in the untreated animal, comparison to other models must ensure treatment and follow up times as well anatomical locations are similar. This research provides a baseline of seasonal and anatomical variations in compact bone remodeling for the untreated adult ovine.

Keywords: Postmenopausal, Osteoporosis, OVX, Ovine, Remodeling, Bone 


\section{ACKNOWLEDGEMENTS}

I would like to thank my advisor Dr. Scott Hazelwood for his guidance and assistance throughout my project and coursework. Without his classes I would not have found a discipline that I enjoy. I would also like to thank Dr. Clifford Les for providing me the opportunity to work on this research and guidance to its completion. I would like to thank the College of Veterinary Medicine and Biomedical Sciences at Colorado State University as well as Henry Ford Medical Hospital for their assistance in this research. Funding was provided by $\mathrm{NIH}-$ NIAMS AR 47434. Finally I would like to thank my family and friends for their never ending support and encouragement during my career at Cal Poly. Without their support I would not be where I am today. 


\section{TABLE OF CONTENTS}

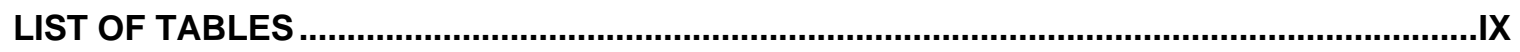

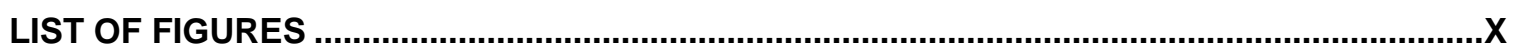

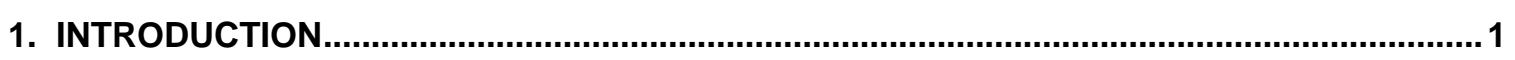

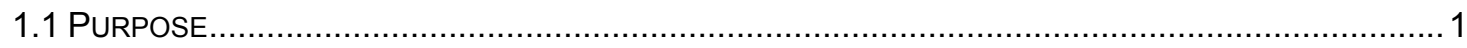

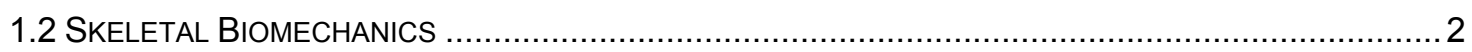

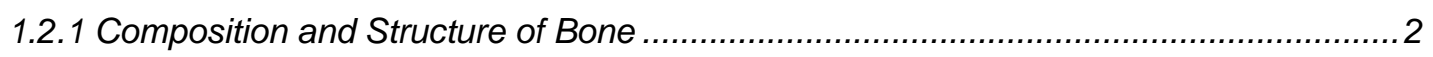

1.2.2 Biomechanical Properties of Bone .................................................................. 5

1.2.3 Quantitative Analysis of Skeletal Biomechanics ................................................. 9

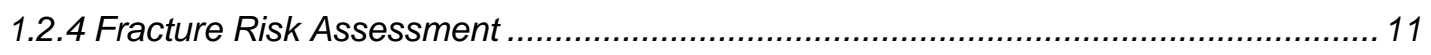

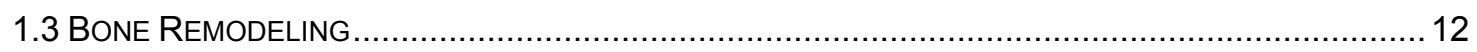

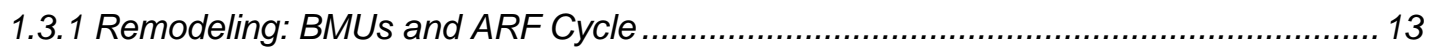

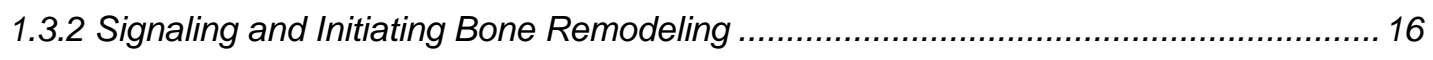

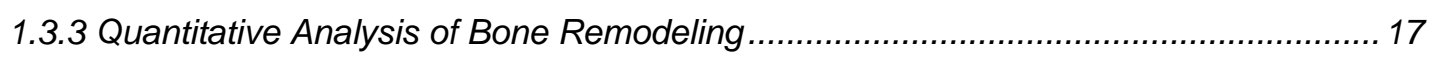

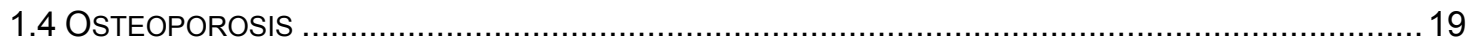

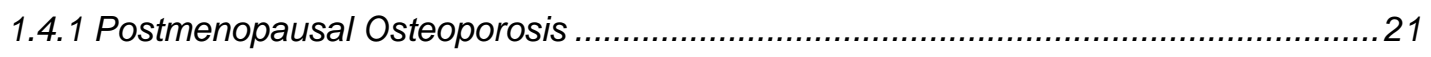

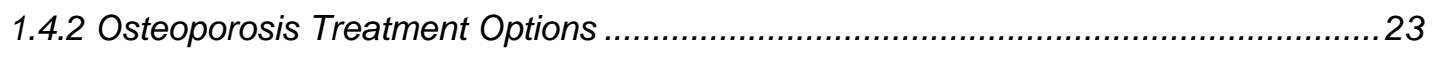

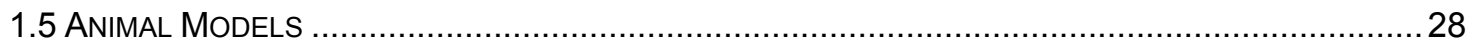

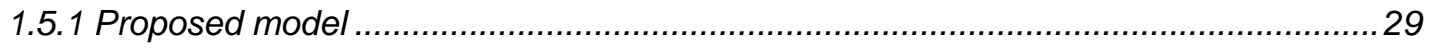

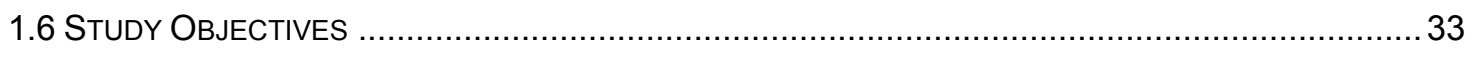

2. METHODS

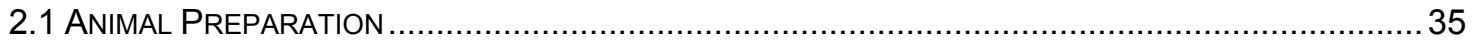

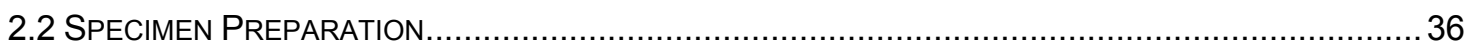

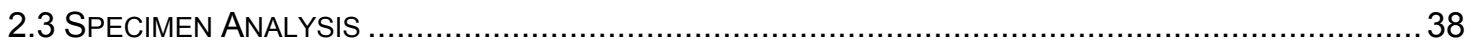

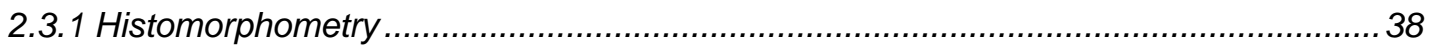

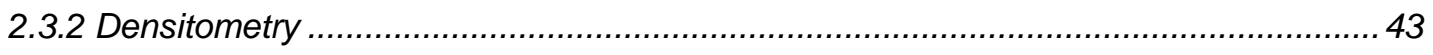

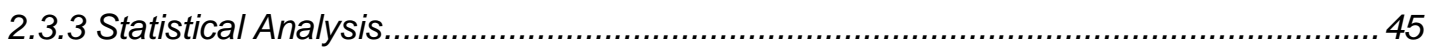

3. RESULTS

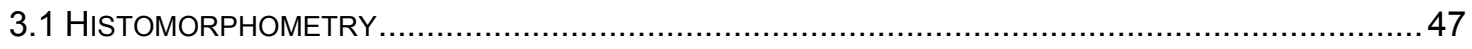




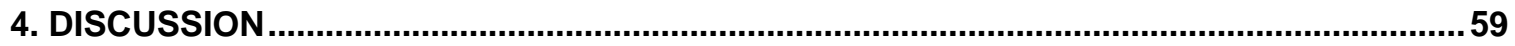

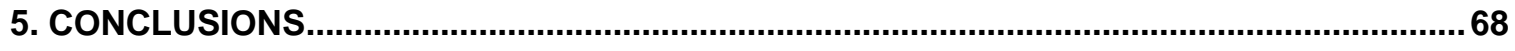

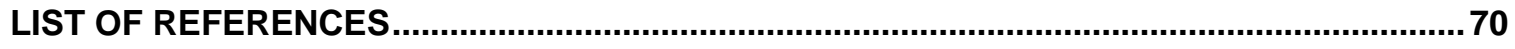

APPENDIX A 12 MONTH CONTROL HISTOMORPHOMETRY DATA ...................................... 74

APPENDIX B 12 MONTH CONTROL DENSITOMETRY DATA ….........................................79

APPENDIX C DENSITOMETRY ALUMINUM STEP WEDGE KEYS........................................ 85

APPENDIX D DENSITOMETRY SECTOR AND STEP WEDGE IMAGES ................................93 


\section{LIST OF TABLES}

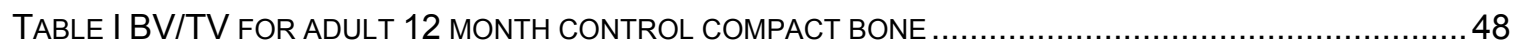

TABLE II PERCENT REMOdELED TISSUE FOR AdULt 12 MONTH CONTROL COMPACT BONE..................... 48

TABLE III PERCENT REMOdELED MATERIAL FOR ADULt 12 MONTH CONTROL COMPACT BONE................4 49

TABLE IV MEAN SECONDARY OSTEONAL RADIUS ( $\mu$ M) FOR ADULT 12 MONTH CONTROL COMPACT BONE 49

TABLE V CEMENT LINE INTERFACES (TISSUE) FOR ADULT 12 MONTH CONTROL COMPACT BONE ............50

TABLE VI CEMENT LINE INTERFACES (MATERIAL) FOR ADULT 12 MONTH CONTROL COMPACT BONE ........50

TABLE VII P VALUES FOR 2-WAY RANDOM MEASURE ANOVA OF REMODELING VARIABLES ...................51

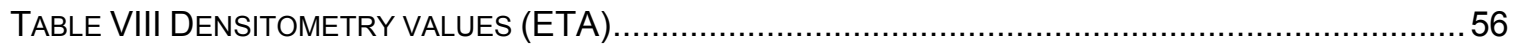




\section{LIST OF FIGURES}

FIGURE 1 SHOWS IMPORTANT FEATURES OF A TYPICAL LONG BONE[6]

FIGURE 2 THE RELATIONSHIP BETWEEN ULTIMATE COMPRESSIVE STRESS, POROSITY, AND APPARENT

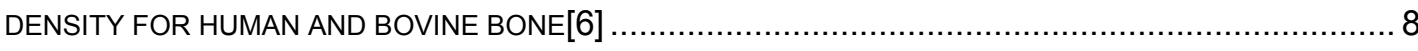

FIGURE 3 SHOWS MERZ GRIDS WITH AND WITHOUT MICROMETERS[9] ........................................... 10

FIGURE 4 SHOWS A TYPICAL MICRO-CRACK (ARROWS) AS SEEN IN A $100 \mu \mathrm{M}$ THICK HISTOLOGIC CROSS SECTION OF HUMAN CORTICAL BONE [6]

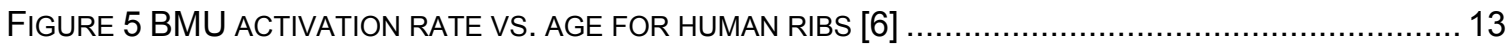

FIGURE 6 SHOWS BOTH OSTEOCLASTS AND OSTEOBLASTS WHICH MAKE UP A BMU[11] .................... 14

FIGURE 7 UPPER: SCHEMATIC DIAGRAM OF BMUS IN A CROSS SECTION OF CORTICAL BONE. BLACK, IRREGULARLY SHAPED BMUS ARE RESORPTION SPACES (R). BMUS WITH LARGE CANALS ARE REFILLING; THEY HAVE EITHER SINGLE LABEL $(F, S)$ OR A DOUBLE LABEL $(F, D)$. COMPLETED osteons haVe SMALl CANALS (C); SOME OF THESE hAVE A Single LABEL (C,S). LOWER: A SINGLE BMU IN THE LAST STAGES OF REFILLING IS DEPICTED. IT HAS A DOUBLE LABEL; THE DISTANCE BETWEEN THE LABELS IS MEASURED AS SHOWN $\left(D_{L}\right)[6]$

FIGURE 8 SHOWS SCANNING ELECTRON MICROGRAPHS TO SHOW STRUCTURE OF L3 VERTEBRA IN A 31 YEAR OLD WOMAN (TOP) AND IN A 70 YEAR OLD WOMAN (BOTTOM). NOTE THAT MANY OF THE PLATE-LIKE STRUCTURE HAVE BECOME CONVERTED TO THIN RODS [18]

FIGURE 9 REGULATION OF IL-1, IL6, AND TNF PRODUCTION. EACH ARROW INDICATES A STIMULATORY EFFECT OF A CYTOKINE ON ITS OWN SYNTHESIS, OR THE SYNTHESIS OF ANOTHER CYTOKINE. DEMONSTRATED SUPPRESSION OF THE STIMULATED SYNTHESIS OF IL-6 AND TNF BY ESTROGEN ("E") IS INDICATED BY FILLED OCTAGONS, AND THE POTENTIAL SUPPRESSION OF IL-6 INDUCED BY IL-6 BY ESTROGEN IS INDICATED BY AN OPEN OCTAGON. THE INTERDEPENDENT NATURE OF THIS REGULATORY CIRCUIT MEANS THAT A SIGNIFICANT INCREASE IN ANY ONE OF THE CYTOKINES DEPENDS ON THE PRESENCE OF THE OTHERS. [21] ...... 22 
FIGURE 10 MEAN BONE DENSITY LOSS BY ESTROGEN USER GROUP. WOMEN IN ALL ESTROGEN USER GROUPS LOST BONE DENSITY AT BOTH THE TOTAL HIP AND CALCANEUS. ASTERISKS INDICATE VALUES SIGNIFICANTLY DIFFERENT FROM THOSE OF NEVER USERS FROM MULTIPLE LINEAR REGRESSION MODELS ADJUSTED FOR AGE AND WEIGHT $(P<.05)[20]$

FiguRe 11 PROBABILITY of HIP FRACTURES. PROBABILITIES ARE ADJUSTED FOR AGE AND WEIGHT. $[20]$

FIGURE 12 MEAN PERCENT CHANGES FROM BASELINE IN BONE MINERAL DENSITIES IN THE SPINE, TOTAL HIP, FEMORAL NECK, AND FEMORAL TROCHANTER [26]

Figure 13 (A) Primary bone from a 3 YeAR old eWE. (B) HAVERSiAn REMOdeling from the CAUDAL FEMORAL CORTEX OF AN 8 YEAR OLD EWE[30]

FIGURE 14 THREE- DIMENSIONAL TRABECULAR MICRO-ARCHITECTURAL IMAGES OF SHEEP FEMORAL NECKS. FROM LEFT TO RIGHT WERE SHAM, GROUP 1 (6 MO), GROUP 2 (12 MO) [38].....

FIGURE 15 APPROXIMATE ANATOMICAL RADIAL-ULNAR SECTORS DIVIDED BY THE GREY LINES. THE CRANIAL SECTOR IS AT THE TOP RIGHT AND LATERAL IS THE TOP LEFT SIDE OF THE IMAGE.

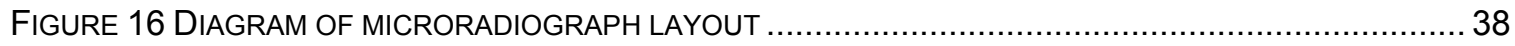

FIGURE 17 MERZ GRID POINTS LOCATED ON POROSITY

FIGURE 18 C5901 SHOWING EXAMPLES OF POROSITY DUE TO VOLKMANN'S CANALS(2), HAVERSIAN

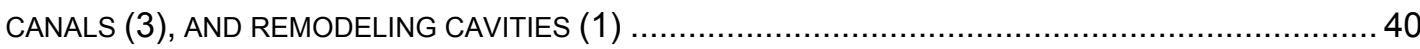

FIGURE 19 MERZ GRID POINTS LOCATED ON SECONDARY BONE

FIGURE 20 COUNTING THE NUMBER OF SECONDARY OSTEONS WITHIN THE MERZ GRID......

FIGURE 21 MERZ GRID USED tO COUNT THE NUMBER OF CEMENT LINE INTERFACES WITH SECONDARY OSTEONS

FIGURE 22 IMAGES OF EACH LEVEL OF AN ALUMINUM STEP WEDGE, INCREASING THICKNESS LEFT TO RIGHT, TOP TO вотTOM (0.025MM, .050Mm, 0.075Mm, 0.100Mm, 0.125Mm, AND 0.150Mm RESPECTIVELY).

Figure 23 C4407, CRANiolateral SeCtor. Showing thicker REgions at the EdGes of the SAMPLE (DARKER REGIONS) 45

FIGURE 24 MEAN BV/TV VALUES AND STANDARD DEVIATIONS FOR EACH SEASON 51 
Figure 25 ANATOMIC VARIABILITY IN THE PERCENTAge OF tisSUe REMODELED. THE VALUES For EACH SECTOR ARE ORIENTED IN THEIR APPROXIMATE ANATOMICAL LOCATION ON THE POLAR GRAPH. DISTANCE RADIALLY AWAY FROM CENTER DETERMINES THE VALUE WITH RESPECT TO THE SCALE.

Figure 26 ANATOMICAL VARIABILITY IN THE PERCENTAGE OF BONE MATERIAL REMOdELED. ThE VALUES FOR EACH SECTOR ARE ORIENTED IN THEIR APPROXIMATE ANATOMICAL LOCATION ON THE POLAR GRAPH. DISTANCE RADIALLY AWAY FROM CENTER DETERMINES THE VALUE WITH RESPECT TO THE SCALE.

FIGURE 27 SEASONAL VARIABILITY IN THE MEAN SECONDARY OSTEONAL RADIUS WITH STANDARD DEVIATIONS

FIGURE 28 ANATOMIC VARIABILITY WITHIN SEASONS FOR THE NUMBER OF TISSUE CEMENT LINE INTERFACES. THE VALUES FOR EACH SECTOR ARE ORIENTED IN THEIR APPROXIMATE ANATOMICAL LOCATION ON THE POLAR GRAPH. DistANCE RADIALLY AWAY FROM CENTER DETERMINES THE VALUE WITH RESPECT TO THE SCALE.

FIGURE 29 ANATOMIC VARIABILITY WITHIN SEASONS FOR THE NUMBER OF BONE CEMENT LINE INTERFACES. THE VALUES FOR EACH SECTOR ARE ORIENTED IN THEIR APPROXIMATE ANATOMICAL LOCATION ON THE POLAR GRAPH. DistanCE RADIALLY AWAY FROM CENTER DETERMINES THE VALUE WITH RESPECT TO THE SCALE.

FIGURE 30 SEASONAL VARIABILITY IN DENSITY MEASURED IN EQUIVALENT THICKNESS OF ALUMINUM,

ETA WITH STANDARD DEVIATIONS.

FIGURE 31 ANATOMICAL VARIABILITY IN DENSITY MEASURED IN EQUIVALENT THICKNESS OF aluminUm, ETA. THE VALUES FOR EACH SECTOR ARE ORIENTED IN THEIR APPROXIMATE ANATOMICAL LOCATION ON THE POLAR GRAPH. DistanCE RADIALLY AWAY FROM CENTER DETERMINES THE VALUE WITH RESPECT TO THE SCALE.

Figure 32 Representative images of the tibia (Left) AND RADIUS (RIGHT). A, SCOUt VIEW DEMONSTRATING THE REFERENCE LINE POSITION (SOLID LINE) AND THE MEASUREMENT SITE

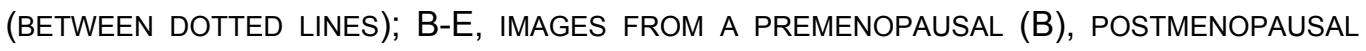


OSTEOPENIC (C), POSTMENOPAUSAL OSTEOPOROTIC (D), AND POSTMENOPAUSAL SEVERE OSTEOPOROTIC (E) SUBJECT [48]

FIGURE 33 YIELD STRENGTH AND STIFFNESS OF COMPACT BONE SAMPLES FROM CONTROL AND OVX GROUPS [2]

FIGURE 34 SEASONAL VARIABILITY IN 25OHD AND S-PTH (UNIVARIATE ANALYSIS). VALUES ARE GIVEN AS PERCENT CHANGE FROM THE ANNUAL MEAN ( \pm SEM) [53] 


\section{Introduction}

\subsection{Purpose}

Osteoporosis is a major public health threat in the United States. Over 40 million people already have the disease or are at high risk due to low bone mass [1]. Osteoporosis can occur in both men and women but is more prevalent in older women. Certain risk factors such as diet and exercise are shown to reduce the chances of developing the disease. Around the age of 30 , bone formation begins to slow and bone resorption increases. Bone resorption has been shown to increase significantly for women after menopause [1]. With a decrease in bone mass the risk of fracture increases [2]. In 2002, between $\$ 12.2$ billion and $\$ 17.9$ billion was spent in the United States on hospitals and nursing homes for people with osteoporosis-related and associated fractures [1]. In addition to medical costs, there is a serious impact on quality of life for patients who fracture their bones. Decreased level of function is a critical issue when osteoporotic patients incur fractures. Chance of death after an osteoporotic fracture can reach up to $35 \%$ depending on the location of the fracture $[3,4]$.

Due to the high prevalence of osteoporosis, particularly postmenopausal women, a large amount of research is directed to the prevention, treatment, or reversal of the disease. The long term goal of this study is to analyze the ovariectomized Columbian-Rambouillet sheep as a model for postmenopausal osteoporosis. This research will quantify compact bone remodeling the normal adult ovine. This introduction will provide the basics behind bone anatomy, physiology, and 
mechanical properties as they relate to fracture risk. It will discuss the remodeling process of bone which is a critical process that affects the rate of bone loss in patients. Osteoporosis and particularly postmenopausal osteoporosis will be discussed along with potential treatment options. The current state of research in the area along with current animal models will be presented. Finally, the compact bone of the untreated adult sheep will be presented as a baseline model for metabolic disease research.

\subsection{Skeletal Biomechanics}

\subsubsection{Composition and Structure of Bone}

Bone provides a framework for motion, protects the body from trauma, acts as a reservoir for calcium, and houses marrow which produces blood and stem cells [5]. Bone is a dynamic tissue that is continually adjusting to its physiologic and mechanical environment [6]. Bone is able to sense changes in the environment through changes in the forces exerted on the tissue. These changes in forces cause bone to modify its structure in order to accommodate the load and prevent damage to the tissue.

Bone is a nearly acellular material. Its mechanical properties reside primarily with the extracellular matrix components discussed later. However, the cellular components of bone tissue play an important role in its continual maintenance [6]. Bone consists of four specialized cell types in order to maintain the homeostasis of the dynamic tissue. Osteoblasts are the cells recruited to synthesize or lay down new bone. Osteoblasts are mononuclear cubodial cells 
differentiated from mesenchymal cells. Osteocytes are former osteoblasts that have embedded themselves into the bone matrix. Bone lining cells are also former osteoblasts that cover bone surfaces that are not in the process of remodeling. Osteoclasts are recruited to remove bone. Osteoclasts are multinuclear cells originating from the formation of monocytes originating in bone marrow [5]. The role of these cells in the remodeling of bone will be discussed in a later section.

The structure of bone can be broken down into two categories. Trabecular bone (also referred to as cancellous or spongy bone) is the porous bone that is found in the cubodial bones, flat bones, and the ends of long bones [6]. This bone is a loose framework that is filled with marrow. The struts of the matrix are the trabeculae. Cancellous bone on average has a porosity of $75 \%-95 \%$ [6]. Compact bone (also referred to as cortical bone) is the dense structure in the shafts of long bones and surrounding the trabecular bone. Compact bone on average has a porosity of $5 \%-10 \%$ [6]. The compact bone provides structural integrity for the skeletal system. Figure 1.1 shows important features of a typical long bone. 


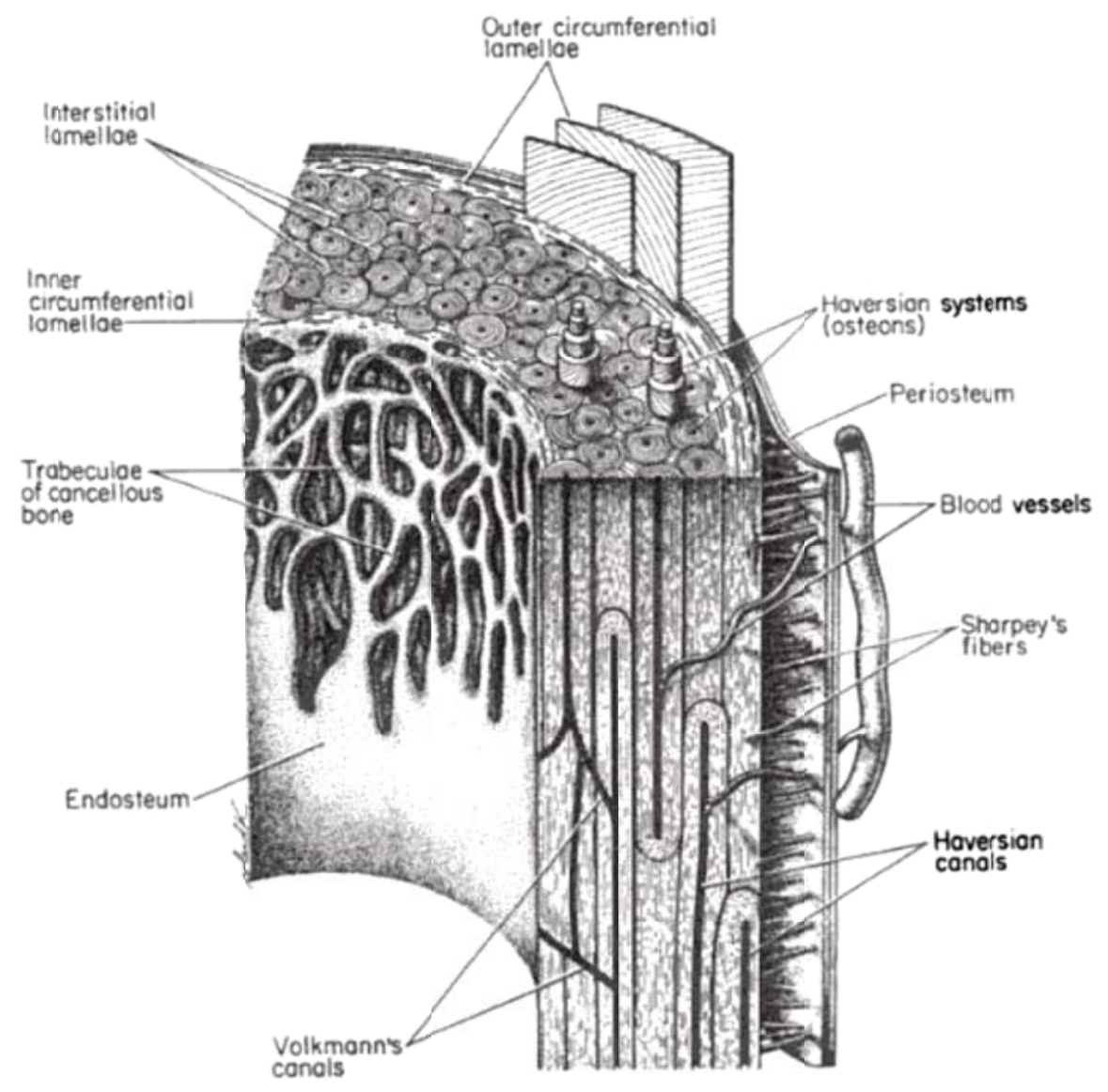

Figure 1 shows important features of a typical long bone[6]

The porosities in the compact bone primarily come from three features: Haversian canals, Volkmann's canals, and resorption cavities. Haversian canals are aligned approximately longitudinally in the long bone diaphysis. These canals house the blood vessels and nerves supplying the bone. They are approximately $50 \mu \mathrm{m}$ in diameter which is equivalent to the diameter of human hair [6]. The Volkmann's canals are the lateral canals that connect Haversian canals to each other and the surrounding tissue outside of the bone. Resorption cavities are regions of bone in the initial stage of the remodeling process. Osteoclasts are removing bone creating a void in the tissue. 
Compact bone can be classified as primary or secondary bone. Primary bone is the original bone laid down during growth. Primary bone can be further classified as circumferential lamellar bone. Lamellar bone is laid down slow and parallel to the bone surface. When a blood vessel is incorporated into the lamellar bone, a primary osteon is formed as well as a primary Haversian canal at its center [6]. These osteons have a circular appearance when cross sectioned. The other form of primary bone is plexiform bone. Plexiform bone occurs during a rapid bone growth. In this case lamellar bone mixes with the woven or trabecular bone creating a brick like appearance [6]. Secondary bone is a result of the resorption and replacement of bone. When new lamellar bone replaces older bone secondary osteons are formed. This occurs due to the remodeling process discussed later. New bone is formed in the resorption spaces. The secondary osteons are approximately $200 \mu \mathrm{m}$ in diameter and contain a Haversian canal at its center $[5,6]$. Surrounding the secondary osteon is a boundary known as the cement line. In most adult humans, cortical bone is almost entirely secondary bone due to the constant turnover of bone [6].

\subsubsection{Biomechanical Properties of Bone}

Bone is primarily made up of its mineral phase, mainly hydroxyapatite. The mineral content is a crystalline structure with a hexagonal symmetry [6]. It also contains collagen, non-collagenous proteins and proteoglycans, and water [5]. The collagen in bone is primarily type I. The collagen provides loci for the deposition of the mineral crystals [6]. The function of the proteoglycans and non- 
collagenous proteins is still unclear, but it is believed they are involved in mineral uptake and homeostasis of the bone tissue [6].

Cortical bone and trabecular bone have significantly different mechanical properties on a millimeter scale. However the trabecular bone is only $20-30 \%$ less stiff than cortical bone on a micrometer scale [5]. On the nanometer scale, bone tissue acts like a reinforced fiber with the hydroxyapatite providing the compressive strength and the collagen providing flexibility and strength in tension.

Cortical bone has a longitudinal arrangement with the long axis of the bone. This orientation of the lamella provide strong anisotropic properties [5]. The properties of cortical bone focus on the strength in the longitudinal direction creating strength for compressive loads. Considering most loading conditions of the skeletal system, it is critical for the primary arrangement of cortical bone to be strongest in compression. Cortical bone is a viscoelastic material making the loading rate important for its material properties [5]. Cortical bone is stiffer and stronger at high loading rates. During traumatic rapid loading of bone, it is important that the bone can accommodate this change while also maintaining flexibility at low loading rates.

Trabecular bone mechanical properties vary depending on densities, structural orientation, and the amount of tissue [5]. Density and architecture vary depending on location, age, and disease. Due to the mesh architecture of trabecular bone it allows for collapse under large compressive strains at a 
constant stress [5]. This allows for a large amount of energy to be absorbed. For the purposes of this study, only cortical bone was observed. However it is important to understand the variation in architecture and their effects on the mechanical properties.

Cortical bone, especially human cortical bone, is an osteonal structure. This is due to the constant turnover of both primary and secondary bone. With the addition of primary and secondary osteons, there is a decrease in the strength of the bone [6]. Reilly and Burstein tested Haversian bone and primary cow bone. They showed that the osteonal bone showed a $20 \%$ decrease in strength in both compression and tension [6]. This study and others supported the fact that the remodeled osteons were mineral deficient as compared to the primary bone [6]. The mineral base of bone provides the foundation for its structural integrity. Hert and coworkers showed that fully mineralized osteonal bovine bone and primary bone demonstrated similar strength in compression [6]. Carter and colleagues indicated that it is not simply a reduction in density that causes decreased strength but also increased levels of porosity and possibly orientation of the collagen fibers [6]. Burr et al. found that the cement line contained $85 \%-90 \%$ of the calcium and phosphorus found in adjacent bone lamella [6]. These results present the possibility that the cement line is more compliant and viscoelastic than the bone matrix. Osteonal bone shows significant amounts of plastic deformation when loaded to failure with greatest deformation when loaded parallel to the collagen fibers [6]. Reilly demonstrated that primary bone exhibits less plastic deformation than osteonal bone. It can be speculated that this is due 
to slippage along the cement line. With constant turnover of bone the mechanical properties are continuously changing with osteonal structure having significant affects on the structural integrity of the bone.

Other than the osteons themselves, other characteristics of osteonal bone affect its mechanical properties. Porosity in most materials will have a detrimental effect on the material strength. This is true for bone as well. At the micrometer scale Haversian canals and Volkmann's canals account for the majority of the porosity in cortical bone. Porosity also occurs from osteoclasts removing old or damaged bone. The level of porosity in bone is the ratio of void (or pore) volume to total volume [6]. The effect of porosity on the ultimate stress of bone is shown in Figure 2. As porosity increases significant decreases in strength occur.

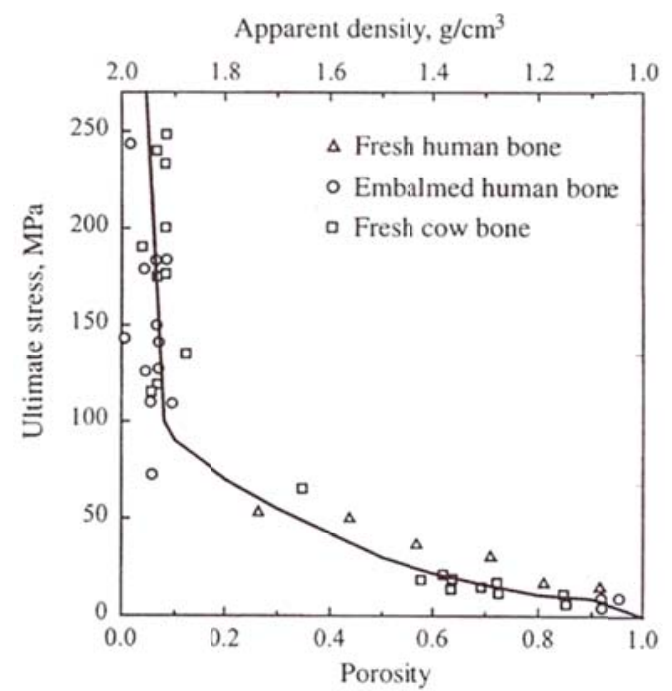

Figure 2 The relationship between ultimate compressive stress, porosity, and apparent density for human and bovine bone[6]

Mineralization plays an important level on the mechanical properties of bone. Changes in mineralization can occur due to trauma, age, or disease [6]. All of 
these reduce the level or rate of mineralization in the newly formed osteonal bone. With decreased mineral content in the bone, the ability to withstand high compressive loads without failing decreases.

Density is a common property when discussing bone material properties. The common significance of density is the specific gravity of the solid matrix. However the apparent density of bone is mass per unit volume of bulk bone [6]. This provides a more significant measurement of density as it relates to bone material properties. Since the measurement is volume of bulk bone it would include the Haversian canals, marrow spaces, and soft tissue spaces [6]. This makes the apparent density dependent on the porosity and the mineral content of the bone.

\subsubsection{Quantitative Analysis of Skeletal Biomechanics}

It is important to quantitatively analyze the skeletal system. There are invasive and non-invasive ways to analyze bone structure and material properties. Micro and quantitative computed tomography can capture a three dimensional representation of bone [7]. This methodology can provide a detailed image and non destructive analysis of the bone tissue from the millimeter to micrometer scale [7]. Bone mass can be measured noninvasively using photon absorptiometry developed by Mazess and Cameron [6]. The method uses beams of photons scanning across the bone. The intensity of the radiation attenuation from the bone is collected and analyzed. This method was improved upon with the dual energy $\mathrm{x}$-ray absorptiometry (DEXA) which replaces the radionuclide source with low-energy X-rays [6]. Methods using ultrasound have proven 
promising for analyzing mechanical properties of trabeculae based on the critical reflection angle [8].

Stereology is the process of analyzing a three dimensional structure using two dimensional structures [6]. This is a common method of invasive testing. Histological samples are developed and analyzed using microscopy. This is an effective way to quantify porosity levels of bone. Various ways to estimate porosity have been developed. One method involves a grid of points. The ratio of points on porosity to the total number of points is used to estimate the percentage of porosity in a section [6]. Other grids involve micrometers in order to measure different structures such as osteonal diameters. Various types of grids have been developed to make multiple measurements using the same grid. A Merz grid (Figure 3) consists of 36 point marks as well as 6 sinusoidal lines. They can come with or without micrometers.
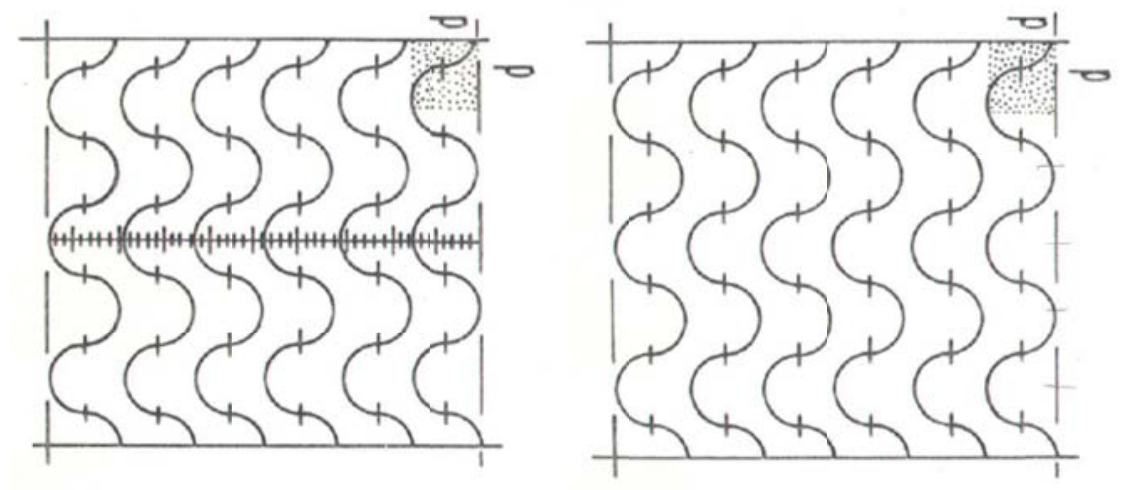

Figure 3 shows Merz grids with and without micrometers[9] 


\subsubsection{Fracture Risk Assessment}

Fracture mechanics considers the conditions under which a flaw or crack in a load bearing structure grows and causes catastrophic failure [6]. Bone is a load bearing structure just as is a concrete bridge. Understanding bone structure and mechanical properties is critical for determining the risk of fractures in bone. Bone will fail under various conditions. If the bone is loaded to a level beyond its ultimate stress then a fracture will occur. This occurs during trauma or impact loading of the bone. Bone can also fail at stress levels well below the yield stress from the growth of preexisting cracks due to fatigue [5]. Bone constantly has micro-cracks developing throughout its structure (Figure 4).

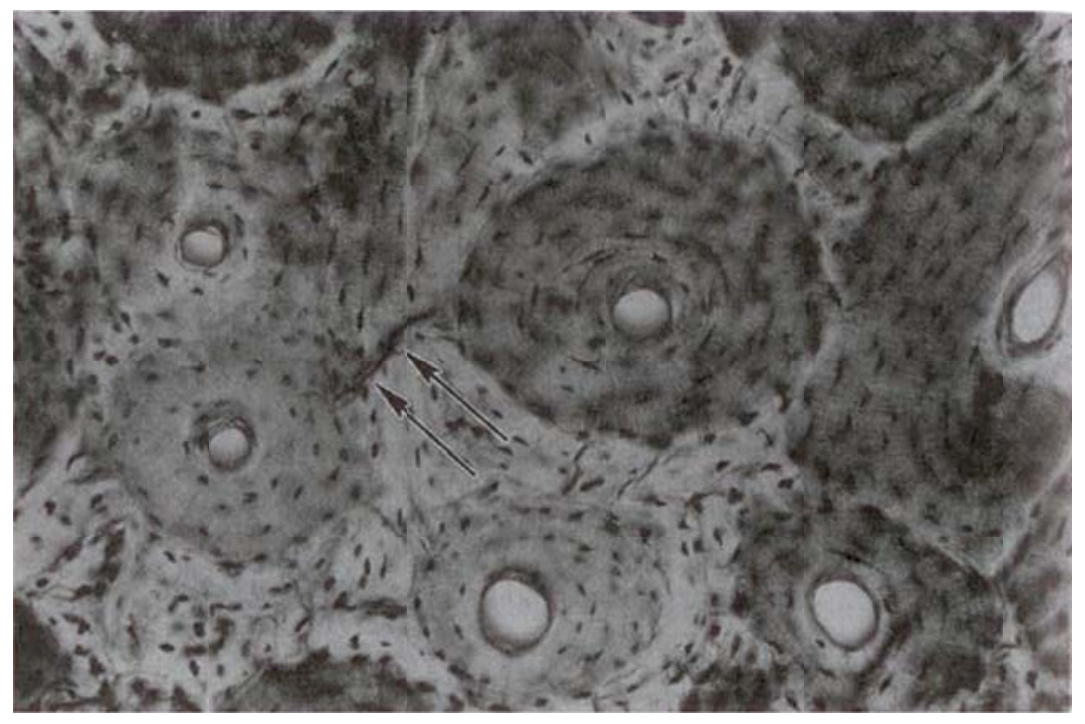

Figure 4 shows a typical micro-crack (arrows) as seen in a $100 \mu \mathrm{m}$ thick histologic cross section of human cortical bone [6]

In a normal healthy bone, these cracks will be continually removed as bone turned over. However, with age in healthy bone, turnover rates can decrease causing an accumulation in micro-cracks. These cracks are located in areas of increased stress concentration and crack to release the stress. If excessive 
loading at the crack location occurs the crack is removed, stress concentrations will rise and propagate the crack. [6]. Two general types of fractures will occur from these locations: fast fractures and fatigue fractures [5]. During a fast fracture there is a rapid expansion of a crack normally due to trauma or an excessive loading condition. Fatigue fractures occur due to repeated cyclic application of a sub-maximal loading condition.

Different researchers are looking at the correlation between bone mechanical properties and the prevention of crack development or propagation. The theory of linear elastic fracture mechanics is commonly used to describe fractures in bones. However others have provided some evidence to suggest that a nonlinear theory can be applied which correlates matrix constituents, micro-crack characteristics, and trabecular architecture [10].

\subsection{Bone Remodeling}

Bone will undergo two processes to add or remove bone. Modeling and remodeling involve the same cells and incorporate the formation and removal of bone. However, there are significant differences in the function and goals of these cells during these two processes. Osteoblasts and osteoclasts are the prime movers in the modeling and remodeling. As discussed earlier osteoblasts lay down new bone and osteoclasts remove bone.

Modeling results in a change in the bone size, shape, or both [6]. Modeling involves independent actions of the osteoclasts and osteoblasts. Modeling rates decrease after skeletal maturity. Remodeling does not normally affect the size 
and shape of bone. Remodeling is primarily used to remove old or damaged bone. Osteoblast and osteoclast function is coupled and has a defined beginning and end [6]. Bone remodeling is constant throughout life. However the rate does decrease with age and disease (Figure 5). Osteonal remodeling replaces approximately $5 \%$ of human cortical bone each year [6].

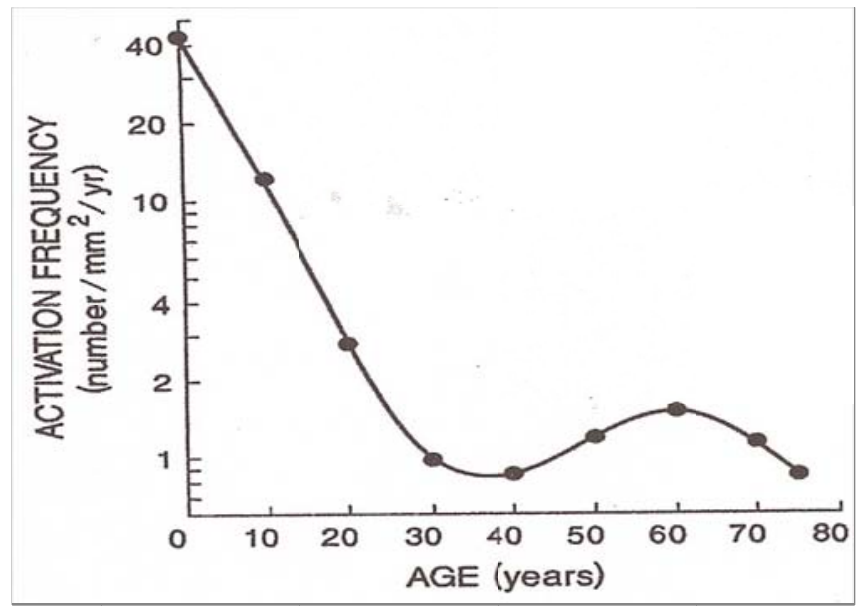

Figure 5 BMU activation rate vs. age for human ribs [6]

\subsubsection{Remodeling: BMUs and ARF Cycle}

Remodeling is performed by the coupled interaction of osteoclasts and osteoblasts. When micro-damage is present in bone, this damage is removed by the remodeling process. Signaling of this process will be discussed later. When this signal is initiated, monocytes fuse to form osteoclasts near the region of the damage [6]. With osteoclasts localized in the region they begin to develop a resorption space. The osteoclasts will develop a tunnel approximately $200 \mu \mathrm{m}$ in diameter. Following the osteoclasts are osteoblasts forming bone to refill the resorption space. This group of osteoclasts and osteoblasts is known as a basic multicellular unit, or BMU [6]. Once the osteoblasts enclose themselves in new 
bone they become osteocytes. Figure 6 depicts a typical BMU with the cutting cone being the region of resorption. Since this occurs deep within the bone a constant blood supply is needed. Osteoblasts do not fill the space completely leaving a Haversian canal providing the vasculature for the new osteon.

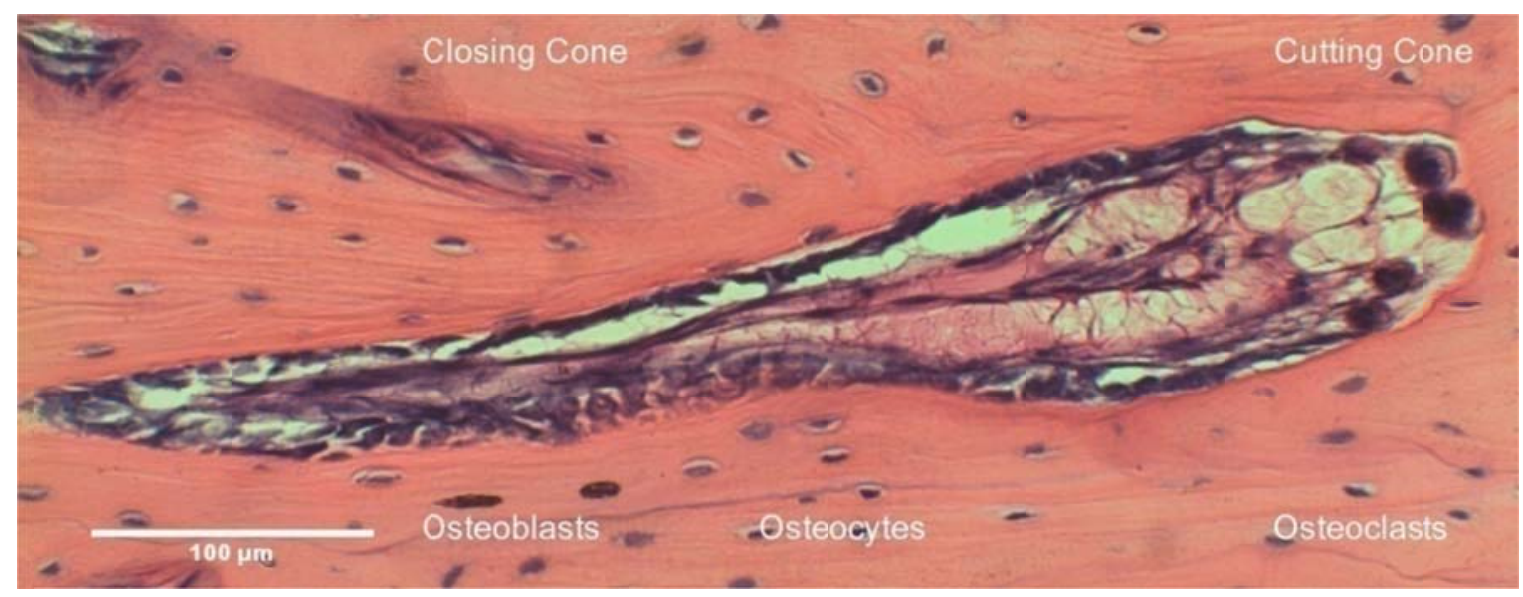

Figure 6 shows both osteoclasts and osteoblasts which make up a BMU[11]

Remodeling does not occur immediately and is not completed in one step. The BMU has three stages until completion: activation, resorption, and formation (ARF) [6]. The time periods for each of these phases to occur are fairly well defined. The two ways to envision these periods are as a moving observer following cells from initiation to completion or as a stationary observer monitoring as cells travel through cross sections of bone. Remodeling is commonly monitored as a stationary observer because bone is routinely analyzed through cross sections [6].

The ARF cycle is broken down further into 6 steps to describe the sequence of events during normal bone remodeling. The steps are described from the perspective of a cross section of bone and are classified as activation, resorption, 
reversal, formation, mineralization, and quiescence [6]. Initiation and signaling of the remodeling process is not the same as the activation phase of the forming resorption space. The activation phase is the process of osteoclasts already recruited, to pass through a plane of observation [6]. Initiation and signaling of the need for remodeling to occur will be discussed in a later section. During the resorption phase the osteoclasts resorb bone at an approximate rate of $40 \mu \mathrm{m}$ per day along the cutting cone shown in Figure 6. The reversal stage is the transition of osteoclastic activity to osteoblastic activity [6]. This process can take several days. The edge of the reversal area is known as the cement line or reversal line. Approximately 30 days are required for humans to pass through the combined resorption and reversal periods [6]. During the formation phase osteoblasts lay down circumferential lamella at a radial closure rate of about 2 $\mu \mathrm{m}$ per day [6]. When completed the osteoblasts leave a Haversian canal of 40$50 \mu \mathrm{m}$ in diameter in order to ensure proper vascularization of the bone tissue. This formation process for adult humans takes an average of 3 months. Following the deposition of new bone by the osteoblasts, mineralization of the organic matrix occurs. This process occurs after a 10 day lag period known as the mineralization lag time [6]. When mineralization occurs, approximately $60 \%$ of the mineral content is laid down in the first few days and is known as primary mineralization [6]. The last $40 \%$ of mineralization occurs at a slower rate over a period of 6 months to several years during secondary mineralization. The difference in mineralization between the high-density removed bone and the newly remodeled low-density bone is enough to change the mechanical 
properties of the new osteon and the surrounding older tissue [6]. After bone removal and formation of the secondary osteon occurs the bone enters a period of quiescence. The osteoclasts are removed from the area through osteoclast apoptosis and the osteoblasts form osteocytes or bone lining cells in the Haversian canal [12].

\subsubsection{Signaling and Initiating Bone Remodeling}

The theory of bone remodeling is controversial and several different theories have been published and supported by scientific work. Wolff's law refers to bone's ability to sense mechanical loads in which it bears and adjust its architecture to sustain these loads [6]. Researchers have developed models to simulate bones ability to adjust to environmental loads [13]. These models assume that remodeling will remove bone when mechanical stimulus is too low and add bone when the stimulus is too high. Other researchers have suggested that osteocytes are mechanosensing cells that can produce signals proportional to mechanical loading through interstial fluid [14], stretch activated ion channels, or electric potentials [15]. A third concept suggested is that osteocytes sense fatigue damage and activate remodeling in order to remove the damage [16]. A key concept in the remodeling process is that cells in the osteoblast lineage control the initiation of remodeling [15]. Work has been performed to show a correlation between osteocytes' apoptosis and remodeling parameters further suggesting osteocytes role in the remodeling initiation [17]. All of these concepts create controversial theories for the initiation of bone remodeling. Work has been done to relate the key concepts and develop a unified theory of bone remodeling 
Martin [15] proposed a model that incorporates five assumptions or hypotheses to unify the theory of remodeling. The first assumption is that bone lining cells are the remodeling activators. Second, osteocytes produce and transmit from cell to cell a signal proportional to strain or another correlate of mechanical loading. Third, osteocytes send an inhibitory signal to osteoblasts that reduces their rate of bone formation. Finally, bone lining cells activate remodeling unless inhibited by this same osteocytic signal [15]. This model is only relevant to remodeling but a connection to modeling must be present due to the same osteocytic cell interactions.

\subsubsection{Quantitative Analysis of Bone Remodeling}

Osteonal remodeling is analyzed using histologic sections of bone. This was first demonstrated by Frost in the cortex of the human rib [6]. Currently human remodeling is analyzed using bone biopsies from the iliac crest. In order to perform histomorphometric analysis on bone, remodeling must be simplified to well-defined steps. Histomorphometric analysis of remodeling is important to the understanding of problems associated with diagnosing pathologic states and defining their etiology [6].

Frost's methods of analysis are still used with adaptations to newer technology. The sample must be labeled twice, most commonly with tetracycline, in order to stain the mineralizing bone and obtain remodeling rates [6]. The time delay between stains is commonly $7-14$ days with the second label normally a day before the specimen is gathered. Cross sections are most commonly taken at $100 \mu \mathrm{m}$ thick. The sample must then be stained with tetrachrome, osteochrome, 
or another stain to distinguish the osteoid from the mineralized bone [6]. Figure 7 depicts a simplified schematic of a section with staining of BMUs. BMUs in the process of resorption are identified as "R". Completed osteons are identified as "C". Refilling osteons are labeled "F", "F,S", or "F,D" for filling with no label, single label, and double label respectively [6].
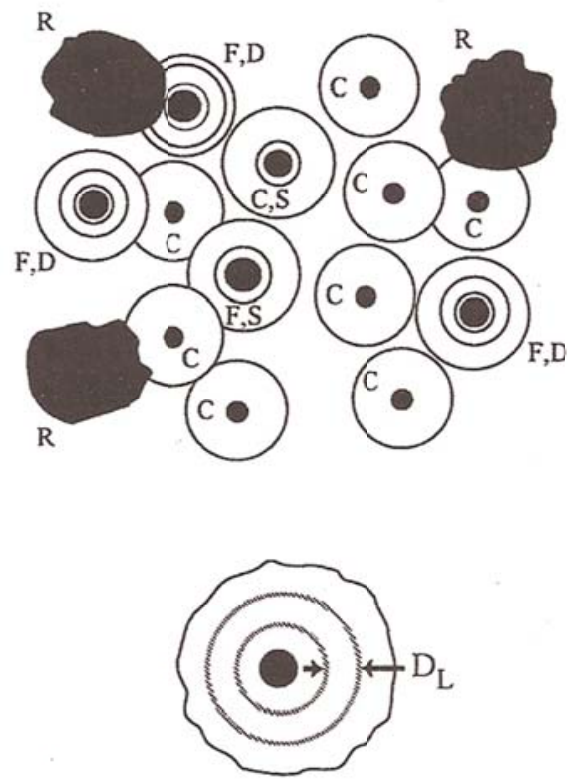

Figure 7 Upper: Schematic diagram of BMUs in a cross section of cortical bone. Black, irregularly shaped BMUs are resorption spaces (R). BMUs with large canals are refilling; they have either single label $(F, S)$ or a double label $(F, D)$. Completed osteons have small canals (C); some of these have a single label (C,S). Lower: A single BMU in the last stages of refilling is depicted. It has a double label; the distance between the labels is measured as shown $\left(D_{L}\right)[6]$

In order to calculate the characteristics of osteonal remodeling, certain measurements need to be made on the histologic sample. The cross sectional area is needed to quantify the amount of bone in the region. The number of resorption spaces per cross section area of bone needs to be determined. Resorption spaces can be identified by the scalloped surfaces and the lack of flourochrome labels [6]. The perimeter of each resorption space is measured and 
the mean perimeter is calculated [6]. The number of BMUs refilling is counted and the number per cross sectional area of bone is calculated. Refilling BMUs are identified by the osteoid seam. The mean perimeter and the thickness of the osteoid seams are measured. The distance between double labels is measured in micrometers. Finally the completed osteons are located and the mean wall thickness from the Haversian canal to the cement line is measured [6]. For the purposes of this study, no staining was performed. The number of cement lines along with the number of secondary osteons can be used in order to determine size of secondary osteons and how much bone turnover is occurring.

\subsection{Osteoporosis}

Osteoporosis is characterized by a decrease in bone mass and disruption of the micro-architecture of bone $[18,19]$. Osteopenia is a less severe form of bone loss than osteoporosis. With this decrease in bone mass and a change in architecture there is a significant decrease in strength in osteoporotic bone. This leads to an increase in fracture risk. Common locations of fracture due to osteoporosis are the spine, hip, wrist, humerus, and pelvis [18]. Bone mass loss and changes in architecture occur due to a mismatch in the rate that bone is removed by osteoclasts and added by osteoblasts. Figure 8 shows a micrograph of a 31 year old woman and 70 year old women. The decrease in size and change in architecture are readily apparent in the older woman. 


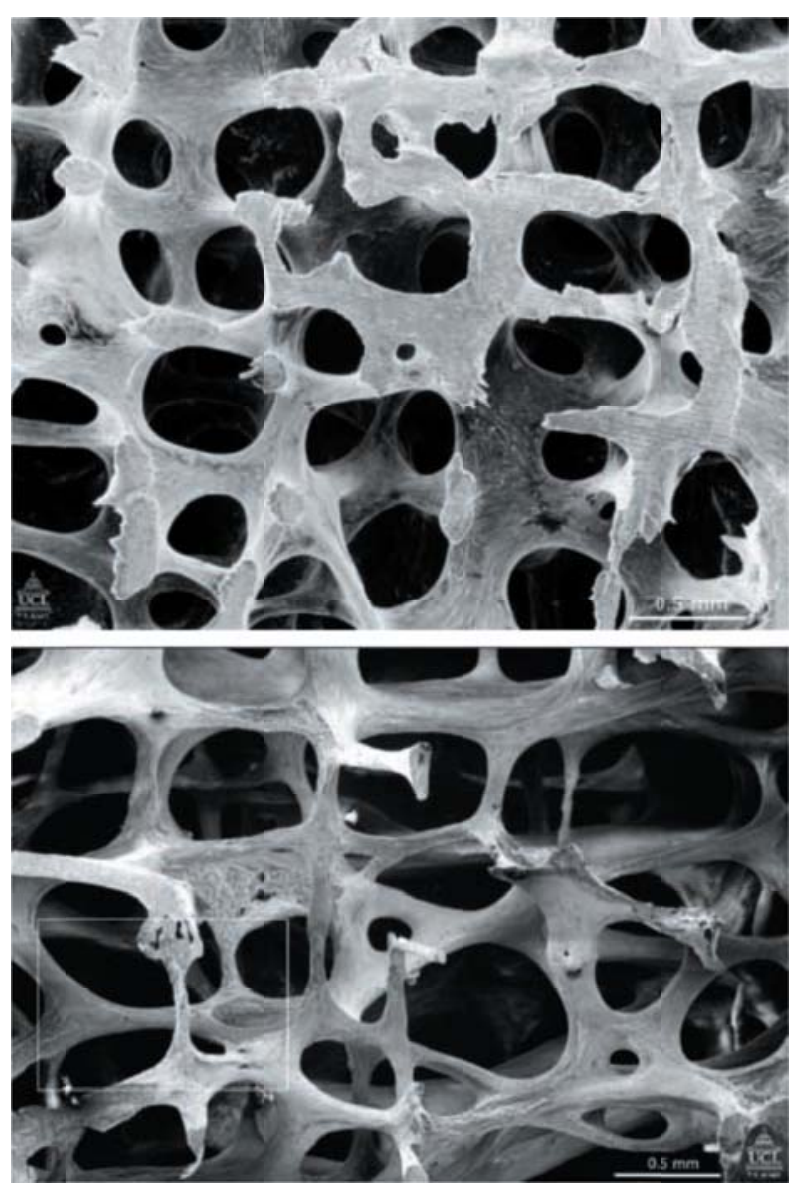

Figure 8 shows scanning electron micrographs to show structure of L3 vertebra in a 31 year old woman (top) and in a 70 year old woman (bottom). Note that many of the plate-like structure have become converted to thin rods [18]

Age plays a large factor in the development of osteoporosis. Bone loss due to age and insufficient levels of estrogen in postmenopausal women has been well documented [18]. In a later section the potential role of estrogen and the pathophysiology of postmenopausal osteoporosis will be discussed. Reduced physical activity due to aging can increase the risk of osteoporosis. Decreased production of insulin-like growth factor produced in the liver is another possible factor in the development of osteoporosis. Genetic factors play a role in peak bone mass obtained in the third decade of life [18]. Developing a high level of 
bone mass early in life plays an important role in determining bone mass later in life.

Women are at a higher risk than men to develop osteoporosis. Men do develop osteoporosis. Men tend to have larger skeletons, their bone loss starts later, and progresses slower. They also do not have a rapid change in hormones related to bone loss [1].It has been shown that the loss of estrogen during menopause correlates to the decrease in bone mass [18]. Some of the risk factors that are independent of bone mineral density are age, alcohol intake greater than or equal to 3 units/day, previous fragility fracture, Rheumatoid arthritis, or a body mass index less than or equal to 19 [18]. Risk factors that are dependent on bone mineral density are endocrine disease, chronic renal disease, chronic liver disease, or malabsorption [18]. These are not all of the risk factors that play a role in the development of osteoporosis.

\subsubsection{Postmenopausal Osteoporosis}

Post-menopausal women undergo significant decreases in circulating estrogen levels due to minimal production in the ovaries. This systemic decrease in estrogen levels can have serious implications in the development of osteoporosis. As many as half of all postmenopausal women will develop a fracture as a result of osteoporosis [20]. As discussed earlier there are many risk factors for the development of osteoporosis. However, systemic estrogen loss in postmenopausal women is a major factor in increased bone loss. 
Estrogen's role in regulating bone loss has been associated to the regulation of cytokines critical to osteoclast stimulation. The cytokines that estrogen regulates are interleukin-1 (IL-1), interleukin-6 (IL-6), and tumor necrosis factor (TNF). [21]. These cytokines regulate osteoclastogenesis and have the ability to stimulate their own synthesis as well as the synthesis of each other. Figure 9 models estrogen's role in the regulation of IL-1, IL-6 and TNF production.

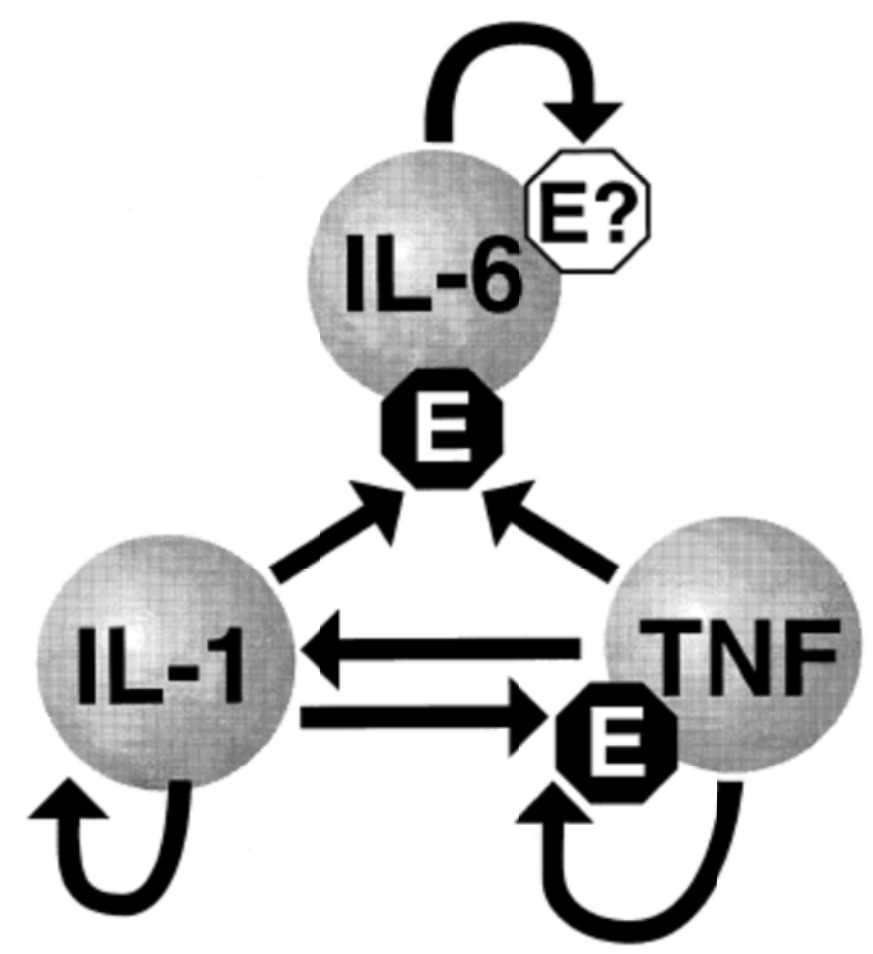

Figure 9 regulation of IL-1, IL6, and TNF production. Each arrow indicates a stimulatory effect of a cytokine on its own synthesis, or the synthesis of another cytokine. Demonstrated suppression of the stimulated synthesis of IL-6 and TNF by estrogen ("E") is indicated by filled octagons, and the potential suppression of IL- 6 induced by IL- 6 by estrogen is indicated by an open octagon. The interdependent nature of this regulatory circuit means that a significant increase in any one of the cytokines depends on the presence of the others. [21]

IL-6 mediates the increase in osteoclast formation in an estrogen deficiency environment. With an increased presence of estrogen, the production of IL-6 is suppressed decreasing the amount of osteoclasts formed. Certain cytokines also 
inhibit osteoclastogenesis. Transforming growth factor- $\beta$ (TGF- $\beta$ ) stimulates osteoclast apoptosis. TGF- $\beta$ is stimulated by estrogen in the osteoblastic cells. Postmenopausal women most likely have increases in IL-1, IL-6, and TNF and decreases in the TGF- $\beta$. This shift in cytokine levels leads to the prolonged lifespan of osteoclasts [21]. Osteoclastogenesis has been shown to be regulated by cytokines in the TNF family. The RANK ligand (RANKL) is expressed on the surface of osteoblasts. The RANK receptor is located on osteoclast precursors. When RANKL and RANK bind the osteoclast precursors differentiate to osteoclasts. Osteoprotegerin is a decoy receptor that binds to RANKL to inhibit osteoclast differentiations [22]. This interaction reinforces the link between the presences osteoblasts and osteoclast function.

\subsubsection{Osteoporosis Treatment Options}

There are two main methods for the treatment of osteoporosis. Due to the significant decreases in estrogen levels post-menopause, estrogen replacement treatments have been researched to compensate for the increased levels of bone loss. Bisphosphonates are also a treatment option for patients with osteoporosis. In order to determine treatment options and dosage requirements physicians use primarily two methods. Most clinicians used bone mineral density (BMD) as a means to determine fracture risk in a patient [23]. Dual energy $x$-ray absorptiometry is used to measure the BMD of a patient. A low BMD is one of the risk factors for fractures. Recently, there is a recommendation to determine treatment options based on estimates of a 10-year fracture risk. This analysis uses information on multiple risk factors such as smoking, corticosteroid uses as 
well as BMD. Using the 10-year method of analysis was shown to better match physician-prescribed medications to the clinical guideline recommendations [23]. Changes in dosing methods have been analyzed in order to improve adherence to treatment protocol. The difficulty with some of the treatment protocols is the demand of weekly medication. Changing dosing of bisphosphonates from a once weekly dose to a once monthly dose showed longer patient usage. However effects of fracture risk were not determined and need to be analyzed before wide spread changes in treatment protocols [24].

As discussed earlier, estrogen inhibits the production of cytokines such as IL-1, IL-6 and TNF that stimulate osteoclastogenesis. It also stimulates cytokines such as TGF- $\beta$ that increase osteoclast apoptosis. Treatment initiation can have an effect of the effectiveness of the estrogen. Four different comparisons were made between users who were continuous users, partial users, past users and those who have never used estrogen[20]. Those with continuous estrogen use and partial use showed significant decreases in mean bone density losses (Figure 10). Probability of fractures also decreased in continuous and partial users as shown in Figure 11. 


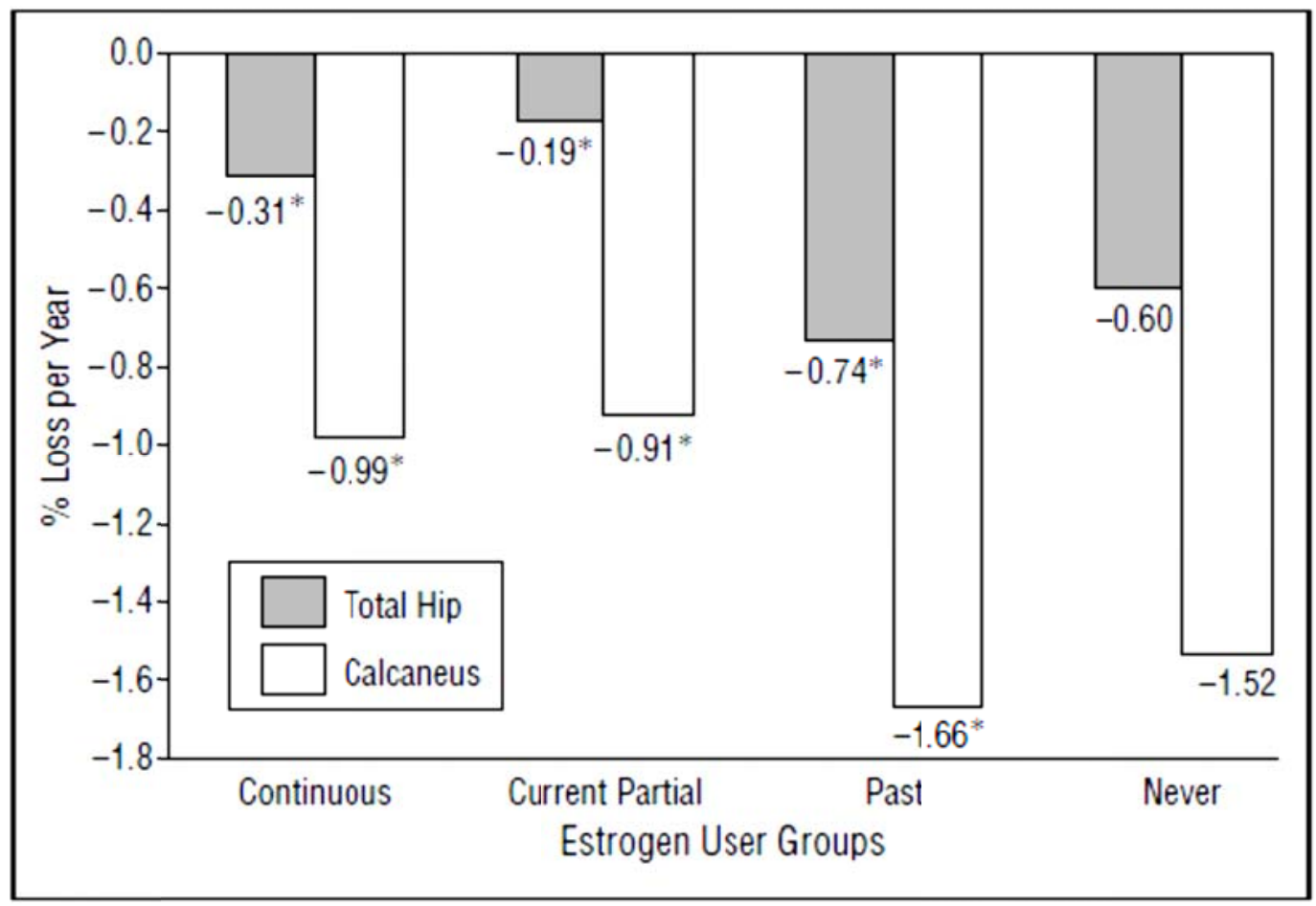

Figure 10 Mean bone density loss by estrogen user group. Women in all estrogen user groups lost bone density at both the total hip and calcaneus. Asterisks indicate values significantly different from those of never users from multiple linear regression models adjusted for age and weight $(P<.05)[20]$

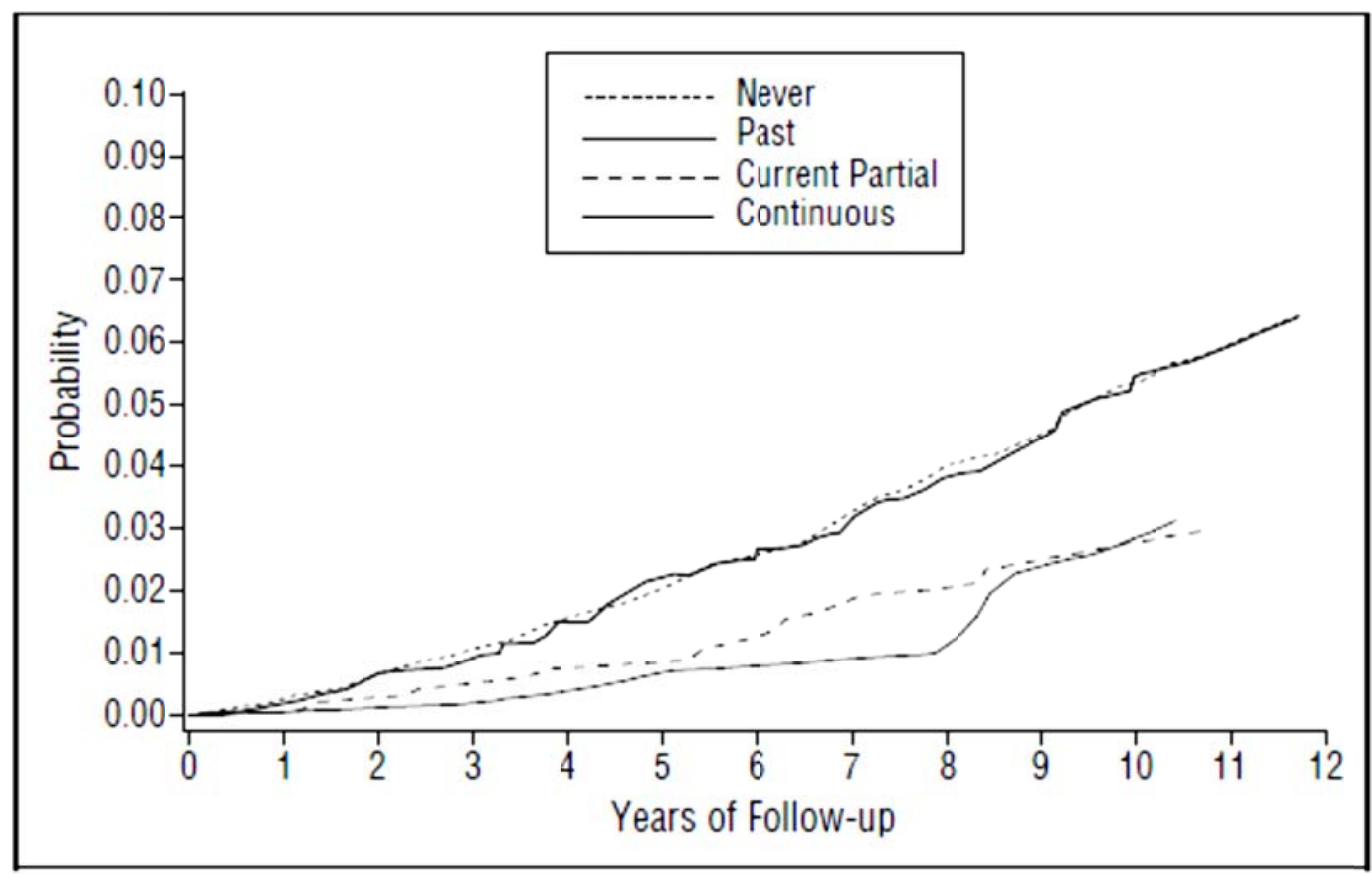

Figure 11 Probability of hip fractures. Probabilities are adjusted for age and weight. [20] 
Treating osteoporosis with estrogen does have potential downsides. Estrogen does have a protective effect against osteoporosis and fractures when compared to those who never used estrogen in the past. However, as shown in Figure 11, fracture risk does continue to increase with age[20]. Other side effects corresponding to estrogen use include possible mastalgia, headaches, and dyspepsia [25].

Bisphosphonates have been shown to provide significant suppression of bone resorption. They have been shown to have long term effects after termination of treatment due to their potential sequestering by hydroxyapatite crystals. The release of the stored bisphosphonates occurs during the remodeling process inhibiting osteoclast function [25]. Bisphosphonates have been shown to inhibit the melavonic acid pathway which is critical for osteoclast function [26]. One downside of inhibiting osteoclast function stems from the coupling action of osteoblasts and osteoclasts in the remodeling process. With inhibition of osteoclast function there is lower levels of bone loss. However, this also means that there are decreased levels of new bone turnover. This causes potential detrimental effects on the quality and strength of the bone. Bisphosphonate treatment has also been shown to cause upper gastrointestinal side effects [25].

Studies have been performed in order to characterize the effects of combining estrogen with a bisphosphonate treatment. With each treatment operating through different mechanism to minimize bone resorption the theoretical benefits are positive. The bisphosphonate alendronate was combined with conjugated equine estrogen and its effects on bone mineral density were compared to a 
placebo group as well as estrogen and alendronate by themselves. This combined treatment was shown to have significant increases in bone mineral density over the placebo group and slight increases over the separate treatments of alendronate and estrogen [26]. Increases in bone mineral density in the various regions are shown in Figure 12.
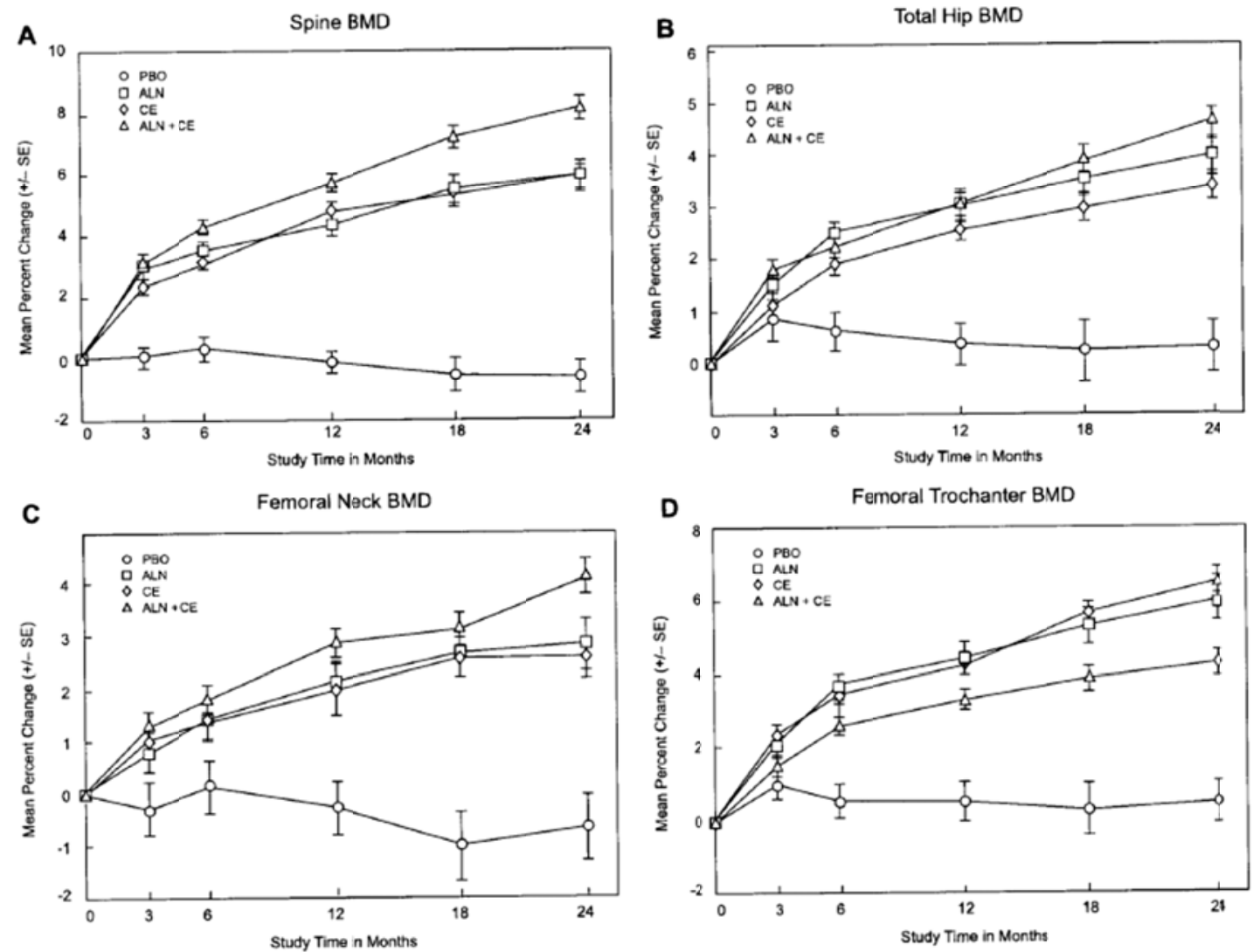

Figure 12 Mean percent changes from baseline in bone mineral densities in the spine, total hip, femoral neck, and femoral trochanter [26] 


\subsection{Animal Models}

In order to develop treatment protocols to be used in humans, they must be deemed safe and effective. This is done through extensive laboratory testing and animal trials. The progression of animal testing starts with an inexpensive small animal model and advances to a diseased large animal model. The goal is to minimize cost and time by troubleshooting treatments in the smaller animals, allowing only promising treatments to be studied on the larger models. Large animal models must have similar characteristics to human osteoporosis and allow for testing of drugs as well as devices used to fix fractures, replace joints, and other orthopedic devices. These devices must be able to perform in low bone density environments and not compromise the structural integrity of the native tissue [27].

Rodents are a common animal model due to their short life span, allowing for easier studies on aging. Rodents do show cortical thinning and increased fragility due to ovariectomy, but the effects on fracture risk are unclear. Research has been performed on the mandible of the mouse. The mouse does not undergo significant amounts of remodeling. By ovariectomizing the mouse, remodeling was stimulated. Suppression of this remodeling with bisphosphonates was observed [28]. Rats are a common animal used in studies due to their relative lower cost. Ovariectomized rats have been used to study the effects of bisphosphonates on estrogen deficiency [29]. Rats' lack of Haversian remodeling reduces the strength of correlation to humans [30]. 
Rabbits have been used as a model of osteoporosis. Rabbits are a good small animal model for bone biomechanics due to the fact that they undergo Haversian canal remodeling and skeletally mature rapidly [31]. They are commonly used to study bone ingrowth to implants and implant surfaces[30]. While these models are useful due to their lower cost and easier housing conditions, they do not provide sufficient means to study implant dynamics on a human scale.

Dogs have been used for bone studies due to their larger size and Haversian system of remodeling. However, there are limitations to the study of postmenopausal osteoporosis. Studies have shown that dogs without ovaries and uterus and with sedentary lifestyles show limited to no fracture risk as compared to postmenopausal women [30]. Nonhuman primates seem like a viable candidate for postmenopausal osteoporosis and osteopenia research. As discussed earlier hormones play a large role in the onset of osteoporosis. Primates have a similar endocrine system to humans. In order for primates to be studied under postmenopausal conditions they must be aged to approximately 9 years [30]. This results in extensive cost for housing and animal management.

\subsubsection{Proposed model}

The sheep, in particular the ewe, is a promising large animal model for osteoporosis research. Its size allows for full scale device implantation and analysis. Sheep have been shown to have similar metabolic rate $\left(\mathrm{O}_{2}\right.$ consumption per gram of body weight), 0.22 , to humans, 0.21 . Rats and dogs have metabolic rates of 0.87 and 0.33 respectively [32, 33]. Young sheep, 3 to 4 years, have primary bone consisting of woven and lamellar bone. As the sheep 
age Haversian remodeling occurs with similar characteristics to human cortical bone (Figure 13) [30, 34].
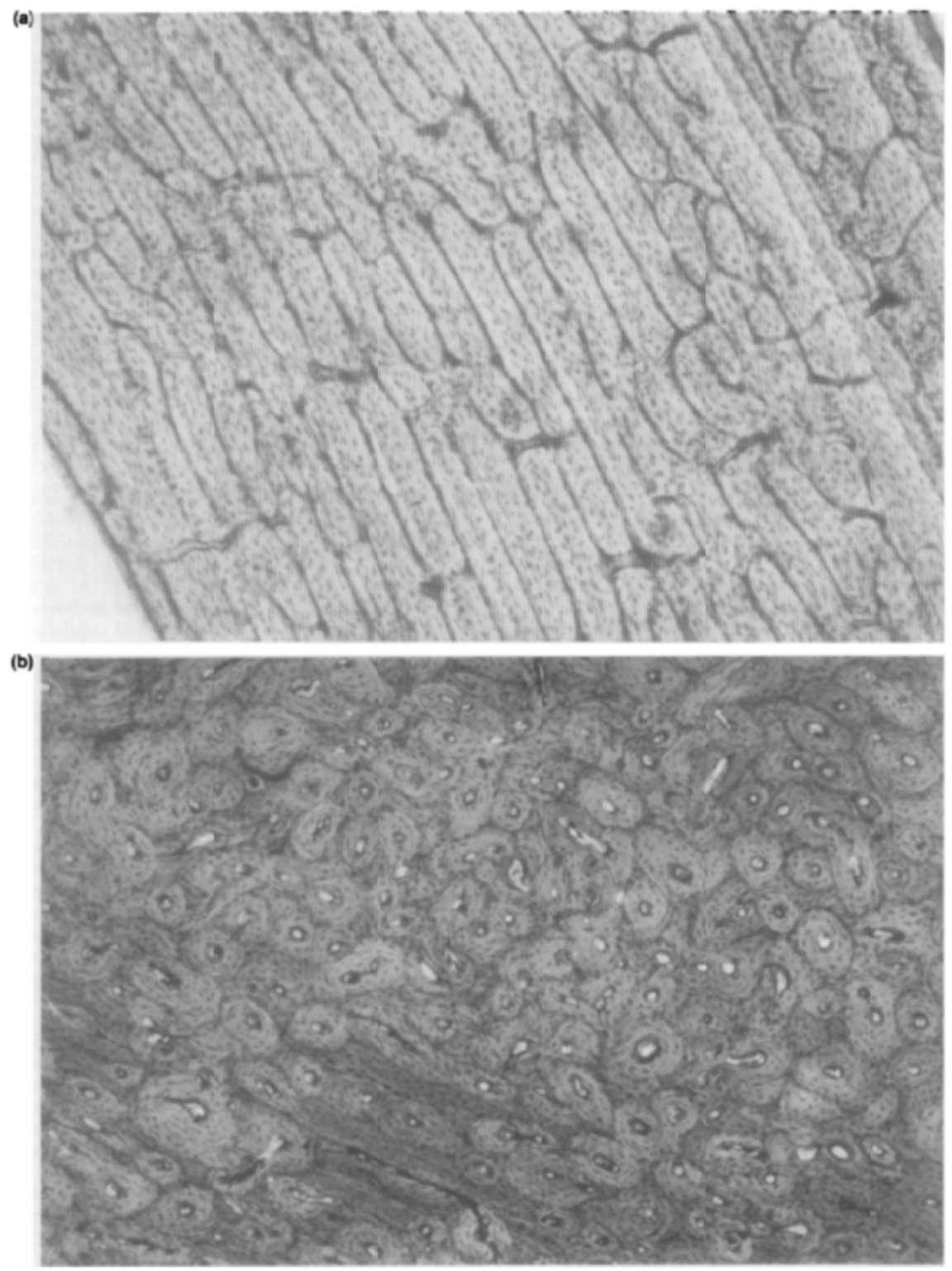

Figure 13 (a) Primary bone from a 3 year old ewe. (b) Haversian remodeling from the caudal femoral cortex of an 8 year old ewe[30]

They also have temporal and quantifiable similarities in hormonal profiles to human females [33, 34]. The ovariectomized sheep has been shown in multiple studies as a feasible model of bone mineral density loss [30, 32, 34]. There are disadvantages of the sheep in relation to modeling human postmenopausal 
osteoporosis. Ewes, unlike human females, have annual anestrus periods lasting approximately 1-2 months [32]. The gastrointestinal system of sheep is different than humans. The rumen microflora can alter the administered drugs. This presents complications when studying the effects of oral absorption of drugs [34, 35].

Two important characteristics of the sheep as a model for osteoporosis and more specifically postmenopausal osteoporosis are the season of analysis and their age. The remodeling cycle in sheep has been shown to complete in approximately three months. Remodeling rates were seen to increase by three months in ovariectomized ewes. Changes in bone loss of the ovariectomized ewes compared to the control were seen by 6 months $[36,37]$. In other studies significant decreases in mechanical and histomorphometric data were not seen in the spine and ilium until 12 months [32, 38]. Using micro-CT, significant changes can be seen in the trabecular micro architecture as seen in Figure 14. The left image is the control. The middle is taken to 6 months and the left image was a ewe sacrificed at 12 months [38]. 


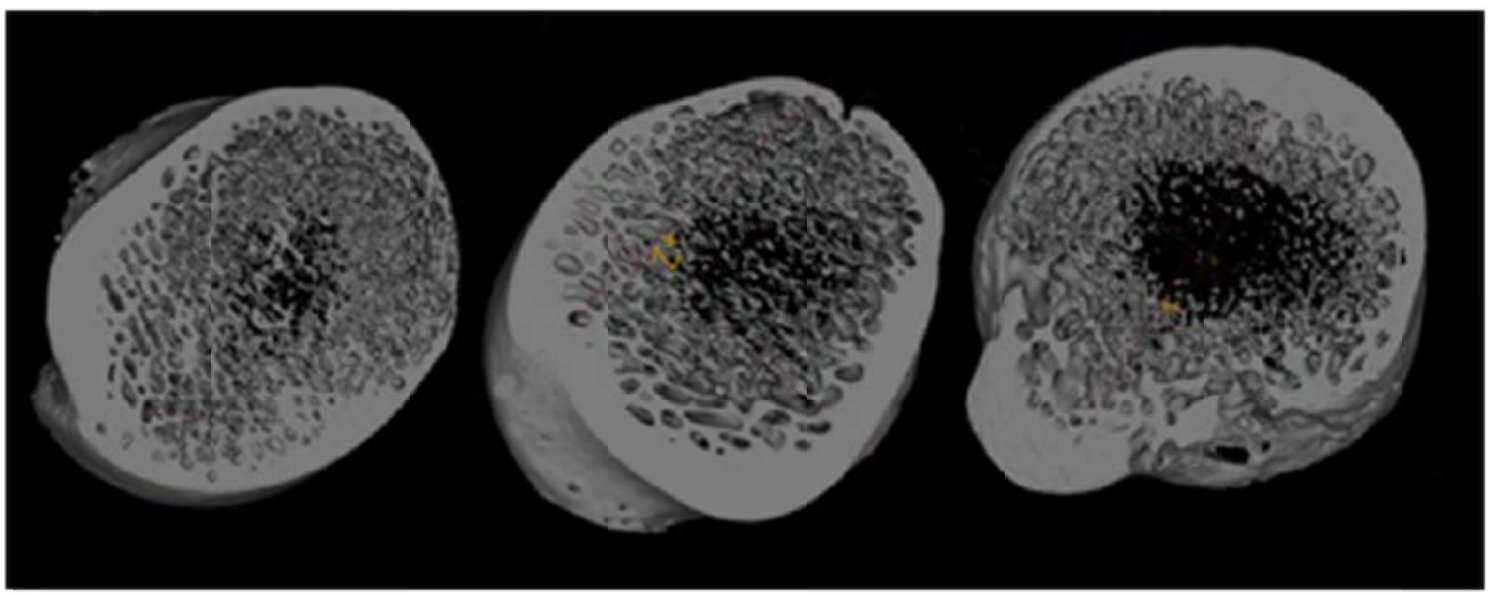

Figure 14 Three- dimensional trabecular micro-architectural images of sheep femoral necks. From left to right were sham, group 1 (6 mo), group 2 (12 mo) [38]

Seasonal changes in bone mass has been shown in elderly female humans with the lowest bone mass being in winter [39]. Sheep also exhibit changes depending on the season. Depending on the climate, winter months mean decreased sunlight and changes in day length which leads to decreased physical activity and changes in breeding habits. This can result in lowered mechanical loading and decreased hormone levels [40,41]. Changes in the factors can alter the ewes remodeling patterns [34]. Calcium and Vitamin D intake can have significant effects on the health of bone tissue. Sheep produce Vitamin D in the skin using ultraviolet radiation. If winter climates result in less sunlight per day, then sheep housed outside will produce lower systemic Vitamin D, potentially effecting the characteristics of their bone [33]. Research characterizing the seasonality of sheep showed that significant variation in cancellous bone mineral density occurred with the lowest values in winter and with significant increases in spring and summer. Histomorphometry showed that the bone volume to total 
volume ratio was significantly higher during autumn when compared to winter [33].

The ovariectomized sheep provides a large scale animal model for postmenopausal osteoporosis. It allows for functional testing of both drugs and devices in an osteoporotic setting. Further characterization of the seasonal effects on the remodeling patterns of the ewe is needed in order to fully grasp the effects of treatment protocols. With this research a quantifiable model of seasonal and anatomical variations in cortical bone remodeling will be determined as a baseline for comparison to ovariectomized sheep.

\subsection{Study Objectives}

The purpose of this study is to quantify compact bone remodeling in adult ovine bone as a function of sampling season. The remodeling parameters that will be measured are the ratio of bone volume to tissue volume, the percent of tissue remodeled, the percent of material remodeled, mean secondary osteonal radii, cement line interfaces with tissue, and cement line interfaces with material. The measurement will be taken from the compact bone of the radius and ulna of the left leg. Variations across seasons, anatomical location, and a possible interaction or seasonality within anatomical regions will be analyzed.

Previous studies have shown that sheep undergo seasonal changes in bone properties [27, 33, 34]. Little research has been done to compare changes in remodeling characteristics at different anatomical locations or an interaction between season and anatomical sectors. Seasonal and anatomical remodeling 
changes are expected in the compact bone. This model will determine where changes are occurring in across each anatomical sector and each season. With this information future studies will be able to ensure that comparisons made between models are showing relevant information and not changes due to these seasonal and anatomical parameters. 


\section{Methods}

\subsection{Animal Preparation}

As part of a larger experiment under Animal and Care Use Committee approval 112 skeletally mature, age greater than 5 years, Columbia-Rambouillet cross ewes were obtained and kept at Colorado State University, Ft. Collins, Colorado. The animals were kept in dry lots and fed a grass-alfalfa hay mixture at $41^{\circ}$ latitude and $1500 \mathrm{~m}$ altitude for the duration of the experiment. These 112 ewes were split into four seasonal groups of 28; autumn, winter, spring, and summer. These seasonal groups were then divided into groups of 14 . Both groups were anesthetized and underwent surgery at the large animal surgery facilities at the College of Veterinary Medicine and Biomedical Sciences at Colorado State University. One group of 14 underwent an ovariectomy (OVX) in which the ovaries were identified and removed. The other 14 underwent a sham surgery in which the ovaries were identified, handled, and not removed. The groups of 14 were further divided into two groups. Seven of the ewes were sacrificed 3 months postoperatively and 7 were sacrificed 12 month postoperatively. The seasonal group represents the month that surgery was performed. Summer sheep underwent surgery in August. Autumn, winter, and spring, underwent surgery in November, February, and May respectively. One of the 12 month autumn sham sheep died prematurely and was included in the 3 month data as part of another experiment. 


\subsection{Specimen Preparation}

Post sacrifice, the right and left radius and ulna of the sheep were removed and stored wrapped in saline-soaked paper towel and stored in sealed plastic bags at a temperature of $-20{ }^{\circ} \mathrm{C}$. These samples were sent to Henry Ford Medical Hospital where they were prepared for analysis. The center $50 \mathrm{~mm}$ of the diaphysis was removed with a band saw (Model 5212, Hobart Corporation, Troy, $\mathrm{OH})$. The radius was then divided into six anatomical sectors using the Exakt cutting-grinding system (Exakt Corporation, Oklahoma City, OK). The sectors were organized into cranial, caudal, craniolateral, craniomedial, caudomedial, and caudolateral regions (Figure 15).

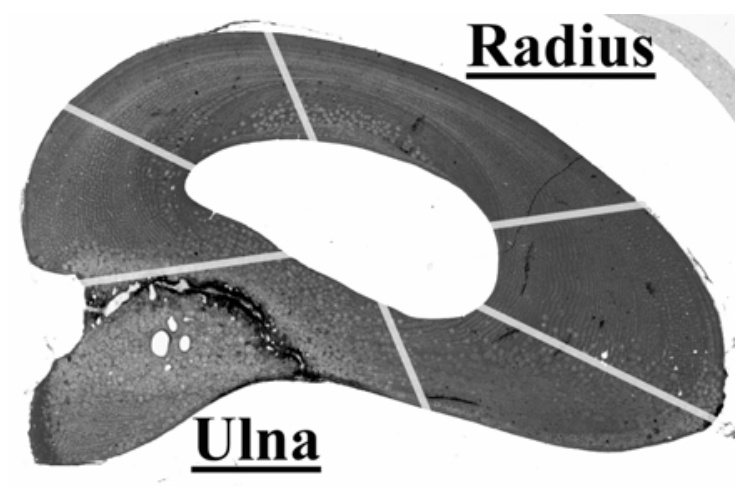

Figure 15 Approximate anatomical radial-ulnar sectors divided by the grey lines. The cranial sector is at the top right and lateral is the top left side of the image.

In each anatomical sector, $1.75 \times 1.75 \times 19 \mathrm{~mm}$ longitudinal cortical beams were obtained. Dynamic mechanical testing was performed on the cortical beams of the left radii and ulnae for analysis in another study. From the center of left radii and ulnae beams a $150 \mu \mathrm{m}$ section was cut out. The remaining distal end of the beam was used for drying and ashing as means to determine density. The proximal section was frozen for analysis at a later time. The $150 \mu \mathrm{m}$ sections 
were then ground down by hand using fine grit sand paper to a finish thickness of $100 \mu \mathrm{m}$. Microradiographs using 2506AGHD 2.5x2.5x0.060 High Definition Photo Emulsion Plates and a HB Cabinet Faxitron (HTA Enterprises, Microtome Technology Products, San Jose, CA) were taken of each section at $25 \mathrm{kV}$ for 20 minutes at $3 \mathrm{~mA}$ (Figure 16). Sections from two sheep were placed on each microradiograph with an aluminum step wedge made with Reynolds Aluminum Foil in the middle. The aluminum step wedge was created by taping multiple layers of aluminum together in stair step pattern creating different levels of thickness. Taking micro-radiographs of both the aluminum and the specimens under the same conditions allows for comparison between the two. The thickness of aluminum is known for each step. By comparing image intensities of the specimens to the aluminum step wedge a measurement of density with respect to aluminum can be made. With this methodology variations in day to day differences in microscope parameters and plate development can be controlled. This also provides a non destructive density measurement unlike ashing in which the specimen is destroyed. This methodology is a modification of Boivin and Meunier [42]. 


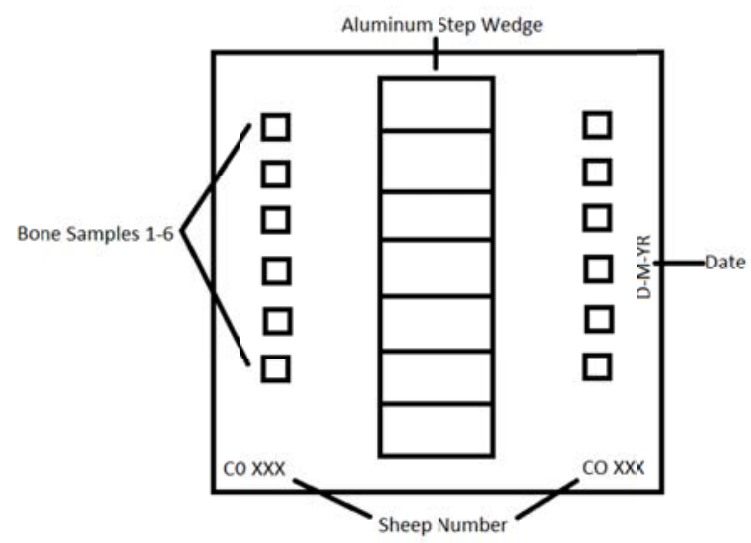

Figure 16 Diagram of microradiograph layout

\subsection{Specimen Analysis}

Henry Ford Medical Hospital sent the microradiographs to California Polytechnic State University, San Luis Obispo for analysis. Two types of analyses were performed on the ovine microradiographs. Histomorphometric measurements to quantify the levels of remodeling were performed. These measurements included porosity, number of cement line interfaces, number of secondary osteons, and the amount of remodeled bone. Densitometry measurements were made in order to quantify the density of the sections. An Olympus BX-41 microscope with the 4X and 10X objectives was used in order to perform both methods of analysis. The 10X objective was used for the histomorphometry measurements. The $4 \mathrm{X}$ objective was used for densitometry measurements.

\subsubsection{Histomorphometry}

In order to perform the histomorphometric measurements each anatomical sector (cranial, caudal, craniolateral, craniomedial, caudomedial, and caudolateral) was divided into four quadrants. Measurements were taken in each quadrant and then averaged in order to provide an accurate analysis of the sector. A Merz grid 
(Figure 3) was used to analyze each quadrant within the sector. Porosity, or a location void of bone tissue, is quantified by counting the number of points that lie on top of a cavity (Figure 17). Porosity most commonly occurs from the presence of Haversian canals, Volkmann's canals, or remodeling cavities (Figure 18).

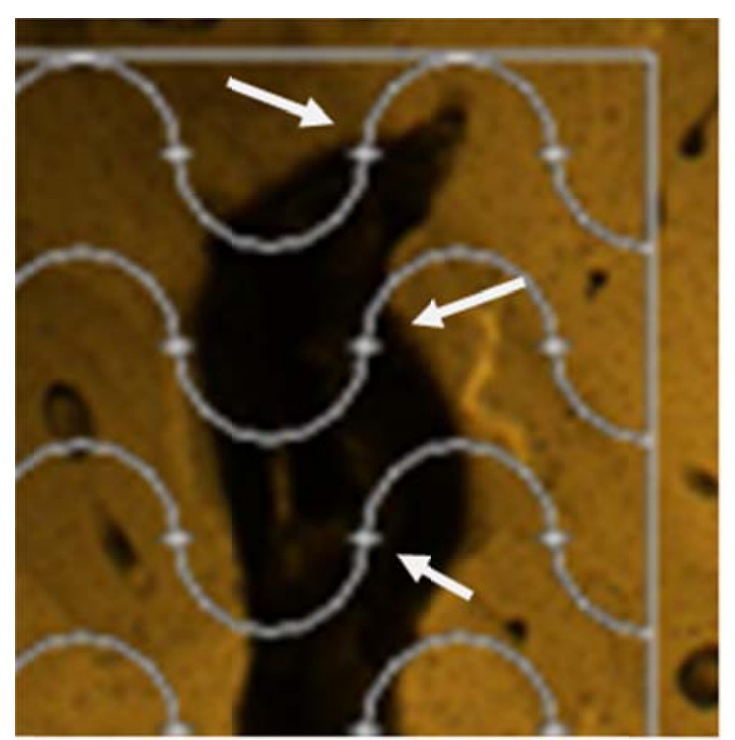

Figure 17 Merz grid points located on porosity 


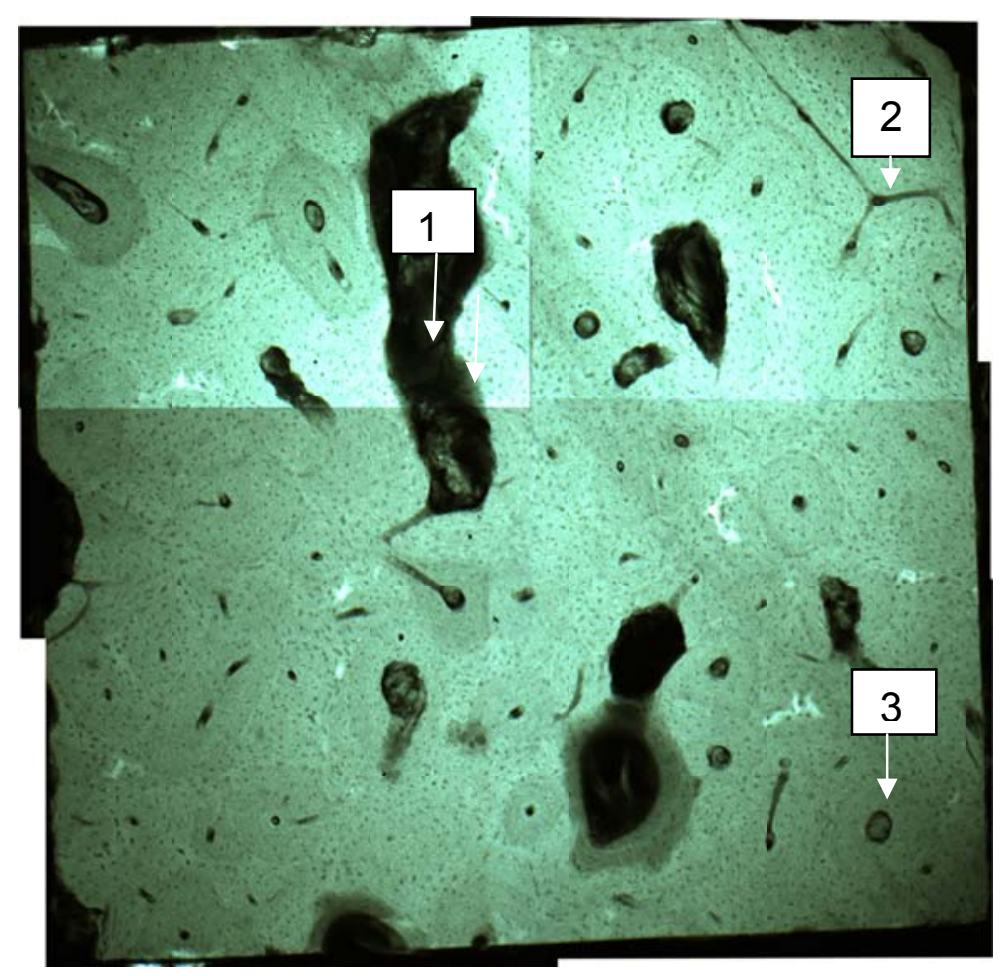

Figure 18 C5901 showing examples of porosity due to Volkmann's canals(2), Haversian canals (3), and remodeling cavities (1)

The number of points that lie on secondary bone is also counted (Figure 19). These points were not required to be located on complete secondary osteons. As long as they were on secondary bone and not primary bone they were counted. The sum of the number of points located on a porosity and the number of points on secondary bone cannot exceed 36; the total number of points on the Merz grid [9]. 


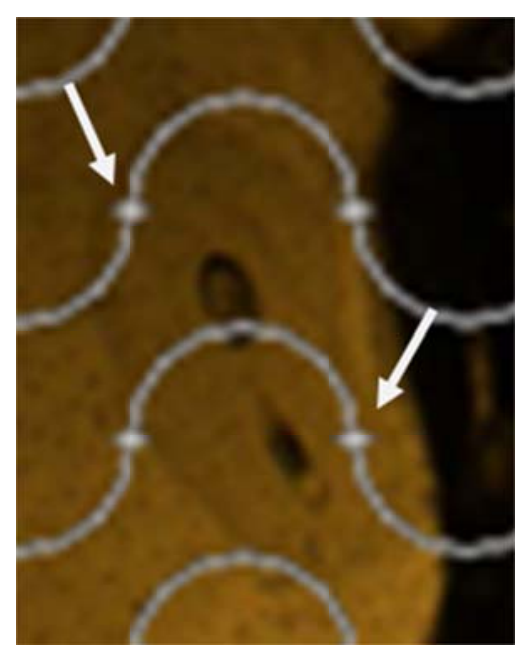

Figure 19 Merz grid points located on secondary bone

The number of secondary osteons inside the grid was quantified (Figure 20). The borders of the Merz grid were used as a guide to count the number of osteons. Since four measurements were made in each sector, the repeated counting of osteons needed to be minimized. If an osteon was on the top or right border of the grid, they were counted. If a secondary osteon was on the left or bottom border of the grid, they were not counted.

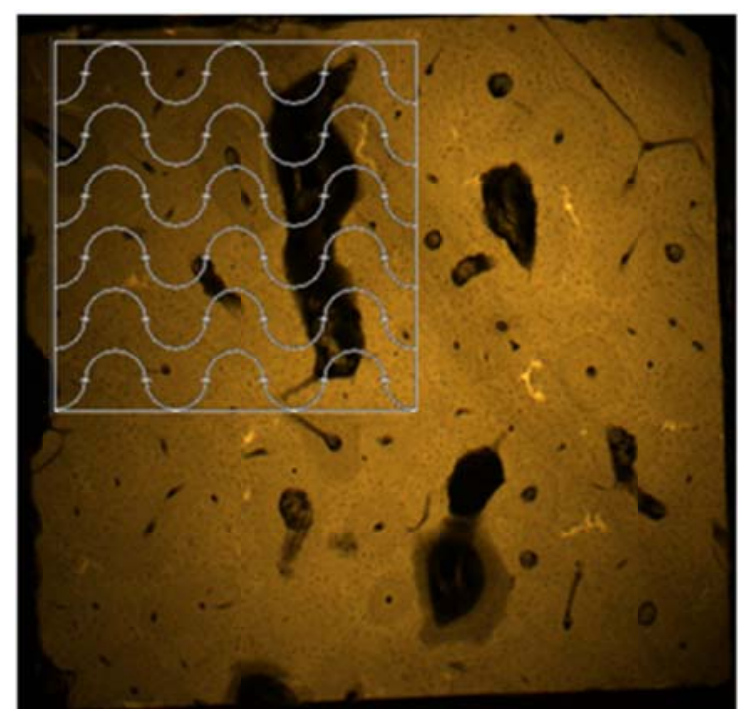

Figure 20 counting the number of secondary osteons within the Merz grid 
Lastly, the half circle curves were used to measure the number of cement line interfaces with secondary osteons (Figure 21). Anytime a curve crossed a cement line of a secondary osteon, it was counted. These four raw measurements were then used to calculate variables used to quantify the levels of remodeling occurring in the section.

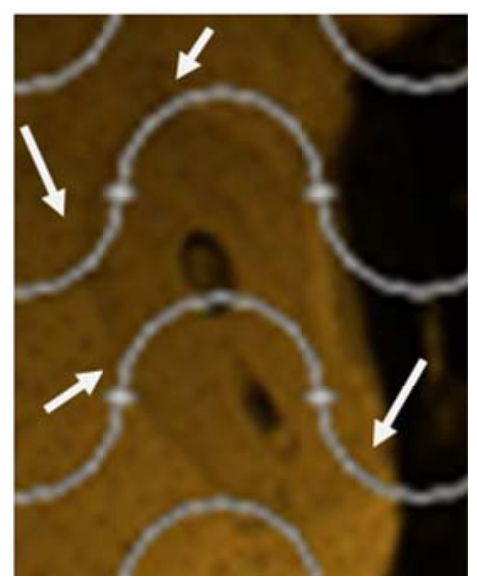

Figure 21 Merz grid used to count the number of cement line interfaces with secondary osteons Bone volume over tissue volume (BV/TV) is used to express the level of porosity in the bone. BV/TV is calculated by taking 1 minus the number of points on porosity over 36 (number of points on the Merz grid). Remodeling levels in the section were quantified in two ways. The percent of tissue remodeled is the amount of remodeling occurring across the whole section. Percent of material remodeled is the amount of bone material remodeled, factoring out the porosity in the bone. Percent tissue remodeled was calculated by dividing the number of points on secondary bone by 36 . The percent of material remodeled was calculated by dividing the number of points on secondary bone by 36 minus the number of points on porosity. Similar calculations were performed for cement line interfaces. The number of tissue cement line interfaces was the raw count of 
cement line interfaces. The material cement line interfaces is the raw cement line interface count divided by the BV/TV. The mean secondary osteon radius was calculated by multiplying the percent of tissue remodeled by a constant of 632025 as determined by Wessel [43], divided by the square root of $\pi$, times the number of secondary osteons. The ratio of cement line interface to mean secondary osteonal radius was also analyzed during the statistical analysis. This is to determine whether the size of the secondary osteons is changing with respect to season and anatomical location.

\subsubsection{Densitometry}

In order to determine the density of the bone, a reference material of known density must be used to quantify the level. Aluminum was used for the purposes of this study. Aluminum is commonly used for cortical bone due to its similar $\mathrm{x}$ ray attenuation. Aluminum is also uniform on a micron scale and accurate measurements of the thickness of aluminum foil are possible [44]. The density measurements of the samples are reported in the equivalent thickness of aluminum (ETA). In order to calculate the density, images were captured using the Olympus BX-41microscope with the attached Retiga EXi Q Image camera and a $4 x$ objective. Pictures of each sample and each level of the aluminum step wedge were taken. In order obtain accurate results the light intensity and all other image settings on the microscope were kept at the same levels when imaging each sample and step wedge on a particular microradiograph. Each sample was compared to the aluminum step wedge on its respective microradiograph. The settings were reset and recalibrated for each microradiograph. 
Once images of each sample and steps of the step wedge were taken, they were cataloged and analyzed using Image J. The images on a microradiograph change based on the density of a material. The thicker and denser the material is the lighter and brighter the image. As the thickness of aluminum increases the image brightness increases (Figure 22).

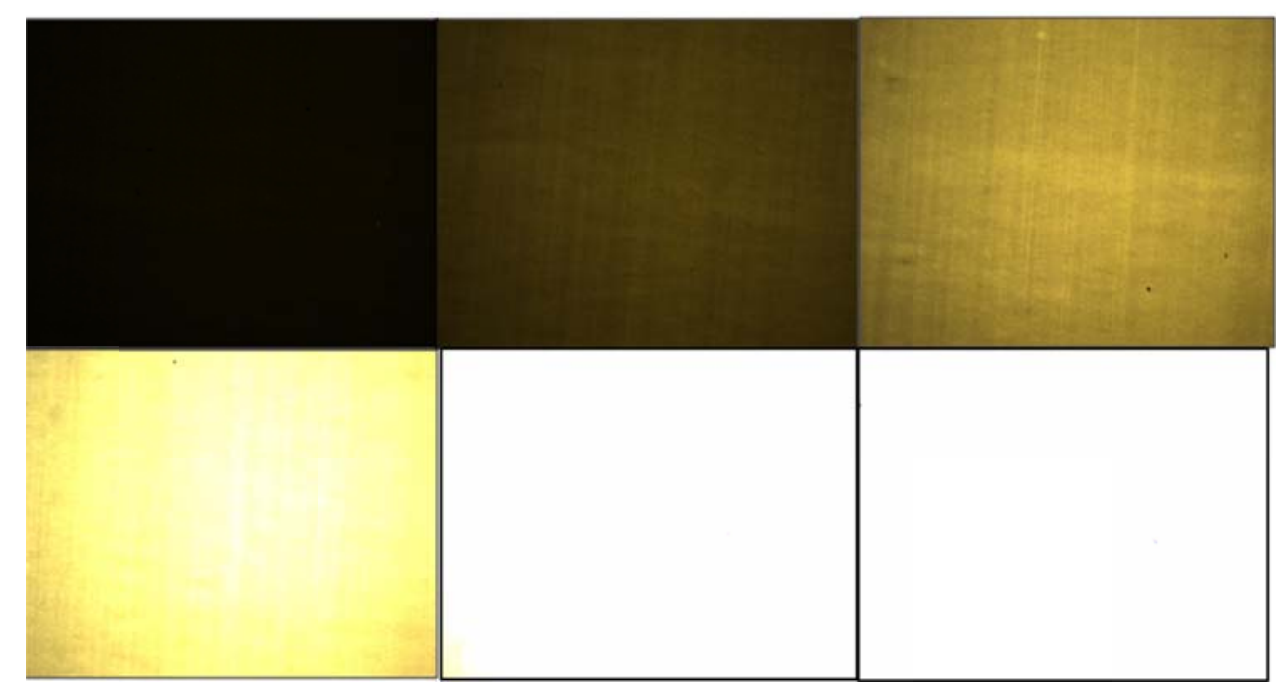

Figure 22 Images of each level of an aluminum step wedge, increasing thickness left to right, top to bottom $(0.025 \mathrm{~mm}, .050 \mathrm{~mm}, 0.075 \mathrm{~mm}, 0.100 \mathrm{~mm}, 0.125 \mathrm{~mm}$, and $0.150 \mathrm{~mm}$ respectively)

Using Image $\mathrm{J}$, the mean pixel intensity provided a quantitative measure of the brightness of the image. The mean pixel intensity of each aluminum step was calculated and tabulated. Each level of aluminum is $0.025 \mathrm{~mm}$ thick. The rectangular selection tool in Image $\mathrm{J}$ was used to measure pixel intensity in the samples. During sample preparation the sections were ground down to $100 \mu \mathrm{m}$ by hand. This resulted in the center of the sample being at the appropriate thickness and the edges being slightly thinner (Figure 23). Therefore, mean pixel intensity was measured at the center encompassing approximately $40 \%$ of the sample to ensure an accurate measure of density. The mean pixel intensity of 
the aluminum steps was graphed versus the thickness of aluminum. A best fit line using the power function was calculated for each graph. Using the equation for the best fit line the mean pixel intensity of the sample was converted to an ETA value.

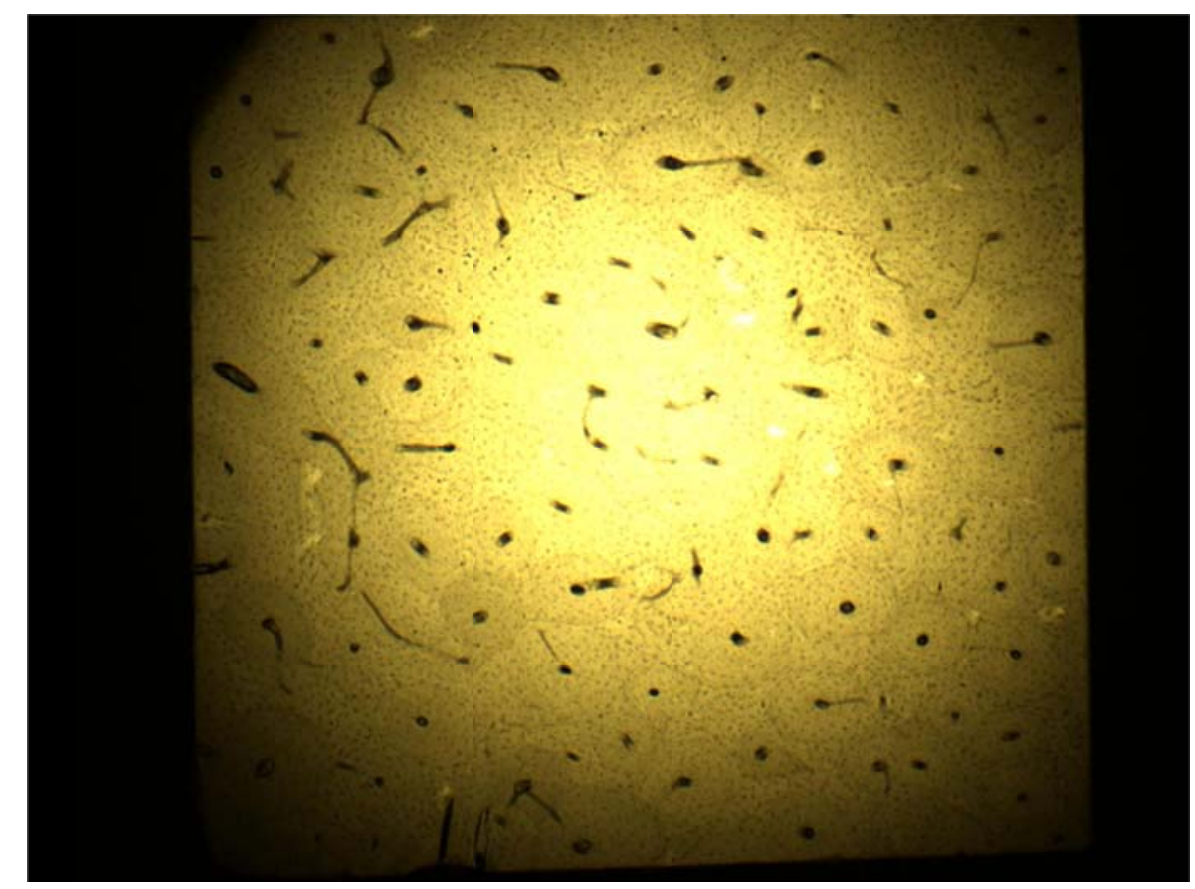

Figure 23 C4407, Craniolateral sector. Showing thicker regions at the edges of the sample (darker regions)

\subsubsection{Statistical Analysis}

The histomorphometry and densitometry data was analyzed with a 2-way repeated measure ANOVA comparing seasons and anatomic sector. This method was chosen in order to determine if season of sacrifice or the anatomical location of the specimen is associated with changes in the remodeling parameters. The individual effect of season on each parameter is determined. Anatomical variations on each parameter are also assessed. Interactions between season and sector are evaluated in two ways. The parameters can 
change with the season differently at different anatomical locations. On the other side, the anatomical distributions of the parameter may change with the seasons. For this reason an interaction between season and sector was included in the analysis. Post-hoc Fisher LSD tests were performed to determine where the differences occurred in the analysis. An alpha of 0.05 was used for both tests. 


\section{Results}

\subsection{Histomorphometry}

Measurements were made for autumn, winter, and spring. Summer histomorphometric measurements were already performed as part of the larger experiment [43]. The average value of the four quadrants in each individual sector for BV/TV, percent remodeled tissue, percent remodeled material, mean secondary osteonal radii, cement line interfaces (tissue), and cement line interfaces (material) are reported in Appendix A. Tables I, II, III, IV, V, and VI summarize the average remodeling factors and their standard error for each season and the anatomical sectors. 
Table I BVITV for adult 12 month control compact bone

\begin{tabular}{|c|c|c|}
\hline \multicolumn{3}{|c|}{ BVITV } \\
\hline \multicolumn{3}{|c|}{ Seasons } \\
\hline Group & Mean & Standard Error \\
\hline Autumn & 0.972 & 0.00472 \\
\hline Winter & 0.951 & 0.00454 \\
\hline Spring & 0.958 & 0.00437 \\
\hline Summer & 0.961 & 0.00437 \\
\hline \multicolumn{3}{|c|}{ Anatomical Sectors } \\
\hline Group & Mean & Standard Error \\
\hline Craniomedial & 0.964 & 0.00430 \\
\hline Cranial & 0.962 & 0.00430 \\
\hline Craniolateral & 0.963 & 0.00430 \\
\hline Caudomedial & 0.958 & 0.00454 \\
\hline Caudal & 0.952 & 0.00430 \\
\hline Caudolateral & 0.965 & 0.00430 \\
\hline
\end{tabular}

Table II Percent remodeled tissue for adult 12 month control compact bone

\begin{tabular}{|l|c|c|}
\hline \multicolumn{3}{|c|}{ Percent Remodeled Tissue (Remodeled Tissue/Total Area) } \\
\hline \multicolumn{1}{|c|}{ Group } & Mean & Standard Error \\
\hline Autumn & 0.330 & 0.0305 \\
\hline Winter & 0.257 & 0.0294 \\
\hline Spring & 0.288 & 0.0283 \\
\hline Summer & 0.339 & 0.0283 \\
\hline \multicolumn{2}{|c|}{ Anatomical Sectors } \\
\hline \multicolumn{2}{|c|}{ Mean } & Standard Error \\
\hline Craniomedial & 0.206 & 0.0258 \\
\hline Cranial & 0.348 & 0.0258 \\
\hline Craniolateral & 0.213 & 0.0258 \\
\hline Caudomedial & 0.312 & 0.0272 \\
\hline Caudal & 0.408 & 0.0258 \\
\hline Caudolateral & 0.334 & 0.0258 \\
\hline
\end{tabular}


Table III Percent remodeled material for adult 12 month control compact bone

\begin{tabular}{|c|c|c|}
\hline \multicolumn{3}{|c|}{ Percent Remodeled Material (Remodeled Tissue/Bone Area } \\
\hline \multicolumn{3}{|c|}{ Seasons } \\
\hline Group & Mean & Standard Error \\
\hline Autumn & 0.339 & 0.0314 \\
\hline Winter & 0.270 & 0.0302 \\
\hline Spring & 0.301 & 0.0291 \\
\hline Summer & 0.351 & 0.0291 \\
\hline \multicolumn{3}{|c|}{ Anatomical Sectors } \\
\hline Group & Mean & Standard Error \\
\hline Craniomedial & 0.214 & 0.0266 \\
\hline Cranial & 0.360 & 0.0266 \\
\hline Craniolateral & 0.220 & 0.0266 \\
\hline Caudomedial & 0.325 & 0.0281 \\
\hline Caudal & 0.427 & 0.0266 \\
\hline Caudolateral & 0.345 & 0.0266 \\
\hline
\end{tabular}

Table IV Mean secondary osteonal radius $(\mu \mathrm{m})$ for adult 12 month control compact bone

\begin{tabular}{|c|c|c|}
\hline \multicolumn{3}{|c|}{ Mean Secondary Osteonal Radius $(\mu \mathrm{m})$} \\
\hline \multicolumn{3}{|c|}{ Seasons } \\
\hline Group & Mean & Standard Error \\
\hline Autumn & 55.133 & 2.383 \\
\hline Winter & 52.667 & 2.292 \\
\hline Spring & 54.582 & 2.206 \\
\hline Summer & 62.093 & 2.206 \\
\hline \multicolumn{3}{|c|}{ Anatomical Sectors } \\
\hline Group & Mean & Standard Error \\
\hline Craniomedial & 55.469 & 2.522 \\
\hline Cranial & 55.668 & 2.522 \\
\hline Craniolateral & 54.056 & 2.522 \\
\hline Caudomedial & 58.056 & 2.663 \\
\hline Caudal & 56.527 & 2.522 \\
\hline Caudolateral & 56.701 & 2.522 \\
\hline
\end{tabular}


Table V Cement line interfaces (tissue) for adult 12 month control compact bone

\begin{tabular}{|c|c|c|}
\hline \multicolumn{3}{|c|}{ Cement Line Interfaces (Tissue) $\left(\mathrm{mm} / \mathrm{mm}^{2}\right)$} \\
\hline \multicolumn{3}{|c|}{ Seasons } \\
\hline Group & Mean & Standard Error \\
\hline Autumn & 37.298 & 3.120 \\
\hline Winter & 28.456 & 3.002 \\
\hline Spring & 28.869 & 2.889 \\
\hline Summer & 33.512 & 2.889 \\
\hline \multicolumn{3}{|c|}{ Anatomical Sectors } \\
\hline Group & Mean & Standard Error \\
\hline Craniomedial & 21.140 & 2.315 \\
\hline Cranial & 39.625 & 2.315 \\
\hline Craniolateral & 23.400 & 2.315 \\
\hline Caudomedial & 31.587 & 2.445 \\
\hline Caudal & 43.080 & 2.315 \\
\hline Caudolateral & 33.519 & 2.615 \\
\hline
\end{tabular}

Table VI Cement line interfaces (material) for adult 12 month control compact bone

\begin{tabular}{|c|c|c|}
\hline \multicolumn{3}{|c|}{ Cement Line Interfaces (Material) $\left(\mathrm{mm} / \mathrm{mm}^{2}\right)$} \\
\hline \multicolumn{3}{|c|}{ Seasons } \\
\hline Group & Mean & Standard Error \\
\hline Autumn & 38.471 & 3.230 \\
\hline Winter & 29.932 & 3.108 \\
\hline Spring & 30.213 & 2.990 \\
\hline Summer & 34.861 & 2.990 \\
\hline \multicolumn{3}{|c|}{ Anatomical Sectors } \\
\hline Group & Mean & Standard Error \\
\hline Craniomedial & 21.914 & 2.392 \\
\hline Cranial & 41.071 & 2.392 \\
\hline Craniolateral & 24.272 & 2.392 \\
\hline Caudomedial & 32.972 & 2.526 \\
\hline Caudal & 45.237 & 2.392 \\
\hline Caudolateral & 34.750 & 2.392 \\
\hline
\end{tabular}

The means and standard errors were obtained from the 2-way repeated measures ANOVA. Seasonal and anatomical differences as well as possible seasonality within the anatomical regions were determined with a $p$ value less than 0.05 . Table VII is the 2-way repeated measures ANOVA $p$ values for each 
variable. The ratio of cement line interface to osteonal radius was calculated within the statistical software. This ratio determines whether there are changes in the size of the osteons with the seasons or within the sectors.

Table VII P values for 2-way random measure ANOVA of remodeling variables

\begin{tabular}{|c|c|c|c|}
\hline \multicolumn{4}{|c|}{ 2-way Repeated Measure ANOVA: $p$ values } \\
\hline Parameter & Season & Sector & Interaction \\
\hline BV/TV & 0.035 & 0.322 & 0.930 \\
\hline \% Remodeled (Tissue) & 0.193 & 0.000 & 0.230 \\
\hline \% Remodeled (Material) & 0.232 & 0.000 & 0.193 \\
\hline Cement Line Interface (Tissue) & 0.150 & 0.000 & 0.008 \\
\hline Cement Line Interface (Material) & 0.196 & 0.000 & 0.005 \\
\hline Mean Secondary Osteon Radius & 0.034 & 0.911 & 0.424 \\
\hline CLI: Osteonal Radius Ratio & 0.107 & 0.000 & 0.000 \\
\hline
\end{tabular}

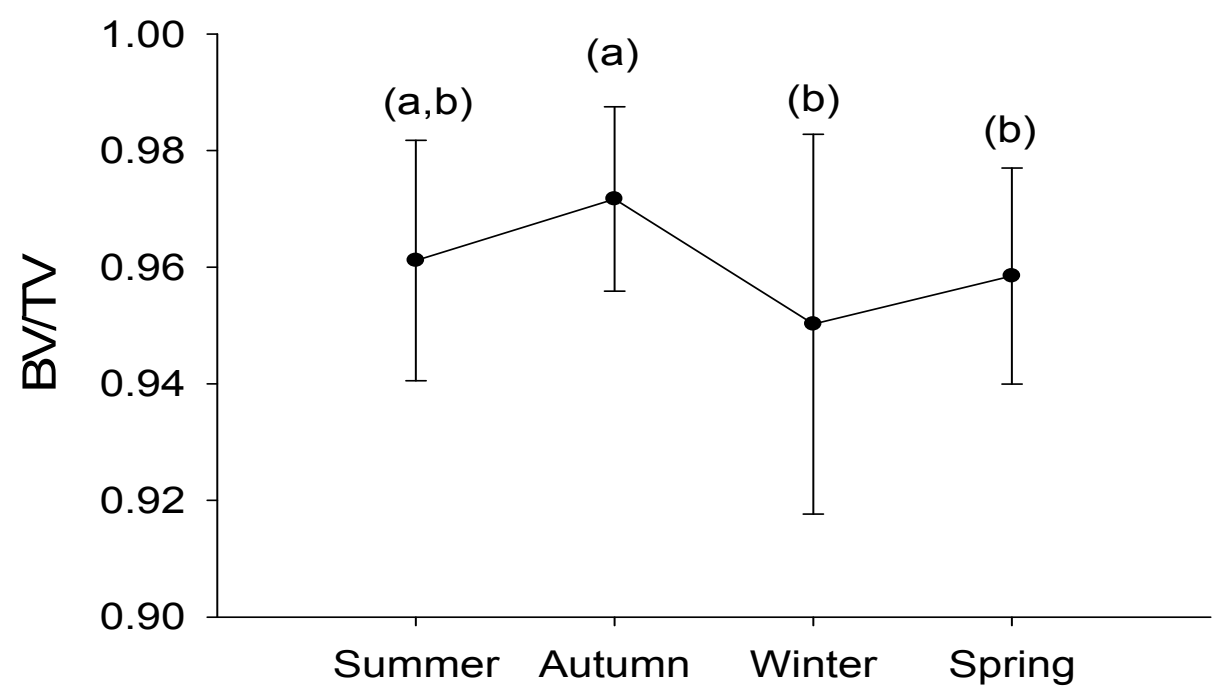

Figure 24 Mean BVITV values and standard deviations for each season 
A subtle but significant difference was seen in the BV/TV between seasons (Figure 24). Winter and spring had significantly lower BV/TV values or higher levels of porosity than autumn. Summer was shown not to be significantly different than any other season. Significant anatomical differences or seasonality within the regions was not seen in the BV/TV. There was clear and significant anatomical variation in the percent of tissue and material remodeled as shown in Figure 25 and 26 respectively. The higher levels of remodeling were seen in the caudal and cranial sides of the bone. These regions correspond to the high tensile (cranial) and compressive (caudal) regions [45]. The lower value measurements were seen to be closer to the neutral axis of the bone. Seasonal variation and seasonality within anatomical regions was not observed in the level of remodeling in the radius/ulna. 


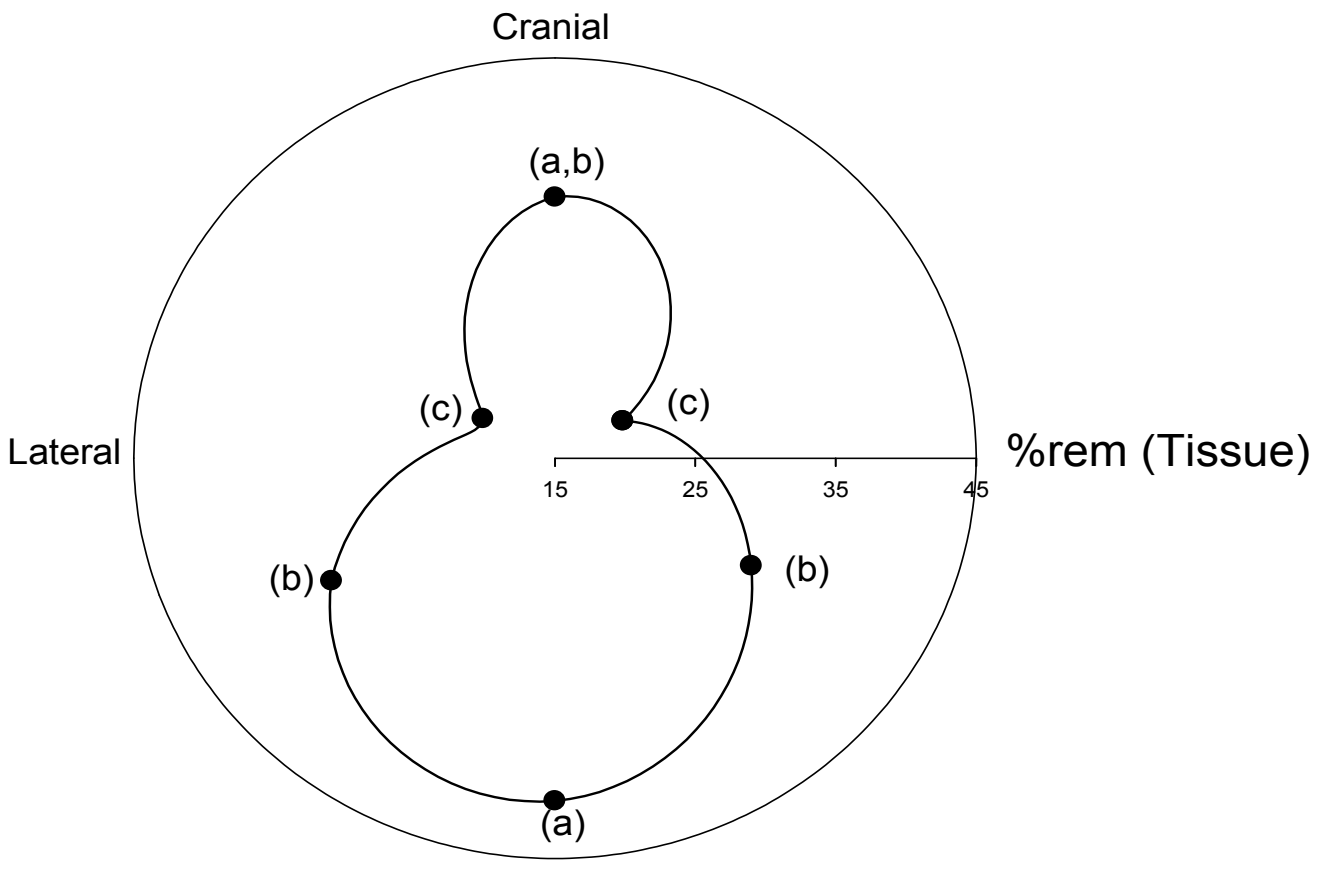

Figure 25 Anatomic variability in the percentage of tissue remodeled. The values for each sector are oriented in their approximate anatomical location on the polar graph. Distance radially away from center determines the value with respect to the scale.

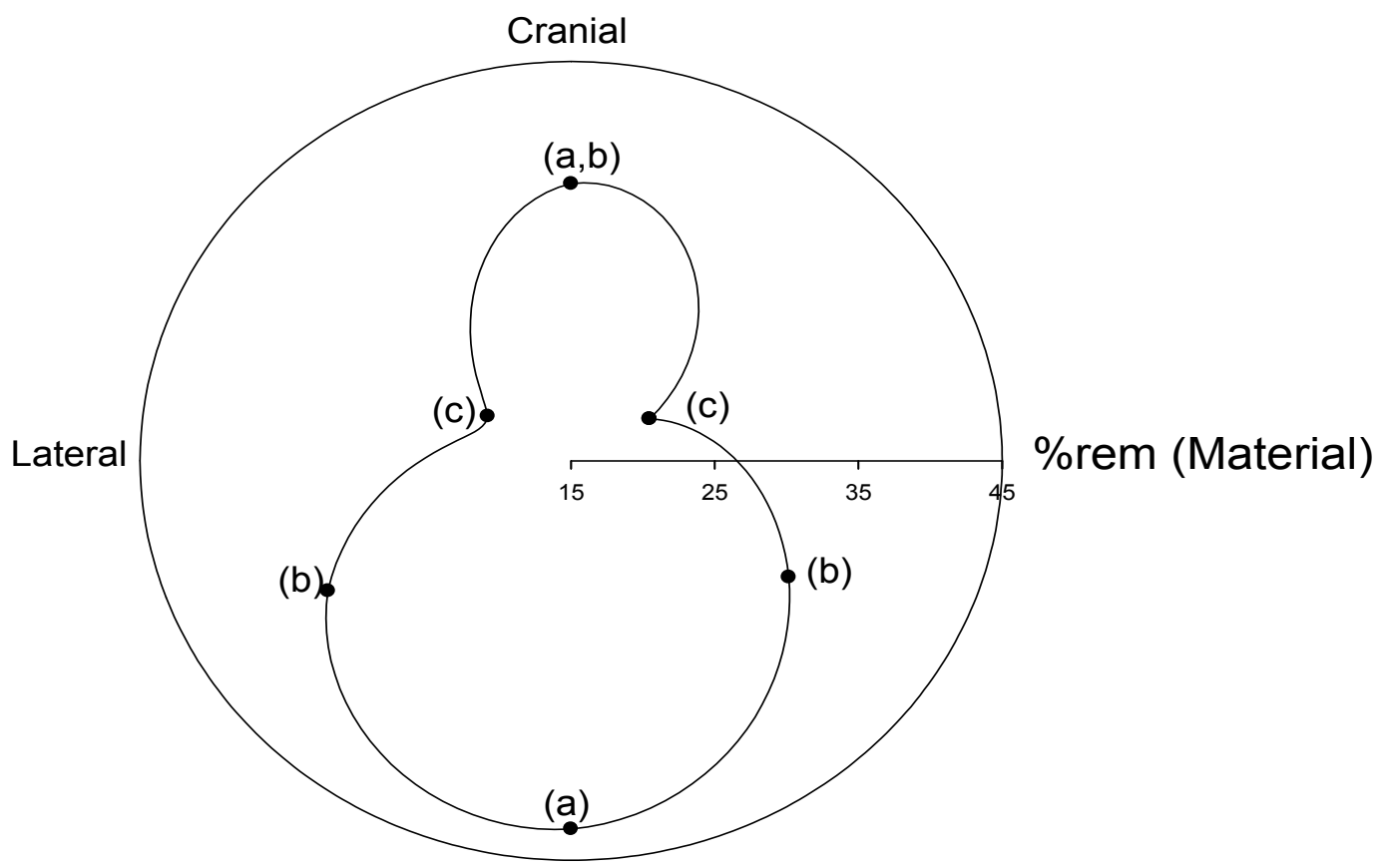

Figure 26 Anatomical variability in the percentage of bone material remodeled. The values for each sector are oriented in their approximate anatomical location on the polar graph. Distance radially away from center determines the value with respect to the scale. 


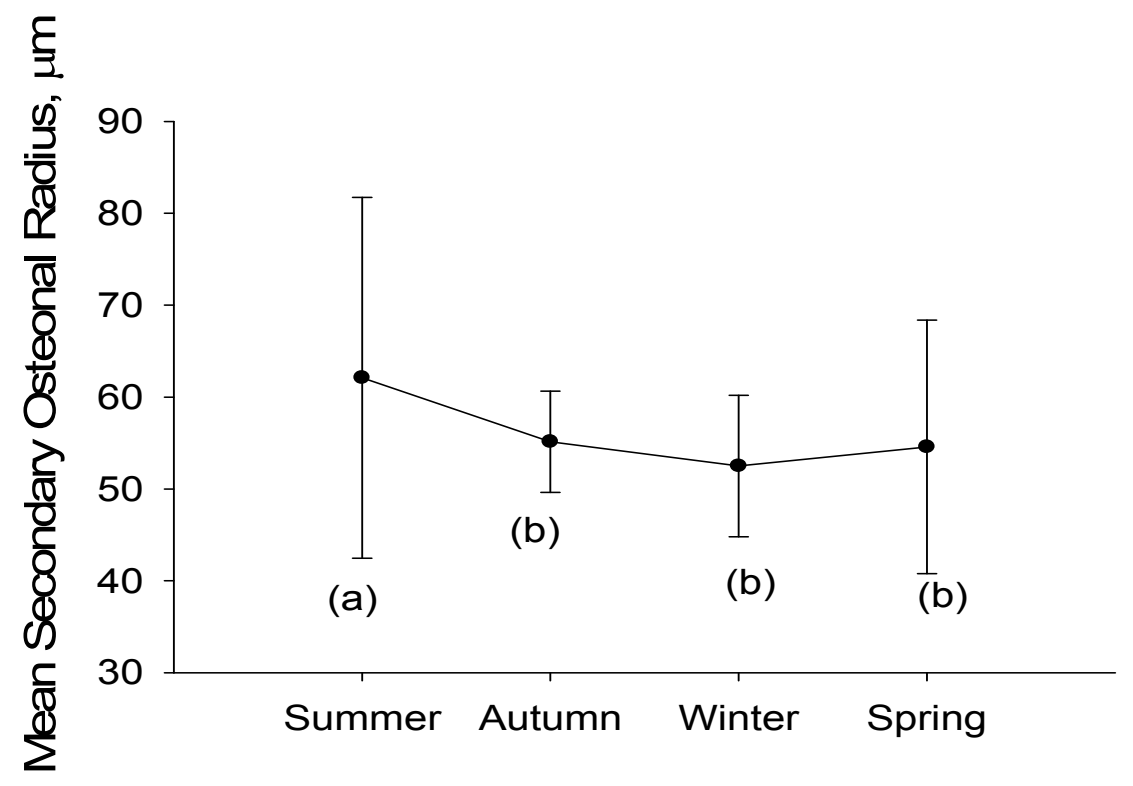

Figure 27 Seasonal variability in the mean secondary osteonal radius with standard deviations

A slight but significant seasonal difference was seen in the mean secondary osteonal radius (Figure 27). Animals sacrificed in the summer were shown to have larger secondary osteons when compared to the other seasons. No significant anatomical differences or seasonality within the anatomical regions was seen in the mean secondary osteonal radii. The mean values of the secondary osteonal radii are smaller than the 100 micrometer reference radii of human secondary osteons. Cement line interfaces for tissue and bone material showed a significant seasonality within the anatomical regions as seen in Figures 28 and 29 respectively. The caudolateral and caudomedial regions showed more seasonality than the other sectors. The other sectors showed more variability between sectors and seasons. The ratio of cement line interfaces to the mean secondary osteons showed a similar seasonal and anatomical distribution as the cement line interface distributions. 


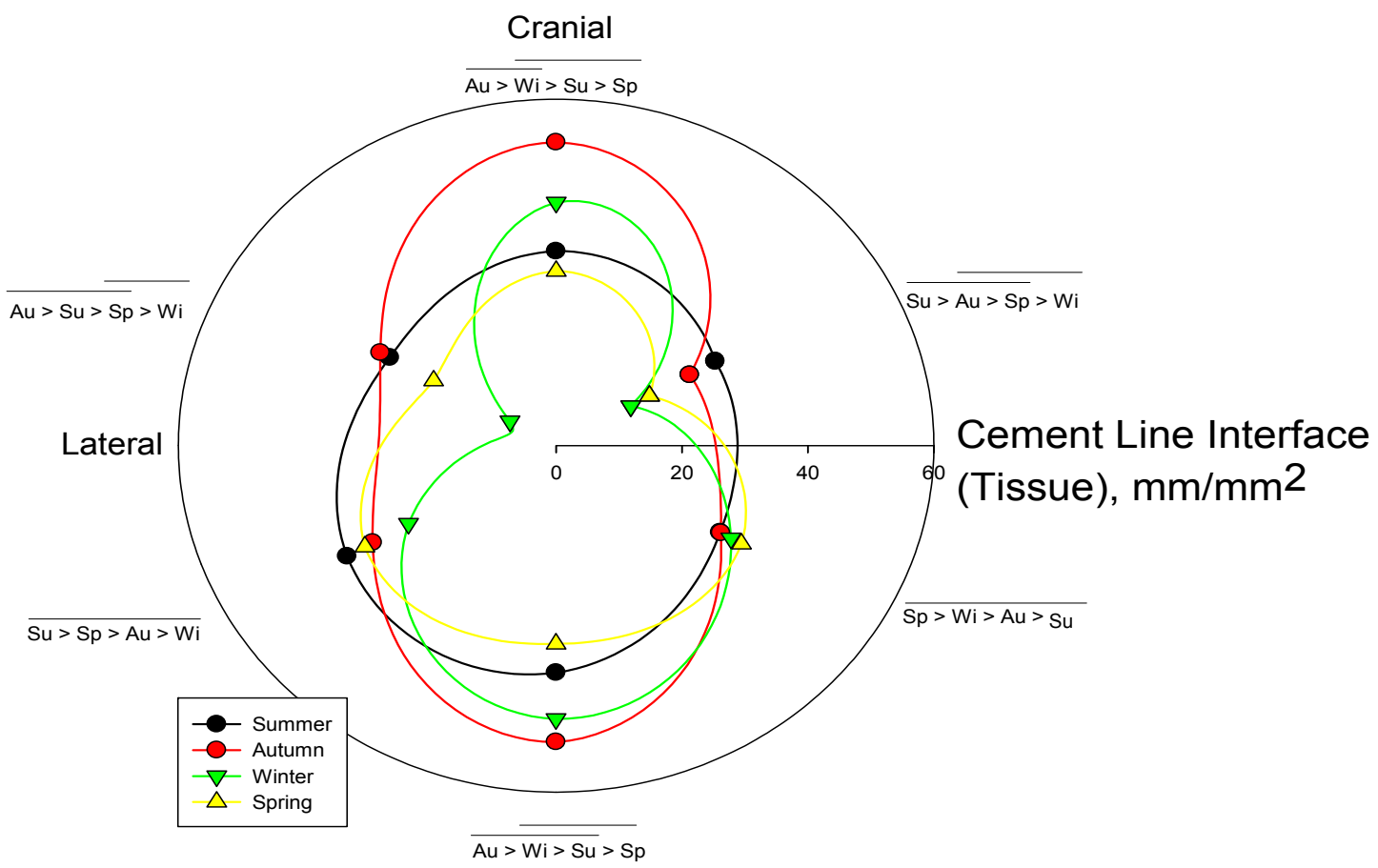

Figure 28 Anatomic variability within seasons for the number of tissue cement line interfaces. The values for each sector are oriented in their approximate anatomical location on the polar graph.

Distance radially away from center determines the value with respect to the scale.

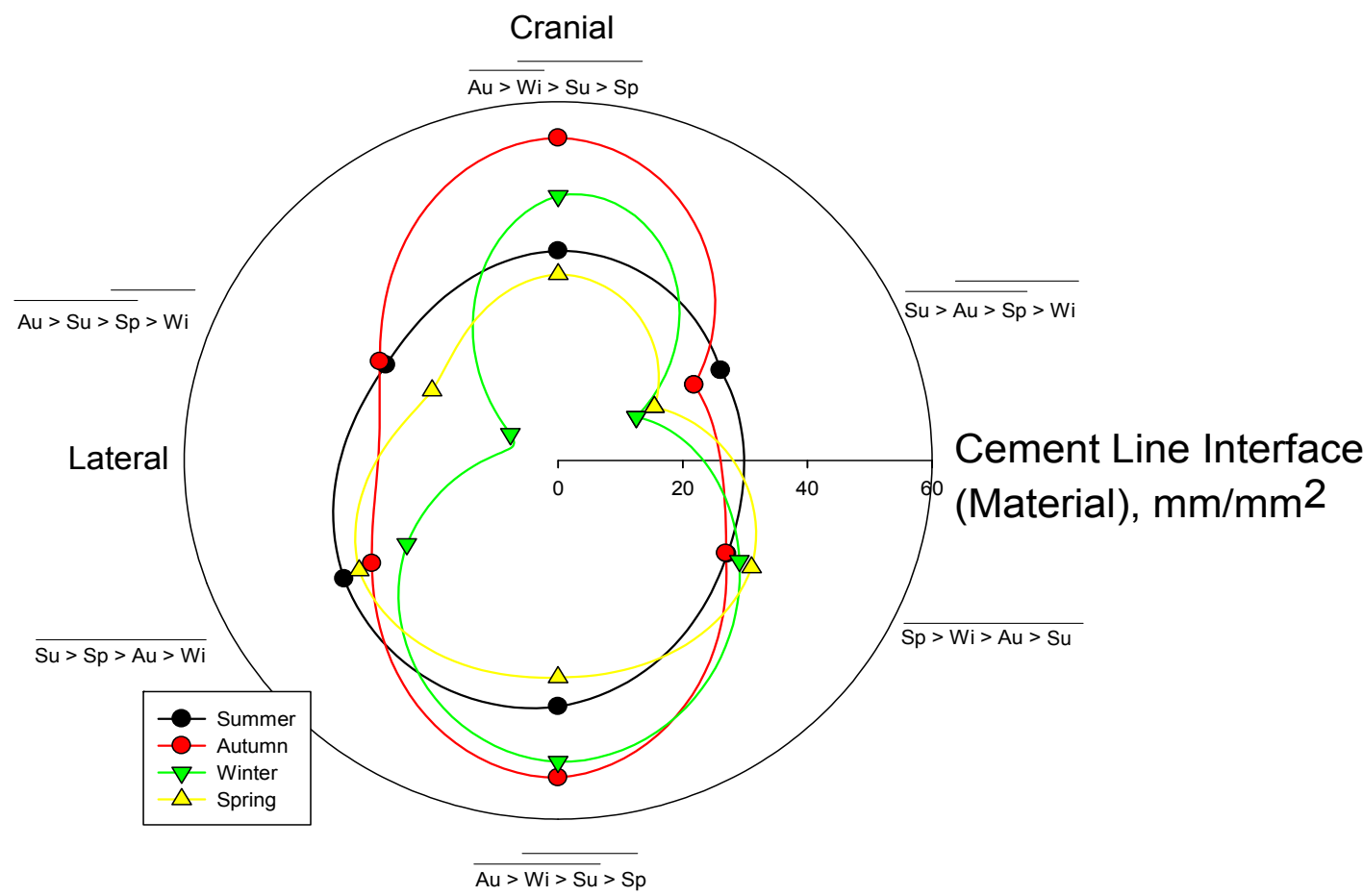

Figure 29 Anatomic variability within seasons for the number of bone cement line interfaces. The values for each sector are oriented in their approximate anatomical location on the polar graph. Distance radially away from center determines the value with respect to the scale. 


\subsection{Densitometry}

The mean pixel intensities and equivalent thicknesses of aluminum for each specimen and the calculation used from the step wedge keys are tabulated and reported in Appendix B and Appendix C. The mean pixel intensities of each level of aluminum in the step edges were measures and graphed versus their equivalent thicknesses. A best fit power function was determined for each graph. The mean pixel intensities of the samples were inputted to their corresponding best fit lines to determine their equivalent thickness of aluminum, ETA. The mean ETA values and the standard error for each season and anatomical sectors are shown in Table VIII.

Table VIII Densitometry values (ETA)

\begin{tabular}{|c|c|c|}
\hline \multicolumn{3}{|c|}{ Densitometry (ETA) (mm) } \\
\hline \multicolumn{3}{|c|}{ Seasons } \\
\hline Group & Mean & Standard Error \\
\hline Autumn & 0.100 & 0.00484 \\
\hline Winter & 0.0989 & 0.00448 \\
\hline Spring & 0.105 & 0.00448 \\
\hline Summer & 0.0844 & 0.00448 \\
\hline \multicolumn{3}{|c|}{ Anatomical Sectors } \\
\hline Group & Mean & Standard Error \\
\hline Craniomedial & 0.0965 & 0.00237 \\
\hline Cranial & 0.101 & 0.00237 \\
\hline Craniolateral & 0.104 & 0.00237 \\
\hline Caudomedial & 0.0980 & 0.00237 \\
\hline Caudal & 0.0922 & 0.00237 \\
\hline Caudolateral & 0.0915 & 0.00237 \\
\hline
\end{tabular}




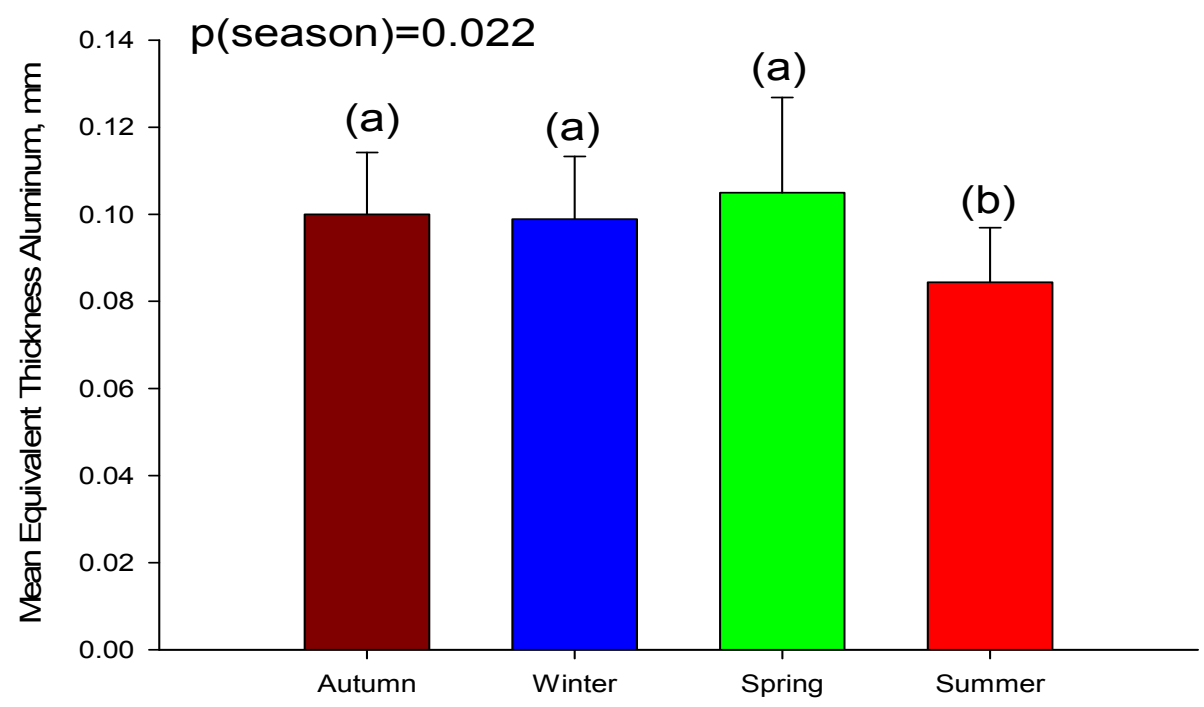

Figure 30 Seasonal variability in density measured in equivalent thickness of aluminum, ETA with standard deviations.

Upon statistical analysis a significant seasonal difference $(p=0.022)$ was seen in the density of the bone (Figure 30). Animals sacrificed in the autumn, winter, and spring had significantly denser bone than those sacrificed in the summer. No significant difference was seen between autumn, winter, and spring. A significant anatomical difference $(p=0.002)$ was also seen in the densities (Figure 31). The densest region in the radius/ulna was the craniolateral sector. Higher levels of density were observed in the cranial, craniolateral, and caudomedial sectors. No significant seasonality within the anatomical regions was seen. 


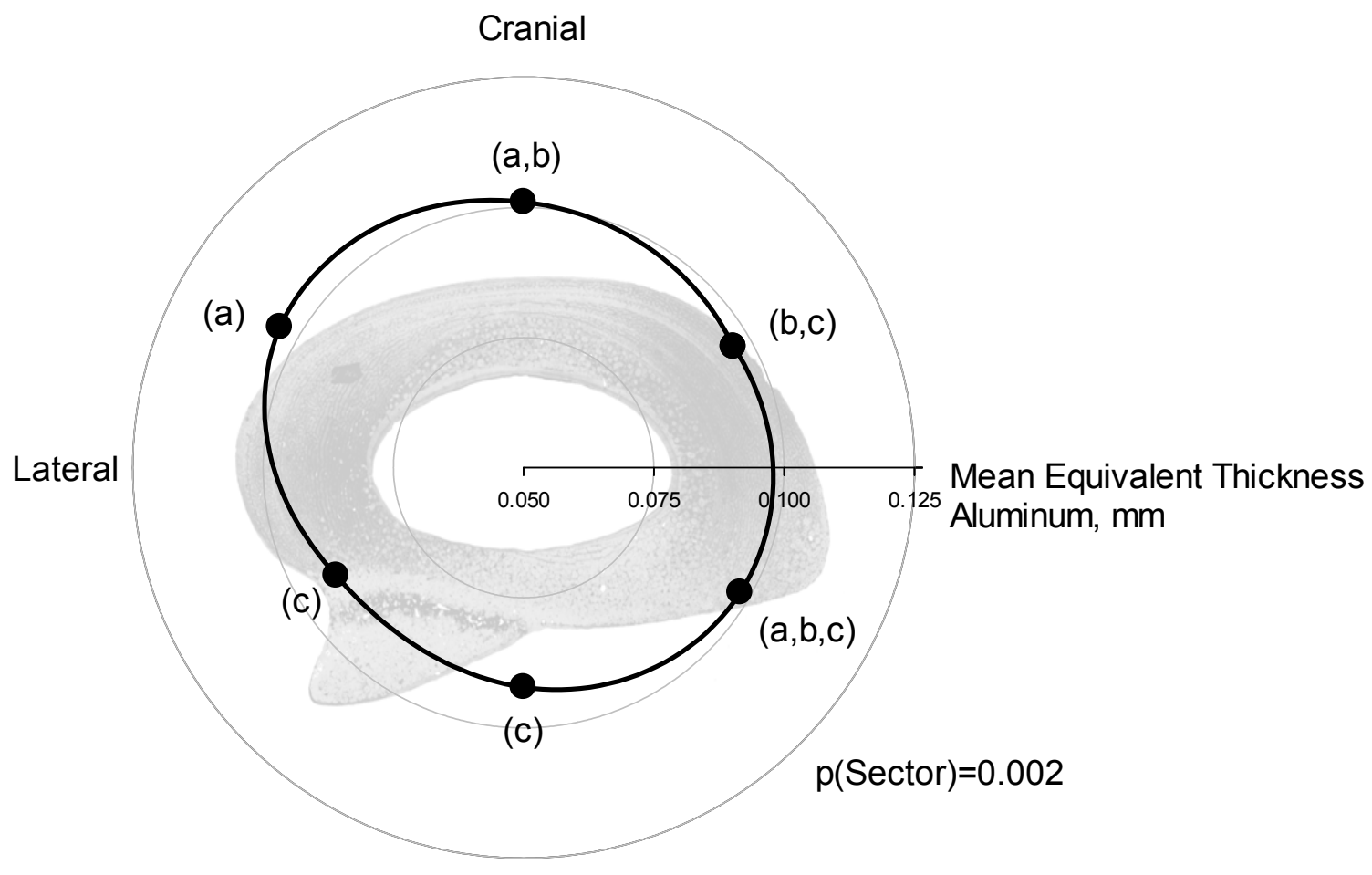

Figure 31 Anatomical variability in density measured in equivalent thickness of aluminum, ETA. The values for each sector are oriented in their approximate anatomical location on the polar graph. Distance radially away from center determines the value with respect to the scale. 


\section{Discussion}

Osteoporosis incidence is increasing rapidly with the ever growing elderly population [46]. Osteoporosis results from a decrease in bone mass. With decreasing bone mass the risk of fracture increases. Osteoporosis related fractures can cause a detriment financially as well as decrease the quality and quantity of life for the patient. Fracture fixation and healing can be difficult in osteoporotic bone. Fracture risk assessment is commonly performed using dual X-ray absorptiometry in order to determine bone mineral density. Most patients are not diagnosed with osteoporosis until after incurring a fracture from a minor traumatic event [19]. It is important to understand the risk factor associated with developing osteoporosis in order to diagnose and treat before fractures occur. There are many risk factors that can increase the risk of fracture in older patients. Exercise, smoking, alcohol intake, and age all increase the risk of osteoporosis related fractures. However, a history of fractures before the age of 50 can increase the risk of fracture in elderly women [47].

Developing methods to diagnose and quantify fracture risk in these patients before fractures occur is critical. High resolution peripheral quantitative computed tomography as well a micro-magnetic resonance imaging can provide in vivo assessment of the bone architecture and let doctors visualize the potential for fracture risk (Figure 32) [48]. Bone density is not the only factor contributing to the strength. Trabecular and cortical architecture, mineralization, and microfractures also contribute to the strength of the bone. Magnetic resonance and 
computed tomography allow for site specific analysis of the patient's bone tissue [49]. With sufficient bone loss imaging techniques, potential models can be analyzed to determine their resemblance to the human model of osteoporosis or osteopenia.

\section{A}
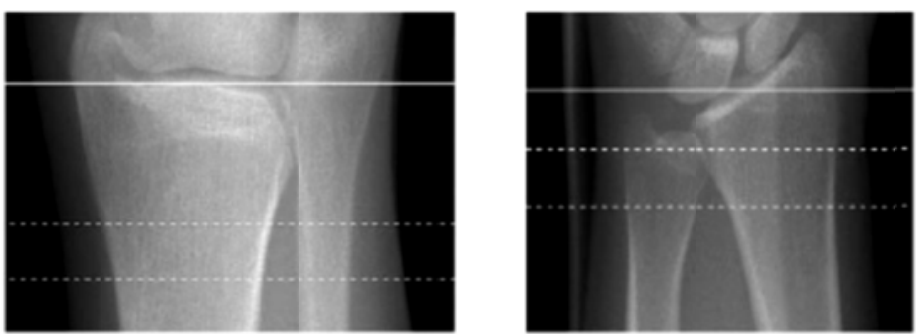

B
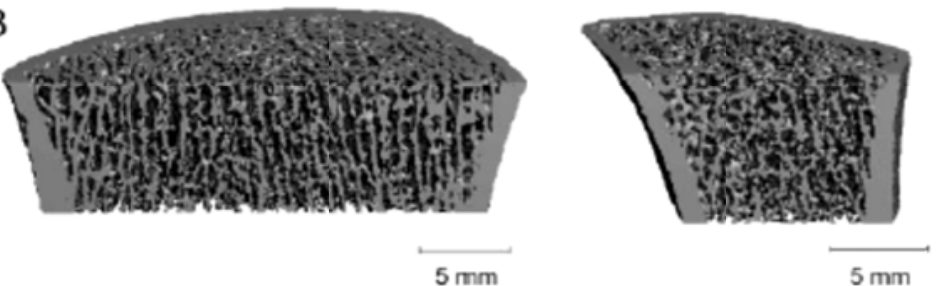

$\mathrm{C}$
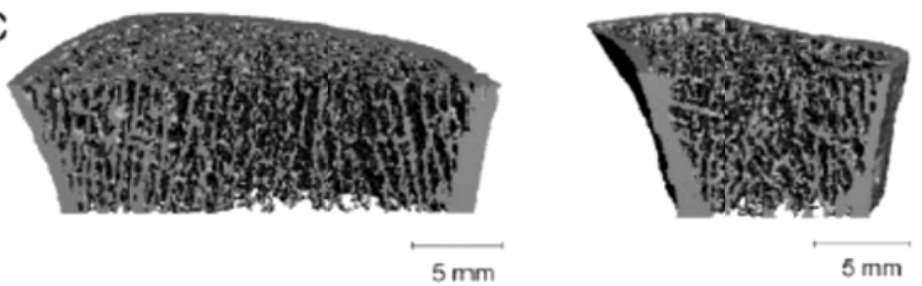

D
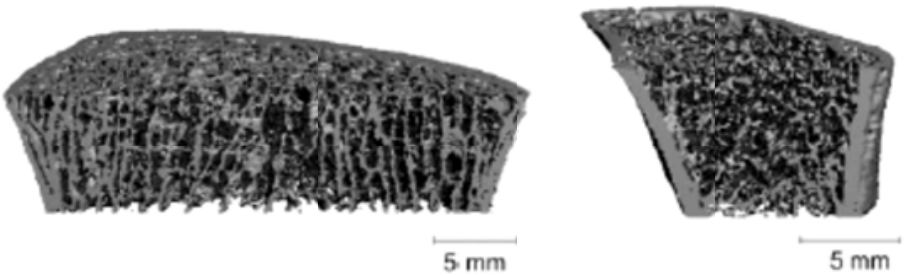

E

$5 \mathrm{~mm}$
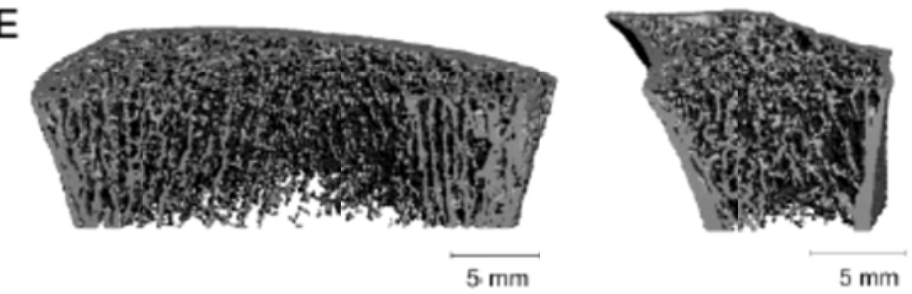

Figure 32 Representative images of the tibia (left) and radius (right). A, Scout view demonstrating the reference line position (solid line) and the measurement site (between dotted lines); B-E, images from a premenopausal (B), postmenopausal osteopenic (C), postmenopausal osteoporotic (D), and postmenopausal severe osteoporotic (E) subject [48] 
By removing the ovaries (ovariectomizing) of animals or humans osteopenia and osteoporosis can be induced. A rapid increase in bone turnover resulting in increased bone loss has been shown in multiple animal models [50]. Cancellous bone loss was seen in the proximal tibial metaphysic of ovariectomized rats and occurred during the first several months post-ovariectomy. Similar transient rapid phase bone loss has been seen in human women in early stages of estrogen deficiency [50]. Similar changes in bone loss were observed in ovariectomized monkeys. Using dual-energy X-ray absorptiometry of the vertebrae showed consistent differences between the control and ovariectomized animals [51]. This interaction in monkeys is critical due to their similarities to human cortical bone remodeling [51].

Significant changes were seen in the biomechanical properties of the ovariectomized ovine when compared to a control. Thirty eight skeletally mature sheep were divided in to an ovariectomized and a control group. Unconfined compression testing was performed on cross sections of the mid-diaphysis of the left metatarsal. The ovariectomized samples showed significantly lower yield strengths and lower mechanical properties than the control sheep (Figure 33) [2]. If devices such as pins and plates are needed for proper healing of the fracture, integration in the weaker bone can cause complications. These devices can not compromise the integrity of the native bone [27]. In order to test drugs or devices to treat osteoporosis an appropriate animal model must be developed. 

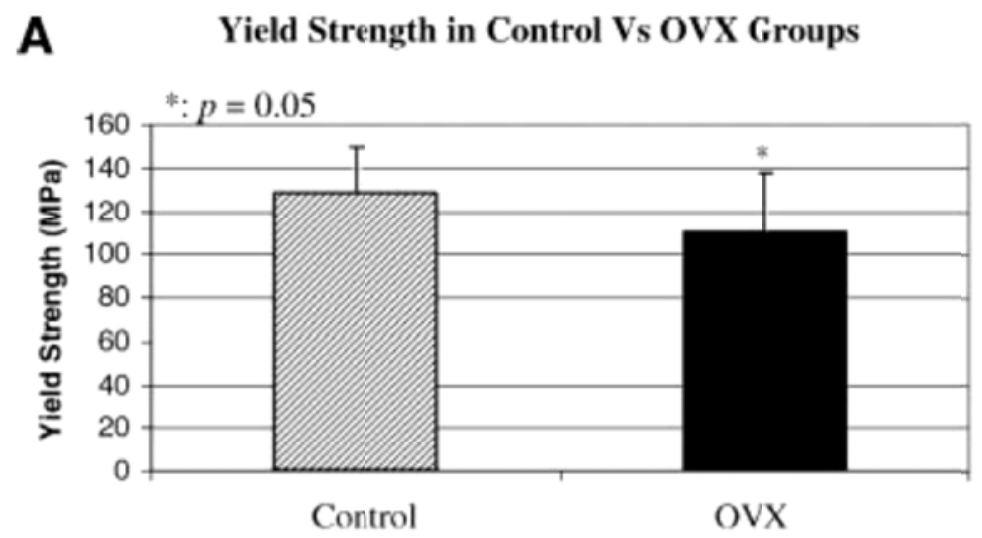

B Stiffness in Control Vs OVX Groups

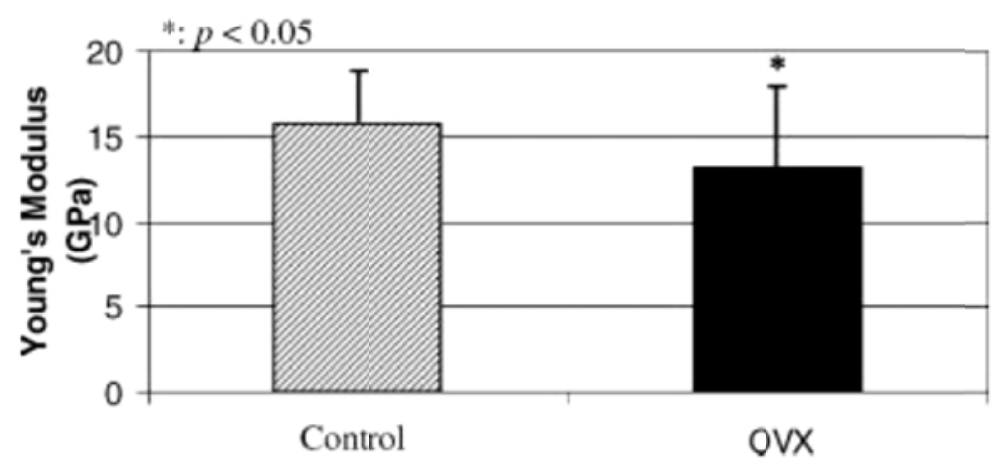

Figure 33 Yield strength and stiffness of compact bone samples from control and OVX groups [2] As discussed earlier, small animals such as rodents and rabbits are a great first step for testing drug interactions and small scale replications of postmenopausal osteoporosis [28-31]. These models however, are missing critical characteristics of human bone tissue and do not provide a large enough model to test full scale device interactions in bone tissue. Primates provide unique characteristics to developing an animal model due to major similarities to the human anatomy [30]. However, due to their lengthy skeletal maturity time and difficult housing conditions they provide an uneconomical model for large scale testing protocols.

Developing a robust economically reasonable large animal model is critical in the development of viable treatment protocols for osteoporosis. The adult sheep 
provides a large animal model with large scale bone remodeling due to hormonal, exercise, or dietary changes. Sheep undergo similar Haversian remodeling to humans in response to these conditions. Most sheep are seasonal breeders and undergo a natural anestrus period resulting in an estrogen depleted state. This condition creates a postmenopausal state during these seasons. From a research perspective this seasonal state can be a benefit. Having the sheep enter anestrus allows for analysis of the effects of menopause without ovariectomizing the sheep assuming the study is finished before spring and the exit of anestrus. However, this is a key component of the model that must be taken into consideration when considering comparisons of treatment and followup times. The seasonality of sheep has been shown to be regulated by hormones such as melatonin $[40,41]$. Changes in the loading patterns of the radius and ulna due to inactivity in different seasons have potential effects on the rate of bone turnover in varying seasons [34].

The data presented in this study shows significant effects of season on the levels of porosity (BV/TV) and the size of the mean secondary osteonal radius. The porosity levels in the bone show a cyclic nature across the seasons. An increase in porosity is seen in winter possibly due to the entering of winter anestrus and changes in the levels of bone turnover. During winter a decrease in activity would result in decrease in loading. With decreases in loading there is the potential for a decrease in the stimulus for remodeling. A recovery is seen through spring and summer until the BV/TV levels reach a maximum in autumn. The secondary osteon size significantly increases in summer. This potentially could be in 
response to the increased porosity in winter. Larger secondary osteons means that there is an increased area of new bone turnover. With increased osteonal size, there is a larger amount of secondary bone. Secondary bone tends to be less dense due to the lower levels of mineralization when compared to primary bone or even with older secondary bone. With a lower mineralization in bone a decrease in density will be seen. This observation is supported by summer showing significantly lower density levels with respect to the other seasons. Significant anatomical variations in the densities of the samples were also seen.

When looking at where the increased levels of remodeling (\% tissue and material remodeled) are occurring, the data shows significant anatomical variation in the sections. Higher levels of remodeling are occurring in areas of high compressive or tensile stress regions. These areas tend to be regions in which remodeling has already occurred with the craniolateral and craniomedial regions showing the highest levels of primary bone. Seasonality was observed in the number of cement line interfaces as well as the ratio of cement line interfaces to mean secondary osteonal radius. Seasonal variation was seen in all sectors except the caudolateral and caudomedial sectors. From this data it can be speculated that remodeling tends to occur in regions that have previously remodeled.

This research has shown seasonal and anatomical variations in various aspects of compact bone remodeling in the adult Columbian-Rambouillet cross ewes. These variations were not due to a treatment or implantation of a device, but provide a baseline of remodeling factors. Since significant changes were observed, future research needs to take these factors into consideration when 
choosing a treatment model. Treatment times and follow up times must be kept consistent between the treatment groups in order to provide a valid comparison. In addition, samples should be obtained from similar anatomic regions. These sheep were all housed in dry lot conditions in a USDA 5/6 climate zone. Comparison of sheep housed in different climate and housing conditions should not be made. These factors should be kept as consistent as possible.

One of the limitations of the study is a purchase cohort effect cannot be excluded from consideration. The sheep were already skeletally mature upon arrival at the facility in Colorado. The cohort effect was minimized with a post operation time span of 12 months or 3 to 4 remodeling cycles allowing any previous tissue responses to be remodeled away. The sheep were also housed at the same facility, with the same feed quality, sunlight, breeding, and exercise conditions.

Another limitation to the study is that the microradiographs are two dimensional integrations or projections of a three dimensional structure. The thickness of the section is a significant proportion of the dimensions of many of the features being measured. This presents difficulties and room for noise in the histomorphometric analysis and whether structures are present in the viewing plane and whether they should be counted.

Micro radiograph exposure presented limitations in the ability to make histomorphometric measurements. A few sectors had to be removed from analysis due to the inability to visualize the structures in the sample. Exposure issues also presented limitations during density measurements. Denser samples 
were washed out under the higher light intensities needed to visualize the less dense sectors. This can be accommodated by capturing a new step wedge key for each section at the appropriate light intensity.

There is a large potential for future work in this study. During densitometry analysis, porosity was not corrected for when calculating equivalent thickness of aluminum measurements. Samples that had larger levels of porosity could be represented as low density bone. Thresholding images to remove for porosity could result in a more accurate measurement of density. This measurement would represent the density of bone material and not tissue density. This measurement would be more equivalent to densities determined by ashing.

The larger study consisted of sheep at different time points and treatment protocols. With these samples similar measures of remodeling in adult ovine bone will be made under the same protocol. Animals in the same purchase cohorts were sacrificed after 1 remodeling cycle or 3 months after arrival at the facility. Adult sheep were also ovariectomized and then sacrificed at 12 and 3 months. These sheep immediately undergo a state of estrogen depletion and provide a potential model for postmenopausal osteoporosis.

Studying seasonality in human bone remodeling is difficult due to inconsistent social and environmental factors. However, research has shown cyclic patterns and seasonal variability in the biochemical markers of remodeling in humans, particularly adult females (Figure 34$)[52,53]$. Other biological factors such as 
Vitamin $D$ levels and the effects of the pineal gland in the remodeling process provide great potential or confounding factors in osteoporosis research [41].

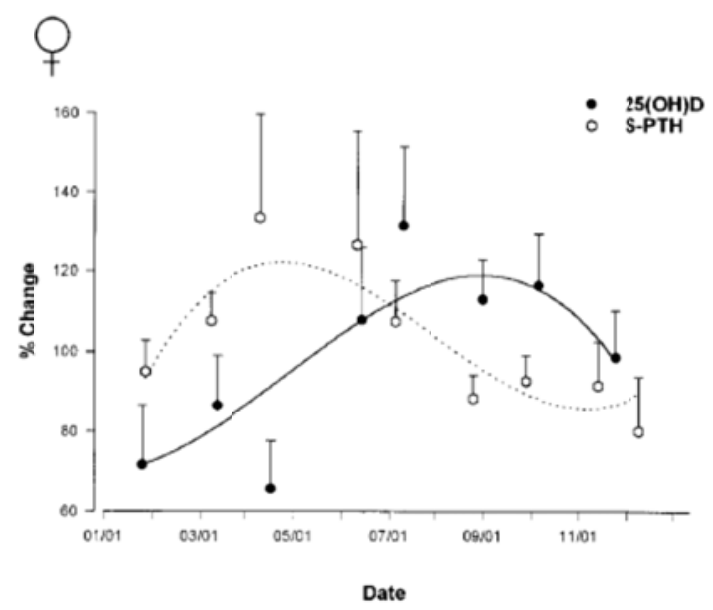

Figure 34 Seasonal variability in $250 \mathrm{HD}$ and S-PTH (univariate analysis). Values are given as percent change from the annual mean ( \pm SEM) [53]

With the significant variations in season, anatomical variation, or seasonality across anatomical regions demonstrated in this research, it is critical to have a quantifiable model of compact bone remodeling. In order for future studies to compare treatment protocols or follow up lengths there must be an understanding of the changes in the remodeling across seasons and locations. Comparing a winter cranial sector to an autumn caudolateral sector and assuming that the remodeling in the regions is equivalent is an incorrect assumption. Overall, the higher variation in remodeling parameters occurred in autumn and summer and the cranial and caudal sectors. The lower levels of variation were seen in the medial and lateral regions as well as winter and spring. This research provides not only support of varying levels of remodeling in adult ovine bone, but provides a control model for the 12 month ovariectomized sheep simulating post-menopausal osteoporosis. 


\section{Conclusions}

The adult ewe provides a robust economical animal model for the study of compact bone remodeling. Sheep have large scale Haversian remodeling due to hormonal, exercise, or dietary changes similar to humans. Their bone size allows for implantation studies of orthopedic implants for the treatment or prevention of osteoporosis related fractures. However, due to the seasonal breeding of most species, treatment effects can be masked by changes in remodeling factors during anestrus. During anestrus, the ewes undergo an estrogen depleted state altering hormone levels critical for regulating remodeling. Remodeling parameters in a control animal must be quantified before disease and treatment models can be analyzed.

This research has shown significant seasonal and anatomical variations in compact bone remodeling. Seasonal variation was seen in porosity, mean secondary osteonal radius, and density across the samples. Significant anatomical variations were seen in both percent remodeling measurements as well as density. Seasonality within the anatomical regions was seen in the cement line interfaces as well as the ratio of cement line interface to secondary osteonal radius.

With significant variations between seasons and anatomical sectors it will be critical that future studies take time of treatment, length of follow up, and sample location into consideration when making comparisons to treatment data. Comparing data in different seasons or anatomical locations might present a false positive in the results due to changes in remodeling characteristics across 
these variables. In order to ensure that data is not masked or amplified by the background remodeling, location and time points should be equivalent between models. However, if time and anatomical variations between models are not possible, smaller deviations in remodeling parameters were seen in the medial and lateral sectors as well as in winter and spring. With these remodeling characteristics quantified for compact bone of the adult sheep comparisons can be made to the ovariectomized ewes' to quantify the models relevance to postmenopausal humans. 


\section{LIST OF REFERENCES}

1. NIH. NIH Osteoporosis and Related Bone Diseases: National Resource Center. Available from: http://www.bones.nih.gov.

2. Kennedy, O.D., et al., Effects of ovariectomy on bone turnover, porosity, and biomechanical properties in ovine compact bone 12 months postsurgery. J Orthop Res, 2009. 27(3): p. 303-9.

3. Cauley, J.A., et al., Risk of mortality following clinical fractures. Osteoporos Int, 2000. 11(7): p. 556-61.

4. Center, J.R., et al., Mortality after all major types of osteoporotic fracture in men and women: an observational study. Lancet, 1999. 353(9156): p. 878-82.

5. Ethier, C.R. and C.A. Simmons, Introductory Biomechanics: From Cells to Organisms. 2007, New York: Cambridge University Press.

6. Martin, R.B., D.B. Burr, and N.A. Sharkey, Skeletal Tissue Mechanics. 2004, New York: Springer.

7. Buchman, S.R., et al., Use of microcomputed tomography scanning as a new technique for the evaluation of membranous bone. Journal of Craniofacial Surgery, 1998. 9(1): p. 48-54.

8. Antich, P.P., et al., Measurement of Mechanical-Properties of Bone Material Invitro by Ultrasound Reflection - Methodology and Comparison with Ultrasound Transmission. Journal of Bone and Mineral Research, 1991. 6(4): p. 417-426.

9. Recker, R.R., Bone Histomorphometry: Techniques and Interpretation. 1983, Boca Raton: CRC Press.

10. Siegmund, T., M.R. Allen, and D.B. Burr, Can deterministic mechanical size effects contribute to fracture and microdamage accumulation in trabecular bone? Journal of Theoretical Biology. 265(2): p. 202-210.

11. Hryce, T., Modeling the Long Term Effects of Alendronate on Bone Mass Preservation of the Femur with Articular Surface and Total Hip Replacements, in Biomedical Engineering. 2010, California Polytechnic State University: San Luis Obispo. p. 130.

12. Teitelbaum, S.L., Bone resorption by osteoclasts. Science, 2000. 289(5484): p. 1504-8.

13. Beaupre, G.S., T.E. Orr, and D.R. Carter, An Approach for Time-Dependent Bone Modeling and Remodeling - Theoretical Development. Journal of Orthopaedic Research, 1990. 8(5): p. 651-661.

14. Cowin, S.C., S. Weinbaum, and Y. Zeng, A Case for Bone Canaliculi as the Anatomical Site of Strain Generated Potentials. Journal of Biomechanics, 1995. 28(11): p. 1281-1297.

15. Martin, R.B., Toward a unifying theory of bone remodeling. Bone, 2000. 26(1): p. 1-6.

16. Burr, D.B., et al., Bone Remodeling in Response to Invivo Fatigue Microdamage. Journal of Biomechanics, 1985. 18(3): p. 189-\&. 
17. Hedgecock, N.L., et al., Quantitative regional associations between remodeling, modeling, and osteocyte apoptosis and density in rabbit tibial midshafts. Bone, 2007. 40(3): p. 627-637.

18. Poole, K.E.S. and J.E. Compston, Osteoporosis and its management. British Medical Journal, 2006. 333(7581): p. 1251-1256B.

19. Augat, P., et al., Osteoporosis prevalence and fracture characteristics in elderly female patients with fractures. Archives of Orthopaedic and Trauma Surgery. 130(11): p. 1405-1410.

20. Nelson, H.D., et al., Osteoporosis and fractures in postmenopausal women using estrogen. Arch Intern Med, 2002. 162(20): p. 2278-84.

21. Jilka, R.L., Cytokines, bone remodeling, and estrogen deficiency: a 1998 update. Bone, 1998. 23(2): p. 75-81.

22. Horowitz, M.C., et al., Control of osteoclastogenesis and bone resorption by members of the TNF family of receptors and ligands. Cytokine Growth Factor Rev, 2001. 12(1): p. 9-18.

23. Leslie, W.D., S. Morin, and L.M. Lix, A Before-and-After Study of Fracture Risk Reporting and Osteoporosis Treatment Initiation. Annals of Internal Medicine. 153(9): p. 580-W200.

24. Briesacher, B.A., et al., Adherence and occurrence of fractures after switching to once-monthly oral bisphophonates. Pharmacoepidemiology and Drug Safety. 19(12): p. 1233-1240.

25. Al-Azzawi, F., Prevention of postmenopausal osteoporosis and associated fractures: Clinical evaluation of the choice between estrogen and bisphosphonates. Gynecol Endocrinol, 2008. 24(11): p. 601-9.

26. Bone, H.G., et al., Alendronate and estrogen effects in postmenopausal women with low bone mineral density. Alendronate/Estrogen Study Group. J Clin Endocrinol Metab, 2000. 85(2): p. 720-6.

27. Turner, A.S., Seasonal changes in bone metabolism in sheep: further characterization of an animal model for human osteoporosis. Vet J, 2007. 174(3): p. 460-1.

28. Kubek, D.J., D.B. Burr, and M.R. Allen, Ovariectomy stimulates and bisphosphonates inhibit intracortical remodeling in the mouse mandible. Orthodontics \& Craniofacial Research. 13(4): p. 214-222.

29. Feher, A., et al., Bisphosphonates do not inhibit periosteal bone formation in estrogen deficient animals and allow enhanced bone modeling in response to mechanical loading. Bone. 46(1): p. 203-207.

30. Newman, E., A.S. Turner, and J.D. Wark, The Potential of Sheep for the Study of Osteopenia - Current Status and Comparison with Other Animal-Models. Bone, 1995. 16(4): p. S277-S284.

31. Baofeng, L., et al., Characterization of a rabbit osteoporosis model induced by ovariectomy and glucocorticoid. Acta Orthop. 81(3): p. 396-401.

32. Newton, B.I., et al., The ovariectomized sheep as a model for human bone loss. J Comp Pathol, 2004. 130(4): p. 323-6. 
33. Arens, D., et al., Seasonal changes in bone metabolism in sheep. Vet J, 2007. 174(3): p. 585-91.

34. Turner, A.S., The sheep as a model for osteoporosis in humans. Vet J, 2002. 163(3): p. 232-9.

35. Kararli, T.T., Comparison of the gastrointestinal anatomy, physiology, and biochemistry of humans and commonly used laboratory animals. Biopharm Drug Dispos, 1995. 16(5): p. 351-80.

36. Turner, A.S., et al., Changes in bone mineral density and bone-specific alkaline phosphatase in ovariectomized ewes. Bone, 1995. 17(4 Suppl): p. 395S-402S.

37. Sigrist, I.M., et al., The long-term effects of ovariectomy on bone metabolism in sheep. J Bone Miner Metab, 2007. 25(1): p. 28-35.

38. Wu, Z.X., et al., Effect of ovariectomy on BMD, micro-architecture and biomechanics of cortical and cancellous bones in a sheep model. Med Eng Phys, 2008. 30(9): p. 1112-8.

39. Rosen, C.J., et al., Elderly women in northern New England exhibit seasonal changes in bone mineral density and calciotropic hormones. Bone Miner, 1994. 25(2): p. 83-92.

40. Rosa, H.J.D. and M.J. Bryant, Seasonality of reproduction in sheep. Small Ruminant Research, 2003. 48(3): p. 155-171.

41. Arendt, J., A.M. Symons, and C. Laud, Pineal function in the sheep: evidence for a possible mechanism mediating seasonal reproductive activity. Experientia, 1981. 37(6): p. 584-6.

42. Boivin, G. and P.J. Meunier, The degree of mineralization of bone tissue measured by computerized quantitative contact microradiography. Calcif Tissue Int, 2002. 70(6): p. 503-11.

43. Wessel, N., Pechey, CL, MacLeay, JM, Turner, AS, and Les, CM, Short- and Medium-term Estrogen-depletion-related Changes in Anatomic Variation of Time-dependent Materials Properties, and Evidence of Compact Bone Secondary Remodeling, in Orthopedic Research Society. 2010. p. 580.

44. Yates, A.J., et al., Radiographic absorptiometry in the diagnosis of osteoporosis. Am J Med, 1995. 98(2A): p. 41S-47S.

45. Lanyon, L.E., P.T. Magee, and D.G. Baggott, The relationship of functional stress and strain to the processes of bone remodelling. An experimental study on the sheep radius. J Biomech, 1979. 12(8): p. 593-600.

46. Parsons, L.C., Osteoporosis: incidence, prevention, and treatment of the silent killer. Nurs Clin North Am, 2005. 40(1): p. 119-33.

47. Cummings, S.R., et al., Risk-Factors for Hip Fracture in White Women. New England Journal of Medicine, 1995. 332(12): p. 767-773.

48. Boutroy, S., et al., In vivo assessment of trabecular bone microarchitecture by high-resolution peripheral quantitative computed tomography. Journal of Clinical Endocrinology \& Metabolism, 2005. 90(12): p. 6508-6515.

49. Majumdar, S., Magnetic resonance imaging for osteoporosis. Skeletal Radiology, 2008. 37(2): p. 95-97. 
50. Wronski, T.J., et al., Long-Term Effects of Ovariectomy and Aging on the Rat Skeleton. Calcified Tissue International, 1989. 45(6): p. 360-366.

51. Jerome, C.P., Primate models of osteoporosis. Laboratory Animal Science, 1998. 48(6): p. 618-622.

52. Woitge, H.W., et al., Circaannual rhythms and interactions of vitamin $D$ metabolites, parathyroid hormone, and biochemical markers of skeletal homeostasis: a prospective study. J Bone Miner Res, 2000. 15(12): p. 2443-50.

53. Woitge, H.W., et al., Seasonal variation of biochemical indexes of bone turnover: results of a population-based study. J Clin Endocrinol Metab, 1998. 83(1): p. 6875. 


\section{Appendix A 12 Month Control Histomorphometry Data}

\begin{tabular}{|c|c|c|c|c|c|c|}
\hline \multicolumn{7}{|c|}{12 Month Summer Control } \\
\hline \multicolumn{7}{|c|}{ Average BV/TV } \\
\hline \multicolumn{7}{|c|}{ Sector } \\
\hline Sheep & Craniomedial & Cranial & Craniolateral & Caudomedial & Caudal & Caudolateral \\
\hline C01 & 0.986 & 0.944 & 0.931 & 0.972 & 0.931 & 0.972 \\
\hline $\mathrm{CO3}$ & 0.963 & 0.951 & 0.951 & 0.972 & 0.944 & 0.944 \\
\hline C06 & 0.972 & 0.944 & 0.972 & 0.958 & 0.931 & 0.993 \\
\hline $\mathrm{CO} 0$ & 0.986 & 0.944 & 0.903 & 0.965 & 0.958 & 0.979 \\
\hline $\mathrm{C} 11$ & 0.931 & 0.958 & 0.951 & 0.958 & 0.979 & 0.972 \\
\hline C22 & 0.972 & 0.979 & 0.991 & 0.972 & 0.979 & 0.938 \\
\hline $\mathrm{C} 26$ & 0.958 & 0.993 & 0.972 & 0.935 & 0.972 & 0.986 \\
\hline \multicolumn{7}{|c|}{ Average Percent Remodeled (Tissue) (Remodeled Tissue/Total Area) } \\
\hline & \multicolumn{6}{|c|}{ Sector } \\
\hline Sheep & Craniomedial & Cranial & Craniolateral & Caudomedial & Caudal & Caudolateral \\
\hline C01 & 0.563 & 0.463 & 0.458 & 0.491 & 0.333 & 0.417 \\
\hline $\mathrm{CO3}$ & 0.444 & 0.500 & 0.208 & 0.090 & 0.389 & 0.438 \\
\hline $\mathrm{CO6}$ & 0.319 & 0.153 & 0.333 & 0.153 & 0.313 & 0.326 \\
\hline $\mathrm{C} 07$ & 0.340 & 0.250 & 0.083 & 0.521 & 0.451 & 0.507 \\
\hline C11 & 0.083 & 0.139 & 0.118 & 0.160 & 0.479 & 0.222 \\
\hline $\mathrm{C} 22$ & 0.111 & 0.444 & 0.324 & 0.375 & 0.243 & 0.500 \\
\hline $\mathrm{C} 26$ & 0.347 & 0.472 & 0.410 & 0.380 & 0.368 & 0.514 \\
\hline \multicolumn{7}{|c|}{ Average Percent Remodeled (Material) (Remodeled Tissue/Bone Area) } \\
\hline & \multicolumn{6}{|c|}{$\begin{array}{c}\text { Sector } \\
\end{array}$} \\
\hline Sheep & Craniomedial & Cranial & Craniolateral & Caudomedial & Caudal & Caudolateral \\
\hline C01 & 0.570 & 0.490 & 0.492 & 0.504 & 0.354 & 0.429 \\
\hline $\mathrm{CO3}$ & 0.462 & 0.525 & 0.220 & 0.092 & 0.409 & 0.463 \\
\hline C06 & 0.327 & 0.159 & 0.345 & 0.159 & 0.335 & 0.329 \\
\hline C07 & 0.346 & 0.265 & 0.092 & 0.542 & 0.469 & 0.518 \\
\hline C11 & 0.089 & 0.146 & 0.124 & 0.166 & 0.489 & 0.226 \\
\hline C22 & 0.113 & 0.454 & 0.327 & 0.385 & 0.249 & 0.529 \\
\hline $\mathrm{C} 26$ & 0.364 & 0.476 & 0.422 & 0.404 & 0.378 & 0.521 \\
\hline \multicolumn{7}{|c|}{ Average Osteonal Radius $(\mu \mathrm{m})$} \\
\hline & \multicolumn{6}{|c|}{$\begin{array}{c}\text { Sector } \\
\end{array}$} \\
\hline Sheep & Craniomedial & Cranial & Craniolateral & Caudomedial & Caudal & Caudolateral \\
\hline $\mathrm{C} 01$ & 63.90 & 61.07 & 85.90 & 100.51 & 49.24 & 95.45 \\
\hline $\mathrm{CO3}$ & 69.32 & 65.99 & 52.73 & 60.40 & 45.66 & 55.15 \\
\hline $\mathrm{C} 06$ & 71.59 & 79.90 & 141.62 & 37.52 & 48.08 & 52.33 \\
\hline $\mathrm{C} 07$ & 65.01 & 60.20 & 26.84 & 76.92 & 61.72 & 63.71 \\
\hline C11 & 61.76 & 27.96 & 34.26 & 50.32 & 60.26 & 40.83 \\
\hline $\mathrm{C} 22$ & 64.43 & 63.68 & 63.45 & 60.74 & 50.11 & 68.27 \\
\hline $\mathrm{C} 26$ & 54.89 & 60.98 & 62.41 & 69.10 & 55.90 & 67.78 \\
\hline \multicolumn{7}{|c|}{ Average CLI (Tissue) $\left(\mathrm{mm} / \mathrm{mm}^{2}\right)$} \\
\hline & \multicolumn{6}{|c|}{ Sector } \\
\hline Sheep & Craniomedial & Cranial & Craniolateral & Caudomedial & Caudal & Caudolateral \\
\hline C01 & 54.75 & 49.67 & 55.75 & 52.33 & 36.00 & 40.50 \\
\hline $\mathrm{C03}$ & 53.33 & 56.25 & 25.25 & 10.25 & 54.75 & 52.75 \\
\hline C06 & 18.75 & 19.00 & 32.50 & 18.00 & 31.00 & 33.75 \\
\hline $\mathrm{C} 07$ & 29.75 & 17.00 & 10.75 & 45.50 & 47.00 & 41.50 \\
\hline C11 & 6.75 & 10.00 & 12.50 & 12.00 & 48.50 & 18.67 \\
\hline C22 & 10.33 & 40.00 & 35.00 & 36.75 & 22.50 & 36.50 \\
\hline $\mathrm{C} 26$ & 30.75 & 43.75 & 41.75 & 35.67 & 35.50 & 44.50 \\
\hline
\end{tabular}




\begin{tabular}{|c|c|c|c|c|c|c|}
\hline \multicolumn{7}{|c|}{ Average CLI (Material) $\left(\mathrm{mm} / \mathrm{mm}^{2}\right)$} \\
\hline & \multicolumn{6}{|c|}{ Sector } \\
\hline Sheep & Craniomedial & Cranial & Craniolateral & Caudomedial & Caudal & Caudolateral \\
\hline $\mathrm{C} 01$ & 55.54 & 52.59 & 59.96 & 53.96 & 38.69 & 41.83 \\
\hline $\mathrm{C} 03$ & 55.44 & 59.13 & 26.56 & 10.50 & 57.87 & 56.11 \\
\hline $\mathrm{C} 06$ & 19.35 & 19.98 & 33.40 & 18.79 & 33.27 & 33.99 \\
\hline $\mathrm{C} 07$ & 30.19 & 18.00 & 11.79 & 47.25 & 49.10 & 42.41 \\
\hline C11 & 7.29 & 10.53 & 13.27 & 12.64 & 49.52 & 19.02 \\
\hline $\mathrm{C} 22$ & 10.56 & 40.98 & 35.32 & 37.77 & 23.09 & 38.82 \\
\hline $\mathrm{C} 26$ & 32.35 & 44.05 & 42.98 & 38.46 & 36.59 & 45.21 \\
\hline \multicolumn{7}{|c|}{12 Month Autumn Control } \\
\hline \multicolumn{7}{|c|}{ Average BV/TV } \\
\hline & \multicolumn{6}{|c|}{ Sector } \\
\hline Sheep & Craniomedial & Cranial & Craniolateral & Caudomedial & Caudal & Caudolateral \\
\hline C44 & 0.972 & 0.958 & 0.986 & 0.965 & 0.951 & 0.972 \\
\hline $\mathrm{C} 46$ & 0.986 & 0.993 & 0.979 & 0.951 & 0.986 & 0.986 \\
\hline C47 & 0.951 & 0.958 & 0.965 & 0.986 & 0.951 & 0.951 \\
\hline C50 & 0.986 & 0.979 & 0.958 & 0.965 & 0.965 & 0.979 \\
\hline C54 & 0.986 & 0.981 & 0.972 & 1.000 & 0.986 & 0.986 \\
\hline C55 & 0.944 & 0.979 & 0.979 & 0.931 & 0.972 & 0.979 \\
\hline \multicolumn{7}{|c|}{ Average Percent Remodeled (Tissue) (Remodeled Tissue/Total Area) } \\
\hline & \multicolumn{6}{|c|}{ Sector } \\
\hline Sheep & Craniomedial & Cranial & Craniolateral & Caudomedial & Caudal & Caudolateral \\
\hline C44 & 0.264 & 0.507 & 0.500 & 0.278 & 0.528 & 0.465 \\
\hline C46 & 0.188 & 0.444 & 0.201 & 0.285 & 0.458 & 0.208 \\
\hline C47 & 0.222 & 0.389 & 0.264 & 0.250 & 0.424 & 0.326 \\
\hline C50 & 0.111 & 0.368 & 0.313 & 0.306 & 0.458 & 0.271 \\
\hline C54 & 0.306 & 0.333 & 0.236 & 0.493 & 0.389 & 0.250 \\
\hline C55 & 0.264 & 0.354 & 0.319 & 0.069 & 0.326 & 0.500 \\
\hline \multicolumn{7}{|c|}{ Average Percent Remodeled (Material) (Remodeled Tissue/Bone Area) } \\
\hline & \multicolumn{6}{|c|}{\begin{tabular}{|c|} 
Sector \\
\end{tabular}} \\
\hline Sheep & Craniomedial & Cranial & Craniolateral & Caudomedial & Caudal & Caudolateral \\
\hline C44 & 0.271 & 0.529 & 0.505 & 0.288 & 0.555 & 0.479 \\
\hline C46 & 0.190 & 0.448 & 0.206 & 0.299 & 0.465 & 0.211 \\
\hline C47 & 0.233 & 0.406 & 0.274 & 0.254 & 0.446 & 0.344 \\
\hline C50 & 0.113 & 0.375 & 0.326 & 0.317 & 0.474 & 0.276 \\
\hline C54 & 0.310 & 0.341 & 0.242 & 0.493 & 0.395 & 0.254 \\
\hline C55 & 0.279 & 0.362 & 0.325 & 0.075 & 0.335 & 0.511 \\
\hline \multicolumn{7}{|c|}{ Average Osteonal Radius ( $\mu \mathrm{m})$} \\
\hline & \multicolumn{6}{|c|}{ Sector } \\
\hline Sheep & Craniomedial & Cranial & Craniolateral & Caudomedial & Caudal & Caudolateral \\
\hline C44 & 55.00 & 58.80 & 64.28 & 52.59 & 66.48 & 57.53 \\
\hline C46 & 57.37 & 63.44 & 55.08 & 59.94 & 54.31 & 53.03 \\
\hline $\mathrm{C} 47$ & 55.48 & 52.13 & 54.36 & 48.70 & 53.22 & 58.03 \\
\hline C50 & 56.86 & 52.58 & 44.09 & 57.86 & 60.12 & 52.79 \\
\hline C54 & 49.52 & 50.55 & 60.66 & 57.99 & 50.35 & 57.53 \\
\hline C55 & 62.09 & 49.59 & 58.82 & 43.10 & 43.68 & 56.82 \\
\hline \multicolumn{7}{|c|}{ Average CLI (Tissue) $\left(\mathrm{mm} / \mathrm{mm}^{2}\right)$} \\
\hline & & & $\mathrm{Se}$ & & & \\
\hline
\end{tabular}




\begin{tabular}{|c|c|c|c|c|c|c|}
\hline Sheep & Craniomedial & Cranial & Craniolateral & Caudomedial & Caudal & Caudolateral \\
\hline $\mathrm{C} 44$ & 29.25 & 60.50 & 42.25 & 36.25 & 57.50 & 44.25 \\
\hline C46 & 20.75 & 48.25 & 24.75 & 29.25 & 58.75 & 26.50 \\
\hline C47 & 22.75 & 52.50 & 28.75 & 24.50 & 55.50 & 28.25 \\
\hline C50 & 13.25 & 53.00 & 35.25 & 31.00 & 42.25 & 26.50 \\
\hline C54 & 38.00 & 50.33 & 28.75 & 48.25 & 48.25 & 27.00 \\
\hline C55 & 23.00 & 50.50 & 33.50 & 12.00 & 45.75 & 49.25 \\
\hline \multicolumn{7}{|c|}{ Average CLI (Material) $\left(\mathrm{mm} / \mathrm{mm}^{2}\right)$} \\
\hline & \multicolumn{6}{|c|}{ Sector } \\
\hline Sheep & Craniomedial & Cranial & Craniolateral & Caudomedial & Caudal & Caudolateral \\
\hline $\mathrm{C} 44$ & 30.09 & 63.30 & 42.75 & 37.59 & 60.47 & 45.54 \\
\hline C46 & 21.05 & 48.60 & 25.32 & 30.81 & 59.67 & 26.90 \\
\hline C47 & 23.83 & 54.55 & 29.78 & 24.83 & 58.52 & 29.76 \\
\hline C50 & 13.47 & 54.10 & 36.76 & 32.14 & 43.81 & 27.02 \\
\hline C54 & 38.49 & 51.37 & 29.50 & 48.25 & 48.96 & 27.47 \\
\hline C55 & 24.38 & 51.59 & 34.09 & 12.93 & 46.98 & 50.31 \\
\hline \multicolumn{7}{|c|}{12 Month Winter Control } \\
\hline \multicolumn{7}{|c|}{ Average BV/TV } \\
\hline & \multicolumn{6}{|c|}{ Sector } \\
\hline Sheep & Craniomedial & Cranial & Craniolateral & Caudomedial & Caudal & Caudolateral \\
\hline C59 & 0.938 & 0.847 & 0.979 & 0.965 & 0.847 & 0.938 \\
\hline C75 & 0.965 & 0.993 & 0.958 & 0.938 & 0.958 & 0.944 \\
\hline C77 & 0.944 & 0.979 & 0.938 & 0.951 & 0.954 & 0.979 \\
\hline C80 & 0.944 & 0.979 & 0.972 & 0.000 & 0.972 & 0.972 \\
\hline C82 & 0.944 & 0.910 & 0.951 & 0.944 & 0.868 & 0.944 \\
\hline C83 & 0.958 & 0.965 & 0.958 & 0.000 & 0.986 & 0.979 \\
\hline C84 & 0.965 & 0.958 & 0.965 & 0.931 & 0.965 & 0.958 \\
\hline \multicolumn{7}{|c|}{ Average Percent Remodeled (Tissue) (Remodeled Tissue/Total Area) } \\
\hline & \multicolumn{6}{|c|}{$\begin{array}{c}\text { Sector } \\
\end{array}$} \\
\hline Sheep & Craniomedial & Cranial & Craniolateral & Caudomedial & Caudal & Caudolateral \\
\hline C59 & 0.042 & 0.229 & 0.069 & 0.132 & 0.299 & 0.167 \\
\hline C75 & 0.083 & 0.431 & 0.118 & 0.188 & 0.563 & 0.167 \\
\hline C77 & 0.326 & 0.438 & 0.007 & 0.486 & 0.500 & 0.708 \\
\hline C80 & 0.264 & 0.417 & 0.188 & 0.000 & 0.465 & 0.118 \\
\hline C82 & 0.063 & 0.299 & 0.083 & 0.611 & 0.326 & 0.042 \\
\hline C83 & 0.132 & 0.417 & 0.028 & 0.000 & 0.368 & 0.431 \\
\hline C84 & 0.014 & 0.243 & 0.035 & 0.021 & 0.417 & 0.188 \\
\hline \multicolumn{7}{|c|}{ Average Percent Remodeled (Material) (Remodeled Tissue/Bone Area) } \\
\hline & \multicolumn{6}{|c|}{ Sector } \\
\hline Sheep & Craniomedial & Cranial & Craniolateral & Caudomedial & Caudal & Caudolateral \\
\hline C59 & 0.044 & 0.272 & 0.072 & 0.139 & 0.352 & 0.179 \\
\hline C75 & 0.086 & 0.434 & 0.125 & 0.199 & 0.587 & 0.174 \\
\hline C77 & 0.345 & 0.446 & 0.008 & 0.512 & 0.521 & 0.723 \\
\hline C80 & 0.279 & 0.426 & 0.196 & 0.000 & 0.479 & 0.121 \\
\hline C82 & 0.068 & 0.333 & 0.089 & 0.648 & 0.374 & 0.044 \\
\hline C83 & 0.138 & 0.433 & 0.028 & 0.000 & 0.373 & 0.440 \\
\hline C84 & 0.015 & 0.253 & 0.036 & 0.022 & 0.432 & 0.194 \\
\hline \multicolumn{7}{|c|}{ Average Osteonal Radius $(\mu \mathrm{m})$} \\
\hline & & & Se & & & \\
\hline
\end{tabular}




\begin{tabular}{|c|c|c|c|c|c|c|}
\hline Sheep & Craniomedial & Cranial & Craniolateral & Caudomedial & Caudal & Caudolateral \\
\hline C59 & 37.97 & 52.97 & 44.50 & 53.49 & 53.17 & 50.67 \\
\hline C75 & 54.43 & 51.13 & 59.53 & 44.76 & 57.65 & 49.62 \\
\hline $\mathrm{C} 77$ & 60.57 & 52.98 & 37.38 & 53.72 & 50.32 & 68.93 \\
\hline C80 & 61.66 & 51.18 & 53.06 & 0.00 & 59.06 & 48.95 \\
\hline C82 & 38.68 & 54.34 & 53.89 & 68.50 & 57.58 & 44.14 \\
\hline C83 & 67.23 & 50.71 & 50.59 & 0.00 & 50.95 & 51.99 \\
\hline C84 & 35.24 & 57.27 & 55.01 & 45.26 & 53.77 & 56.86 \\
\hline \multicolumn{7}{|c|}{ Average CLI (Tissue) $\left(\mathrm{mm} / \mathrm{mm}^{2}\right)$} \\
\hline & \multicolumn{6}{|c|}{ Sector } \\
\hline Sheep & Craniomedial & Cranial & Craniolateral & Caudomedial & Caudal & Caudolateral \\
\hline C59 & 7.25 & 30.25 & 7.00 & 16.25 & 38.75 & 20.00 \\
\hline C75 & 8.75 & 50.75 & 13.50 & 28.50 & 55.25 & 22.75 \\
\hline $\mathrm{C} 77$ & 29.75 & 51.00 & 0.50 & 54.75 & 57.67 & 50.00 \\
\hline $\mathrm{C} 80$ & 26.75 & 51.00 & 22.50 & 0.00 & 52.50 & 14.75 \\
\hline C82 & 9.50 & 36.00 & 7.75 & 47.50 & 37.00 & 8.50 \\
\hline C83 & 10.50 & 49.75 & 3.50 & 0.00 & 48.50 & 51.75 \\
\hline C84 & 3.50 & 26.00 & 4.25 & 2.50 & 41.75 & 21.75 \\
\hline \multicolumn{7}{|c|}{ Average CLI (Material) $\left(\mathrm{mm} / \mathrm{mm}^{2}\right)$} \\
\hline & \multicolumn{6}{|c|}{ Sector } \\
\hline Sheep & Craniomedial & Cranial & Craniolateral & Caudomedial & Caudal & Caudolateral \\
\hline C59 & 7.72 & 35.98 & 7.27 & 17.00 & 45.66 & 21.43 \\
\hline C75 & 9.04 & 51.14 & 14.30 & 30.34 & 57.71 & 23.93 \\
\hline C77 & 31.50 & 51.97 & 0.56 & 57.66 & 60.61 & 51.05 \\
\hline C80 & 28.41 & 52.13 & 23.38 & 0.00 & 54.08 & 15.19 \\
\hline C82 & 10.32 & 39.59 & 8.19 & 50.48 & 42.45 & 9.14 \\
\hline C83 & 10.95 & 51.55 & 3.67 & 0.00 & 49.11 & 52.89 \\
\hline C84 & 3.65 & 27.16 & 4.37 & 2.68 & 43.29 & 22.51 \\
\hline \multicolumn{7}{|c|}{12 Month Spring Control } \\
\hline \multicolumn{7}{|c|}{ Average BVITV } \\
\hline & \multicolumn{6}{|c|}{ Sector } \\
\hline Sheep & Craniomedial & Cranial & Craniolateral & Caudomedial & Caudal & Caudolateral \\
\hline C91 & 0.938 & 0.958 & 0.972 & 0.965 & 0.938 & 0.958 \\
\hline C96 & 0.986 & 0.958 & 0.951 & 0.944 & 0.958 & 0.924 \\
\hline C97 & 0.958 & 1.000 & 0.951 & 0.924 & 0.944 & 0.965 \\
\hline C99 & 0.972 & 0.986 & 0.979 & 0.938 & 0.931 & 0.951 \\
\hline C103 & 0.993 & 0.944 & 0.972 & 0.965 & 0.931 & 0.979 \\
\hline C108 & 0.965 & 0.931 & 0.972 & 0.958 & 0.965 & 0.951 \\
\hline C109 & 0.951 & 0.979 & 0.951 & 0.951 & 0.972 & 0.951 \\
\hline \multicolumn{7}{|c|}{ Average Percent Remodeled (Tissue) (Remodeled Tissue/Total Area) } \\
\hline & \multicolumn{6}{|c|}{ Sector } \\
\hline Sheep & Craniomedial & Cranial & Craniolateral & Caudomedial & Caudal & Caudolateral \\
\hline C91 & 0.174 & 0.125 & 0.306 & 0.549 & 0.590 & 0.535 \\
\hline C96 & 0.160 & 0.250 & 0.090 & 0.215 & 0.521 & 0.410 \\
\hline C97 & 0.410 & 0.389 & 0.118 & 0.403 & 0.549 & 0.125 \\
\hline C99 & 0.035 & 0.396 & 0.389 & 0.292 & 0.125 & 0.076 \\
\hline C103 & 0.083 & 0.313 & 0.000 & 0.444 & 0.479 & 0.389 \\
\hline C108 & 0.090 & 0.188 & 0.007 & 0.153 & 0.542 & 0.188 \\
\hline C109 & 0.118 & 0.382 & 0.444 & 0.444 & 0.083 & 0.528 \\
\hline \multicolumn{7}{|c|}{ Average Percent Remodeled (Material) (Remodeled Tissue/Bone Area) } \\
\hline & \multicolumn{6}{|c|}{ Sector } \\
\hline Sheep & Craniomedial & Cranial & Craniolateral & Caudomedial & Caudal & Caudolateral \\
\hline C91 & 0.184 & 0.129 & 0.316 & 0.569 & 0.627 & 0.557 \\
\hline
\end{tabular}




\begin{tabular}{|c|c|c|c|c|c|c|}
\hline C96 & 0.163 & 0.261 & 0.095 & 0.228 & 0.544 & 0.444 \\
\hline C97 & 0.426 & 0.389 & 0.125 & 0.434 & 0.581 & 0.129 \\
\hline C99 & 0.036 & 0.399 & 0.396 & 0.313 & 0.132 & 0.080 \\
\hline C103 & 0.084 & 0.329 & 0.000 & 0.459 & 0.514 & 0.398 \\
\hline C108 & 0.093 & 0.203 & 0.007 & 0.158 & 0.562 & 0.199 \\
\hline C109 & 0.124 & 0.390 & 0.469 & 0.465 & 0.087 & 0.554 \\
\hline \multicolumn{7}{|c|}{ Average Osteonal Radius $(\mu \mathrm{m})$} \\
\hline & \multicolumn{6}{|c|}{$\begin{array}{l}\text { Sector } \\
\end{array}$} \\
\hline Sheep & Craniomedial & Cranial & Craniolateral & Caudomedial & Caudal & Caudolateral \\
\hline C91 & 48.97 & 43.73 & 58.21 & 80.83 & 67.27 & 61.33 \\
\hline C96 & 50.45 & 55.82 & 38.74 & 43.50 & 60.55 & 55.43 \\
\hline C97 & 62.01 & 52.53 & 51.41 & 64.80 & 64.41 & 53.87 \\
\hline C99 & 33.40 & 55.53 & 57.72 & 56.27 & 74.76 & 32.80 \\
\hline C103 & 61.16 & 51.76 & 0.00 & 58.82 & 53.10 & 55.68 \\
\hline C108 & 53.94 & 69.94 & 26.43 & 56.91 & 66.49 & 59.42 \\
\hline C109 & 44.13 & 57.40 & 66.36 & 63.98 & 59.86 & 62.72 \\
\hline \multicolumn{7}{|c|}{ Average CLI (Tissue) $\left(\mathrm{mm} / \mathrm{mm}^{2}\right)$} \\
\hline & \multicolumn{6}{|c|}{ Sector } \\
\hline Sheep & Craniomedial & Cranial & Craniolateral & Caudomedial & Caudal & Caudolateral \\
\hline C91 & 28.50 & 14.50 & 36.50 & 39.50 & 47.75 & 49.00 \\
\hline C96 & 19.75 & 28.00 & 11.75 & 32.75 & 43.75 & 49.00 \\
\hline C97 & 33.75 & 41.00 & 17.25 & 29.50 & 44.00 & 16.50 \\
\hline C99 & 6.75 & 37.50 & 43.75 & 35.25 & 9.00 & 14.25 \\
\hline C103 & 7.25 & 35.75 & 0.00 & 43.25 & 45.75 & 40.50 \\
\hline C108 & 9.75 & 15.25 & 2.00 & 18.25 & 43.50 & 24.25 \\
\hline C109 & 14.25 & 39.50 & 46.00 & 39.50 & 6.50 & 52.00 \\
\hline \multicolumn{7}{|c|}{ Average CLI (Material) $\left(\mathrm{mm} / \mathrm{mm}^{2}\right)$} \\
\hline & \multicolumn{6}{|c|}{ Sector } \\
\hline Sheep & Craniomedial & Cranial & Craniolateral & Caudomedial & Caudal & Caudolateral \\
\hline C91 & 30.23 & 14.95 & 37.65 & 40.95 & 51.53 & 51.17 \\
\hline C96 & 20.14 & 29.22 & 12.38 & 34.78 & 45.60 & 53.18 \\
\hline C97 & 35.06 & 41.00 & 18.32 & 31.95 & 46.51 & 17.10 \\
\hline C99 & 7.00 & 37.84 & 44.59 & 37.88 & 9.53 & 15.00 \\
\hline C103 & 7.30 & 37.90 & 0.00 & 44.71 & 49.19 & 41.41 \\
\hline C108 & 10.07 & 16.48 & 2.04 & 19.07 & 45.06 & 25.47 \\
\hline C109 & 14.97 & 40.36 & 48.38 & 41.62 & 6.71 & 54.64 \\
\hline
\end{tabular}




\section{Appendix B 12 Month Control Densitometry Data}

\begin{tabular}{|c|c|c|c|c|c|c|}
\hline Key & Sheep & Specimen & Season & Sector & $\begin{array}{c}\text { Mean Pixel } \\
\text { Intensity }\end{array}$ & ETA $(\mathrm{mm})$ \\
\hline 10 & C44 & C4414 & Autumn & Craniomedial & 172.7765 & 0.09501686 \\
\hline 10 & C44 & C4412 & Autumn & Cranial & 198.5427 & 0.100925894 \\
\hline 10 & C44 & C4407 & Autumn & Craniolateral & 176.8247 & 0.095976794 \\
\hline 10 & C44 & C4418 & Autumn & Caudomedial & 132.9139 & 0.084792749 \\
\hline 10 & C44 & C4411 & Autumn & Caudal & 168.4556 & 0.09397811 \\
\hline 10 & C44 & C4403 & Autumn & Caudolateral & 77.5224 & 0.067101784 \\
\hline 10 & C46 & C4611 & Autumn & Craniomedial & 200.3506 & 0.10132375 \\
\hline 10 & C46 & C4608 & Autumn & Cranial & 197.8032 & 0.100762566 \\
\hline 10 & $\mathrm{C} 46$ & C4605 & Autumn & Craniolateral & 251.2486 & 0.111784562 \\
\hline 10 & C46 & C4613 & Autumn & Caudomedial & 224.8937 & 0.106535329 \\
\hline 10 & $\mathrm{C} 46$ & C4607 & Autumn & Caudal & 217.7813 & 0.105059675 \\
\hline 10 & C46 & C4603 & Autumn & Caudolateral & 212.5517 & 0.103957172 \\
\hline 11 & $\mathrm{C} 47$ & C4712 & Autumn & Craniomedial & 124.2711 & 0.100330882 \\
\hline 11 & $\mathrm{C} 47$ & C4711 & Autumn & Cranial & 121.618 & 0.099388679 \\
\hline 11 & $\mathrm{C} 47$ & C4706 & Autumn & Craniolateral & 65.3278 & 0.075741246 \\
\hline 11 & $\mathrm{C} 47$ & C4715 & Autumn & Caudomedial & 97.5209 & 0.090241822 \\
\hline 11 & $\mathrm{C} 47$ & C4709 & Autumn & Caudal & 116.1901 & 0.097424342 \\
\hline 11 & $\mathrm{C} 47$ & C4703 & Autumn & Caudolateral & 71.5131 & 0.078796984 \\
\hline 11 & C50 & C5012 & Autumn & Craniomedial & 184.4855 & 0.11924973 \\
\hline 11 & C50 & C5010 & Autumn & Cranial & 190.7018 & 0.120990162 \\
\hline 11 & C50 & C5005 & Autumn & Craniolateral & 170.6471 & 0.11525289 \\
\hline 25 & C50 & C5015 & Autumn & Caudomedial & 187.6702 & 0.120145433 \\
\hline 11 & C50 & C5007 & Autumn & Caudal & 60.0003 & 0.111860173 \\
\hline 11 & C50 & C5004 & Autumn & Caudolateral & 180.607 & 0.118147062 \\
\hline 12 & C54 & C5420 & Autumn & Craniomedial & 58.7373 & 0.077361957 \\
\hline
\end{tabular}




\begin{tabular}{|c|c|c|c|c|c|c|}
\hline 12 & C54 & C5418 & Autumn & Cranial & 175.7131 & 0.119257354 \\
\hline 12 & C54 & C5412 & Autumn & Craniolateral & 136.6325 & 0.107978106 \\
\hline 12 & C54 & C5423 & Autumn & Caudomedial & 98.3766 & 0.094839619 \\
\hline 12 & C54 & C5415 & Autumn & Caudal & 121.1593 & 0.102972169 \\
\hline 12 & C54 & C5409 & Autumn & Caudolateral & 91.5002 & 0.092163825 \\
\hline 13 & C55 & C5512 & Autumn & Craniomedial & 81.3381 & 0.09434105 \\
\hline 13 & C55 & C5510 & Autumn & Cranial & 127.7924 & 0.112495111 \\
\hline 13 & C55 & C5505 & Autumn & Craniolateral & 140.226 & 0.116638374 \\
\hline 13 & C55 & C5515 & Autumn & Caudomedial & 129.2474 & 0.112992328 \\
\hline 13 & C55 & C5507 & Autumn & Caudal & 45.3482 & 0.075138064 \\
\hline 13 & C55 & C5503 & Autumn & Caudolateral & 71.9124 & 0.089921568 \\
\hline 2 & $\mathrm{C} 75$ & C7405 & Winter & Craniomedial & 17.3362 & 0.084593797 \\
\hline 2 & $\mathrm{C} 75$ & C7501 & Winter & Cranial & 22.7143 & 0.092846349 \\
\hline 2 & $\mathrm{C} 75$ & C7517 & Winter & Craniolateral & 19.2933 & 0.087769124 \\
\hline 2 & C75 & C7506 & Winter & Caudomedial & 28.6612 & 0.100590809 \\
\hline 2 & C75 & C7511 & Winter & Caudal & 15.7269 & 0.081801669 \\
\hline 2 & $\mathrm{C} 75$ & C7514 & Winter & Caudolateral & 36.5457 & 0.109375037 \\
\hline 2 & $\mathrm{C} 77$ & C7703 & Winter & Craniomedial & 43.0213 & 0.115697926 \\
\hline 2 & $\mathrm{C} 77$ & C7701 & Winter & Cranial & 29.7938 & 0.101942875 \\
\hline 2 & $\mathrm{C} 77$ & C7719 & Winter & Craniolateral & 50.389 & 0.12217342 \\
\hline 2 & $\mathrm{C} 77$ & C7706 & Winter & Caudomedial & 28.0252 & 0.09981616 \\
\hline 2 & $\mathrm{C} 77$ & C7710 & Winter & Caudal & 26.3054 & 0.097661999 \\
\hline 2 & $\mathrm{C} 77$ & C7715 & Winter & Caudolateral & 19.1599 & 0.087559579 \\
\hline 3 & C80 & C8003 & Winter & Craniomedial & 5.9776 & 0.089341979 \\
\hline 3 & $\mathrm{C} 80$ & C8001 & Winter & Cranial & 15.3021 & 0.110292157 \\
\hline 3 & $\mathrm{C} 80$ & C8017 & Winter & Craniolateral & 13.5217 & 0.10727666 \\
\hline 3 & C80 & C8006 & Winter & Caudomedial & 4.2049 & 0.082569051 \\
\hline 3 & $\mathrm{C} 80$ & C8009 & Winter & Caudal & 8.1626 & 0.095802902 \\
\hline
\end{tabular}




\begin{tabular}{|c|c|c|c|c|c|c|}
\hline 3 & C80 & C8013 & Winter & Caudolateral & 9.3176 & 0.098686963 \\
\hline 3 & C83 & C8302 & Winter & Craniomedial & 10.8348 & 0.102080567 \\
\hline 3 & C83 & C8314 & Winter & Cranial & 16.8236 & 0.112660315 \\
\hline 3 & C83 & C8311 & Winter & Craniolateral & 16.7434 & 0.112539728 \\
\hline 3 & C83 & C8305 & Winter & Caudomedial & 3.9852 & 0.081581968 \\
\hline 3 & C83 & C8308 & Winter & Caudal & 12.4731 & 0.105353381 \\
\hline 3 & C83 & C8310 & Winter & Caudolateral & 7.9961 & 0.095361434 \\
\hline 5 & C82 & C8202 & Winter & Craniomedial & 11.494 & 0.077730519 \\
\hline 5 & C82 & C8218 & Winter & Cranial & 13.35 & 0.081898429 \\
\hline 5 & C82 & C8215 & Winter & Craniolateral & 32.9326 & 0.112229453 \\
\hline 5 & C82 & C8205 & Winter & Caudomedial & 12.4761 & 0.079986403 \\
\hline 5 & C82 & C8209 & Winter & Caudal & 14.8269 & 0.084952471 \\
\hline 5 & C82 & C8213 & Winter & Caudolateral & 18.0087 & 0.090915288 \\
\hline 5 & C84 & C8402 & Winter & Craniomedial & 14.0008 & 0.083269991 \\
\hline 5 & C84 & C8423 & Winter & Cranial & 32.3698 & 0.111556466 \\
\hline 5 & C84 & C8420 & Winter & Craniolateral & 30.8389 & 0.109686418 \\
\hline 5 & C84 & C8406 & Winter & Caudomedial & 41.4777 & 0.121637006 \\
\hline 5 & C84 & C8411 & Winter & Caudal & 24.1241 & 0.100679302 \\
\hline 5 & C84 & C8417 & Winter & Caudolateral & 24.0128 & 0.10051698 \\
\hline 12 & C59 & C5904 & Winter & Craniomedial & 147.7237 & 0.111128865 \\
\hline 12 & C59 & C5901 & Winter & Cranial & 77.9116 & 0.086317913 \\
\hline 12 & C59 & C5912 & Winter & Craniolateral & 170.0527 & 0.117481442 \\
\hline 12 & C59 & C5905 & Winter & Caudomedial & 147.7092 & 0.111124558 \\
\hline 12 & C59 & C5908 & Winter & Caudal & 97.5877 & 0.094345391 \\
\hline 12 & C59 & C5910 & Winter & Caudolateral & 118.7244 & 0.101940219 \\
\hline 14 & C103 & C10312 & Spring & Craniomedial & 65.8778 & 0.086881496 \\
\hline 14 & C103 & C10308 & Spring & Cranial & 67.639 & 0.087689488 \\
\hline 14 & C103 & C10306 & Spring & Craniolateral & 99.1794 & 0.100292811 \\
\hline
\end{tabular}




\begin{tabular}{|c|c|c|c|c|c|c|}
\hline 14 & C103 & C10313 & Spring & Caudomedial & 94.2229 & 0.09850489 \\
\hline 14 & C103 & C10301 & Spring & Caudal & 71.9 & 0.08958939 \\
\hline 14 & C103 & C10303 & Spring & Caudolateral & 127.2903 & 0.109469812 \\
\hline 18 & C91 & C9120 & Spring & Craniomedial & 149.1565 & 0.140153638 \\
\hline 18 & C91 & C9109 & Spring & Cranial & 60.5506 & 0.105727551 \\
\hline 18 & C91 & C9112 & Spring & Craniolateral & 46.3238 & 0.097234558 \\
\hline 18 & C91 & C9118 & Spring & Caudomedial & 128.9875 & 0.133929684 \\
\hline 18 & C91 & C9101 & Spring & Caudal & 44.139 & 0.095776813 \\
\hline 18 & C91 & C9106 & Spring & Caudolateral & 16.7868 & 0.070792311 \\
\hline 19 & C96 & C9615 & Spring & Craniomedial & 80.8929 & 0.101466725 \\
\hline 19 & C96 & C9607 & Spring & Cranial & 97.1444 & 0.107639788 \\
\hline 19 & C96 & C9606 & Spring & Craniolateral & 100.0217 & 0.108658143 \\
\hline 19 & C96 & C9614 & Spring & Caudomedial & 83.479 & 0.102502058 \\
\hline 19 & C96 & C9601 & Spring & Caudal & 40.804 & 0.081366197 \\
\hline 19 & C96 & C9604 & Spring & Caudolateral & 57.8857 & 0.091082938 \\
\hline 20 & C99 & C9914 & Spring & Craniomedial & 45.2735 & 0.091092131 \\
\hline 20 & C99 & C9909 & Spring & Cranial & 33.5372 & 0.082924239 \\
\hline 20 & C99 & C9906 & Spring & Craniolateral & 111.1485 & 0.120670087 \\
\hline 20 & C99 & C9917 & Spring & Caudomedial & 102.7885 & 0.11775187 \\
\hline 20 & C99 & C9911 & Spring & Caudal & 66.0649 & 0.102533363 \\
\hline 25 & C99 & C9904 & Spring & Caudolateral & 54.9245 & 0.108222154 \\
\hline 22 & C108 & C10819 & Spring & Craniomedial & 63.5892 & 0.114333834 \\
\hline 22 & C108 & C10808 & Spring & Cranial & 126.1518 & 0.127219225 \\
\hline 22 & C108 & C10806 & Spring & Craniolateral & 80.0818 & 0.118518714 \\
\hline 22 & C108 & C10814 & Spring & Caudomedial & 56.2488 & 0.112168432 \\
\hline 22 & C108 & C10811 & Spring & Caudal & 47.9457 & 0.109410187 \\
\hline 22 & C108 & C10804 & Spring & Caudolateral & 15.5686 & 0.091813577 \\
\hline 23 & C109 & C10914 & Spring & Craniomedial & 88.2094 & 0.106942229 \\
\hline
\end{tabular}




\begin{tabular}{|c|c|c|c|c|c|c|}
\hline 23 & C109 & C10918 & Spring & Cranial & 96.0997 & 0.10981393 \\
\hline 23 & C109 & C10906 & Spring & Craniolateral & 53.2935 & 0.091508551 \\
\hline 23 & C109 & C10910 & Spring & Caudomedial & 79.2492 & 0.103457164 \\
\hline 23 & C109 & C10901 & Spring & Caudal & 51.3666 & 0.090472148 \\
\hline 23 & C109 & C10904 & Spring & Caudolateral & 94.6498 & 0.109298783 \\
\hline 25 & C97 & C9712 & Spring & Craniomedial & 112.6496 & 0.12528764 \\
\hline 25 & C97 & C9706 & Spring & Cranial & 78.2456 & 0.116317702 \\
\hline 25 & C97 & C9707 & Spring & Craniolateral & 81.1494 & 0.117184921 \\
\hline 25 & C97 & C9714 & Spring & Caudomedial & 71.2028 & 0.114102658 \\
\hline 25 & C97 & C9702 & Spring & Caudal & 62.6332 & 0.111158623 \\
\hline 25 & C97 & C9705 & Spring & Caudolateral & 56.9746 & 0.109033611 \\
\hline $1 / 3$ & $\mathrm{C} 01$ & C0121 & Summer & Craniomedial & 22.5089 & 0.035315395 \\
\hline $1 / 3$ & $\mathrm{C} 01$ & $\mathrm{C} 0114$ & Summer & Cranial & 121.8515 & 0.084315695 \\
\hline $1 / 3$ & $\mathrm{C} 01$ & C0111 & Summer & Craniolateral & 110.6426 & 0.08022577 \\
\hline $1 / 3$ & $\mathrm{C} 01$ & $\mathrm{C} 0117$ & Summer & Caudomedial & 56.1824 & 0.056579122 \\
\hline $1 / 3$ & $\mathrm{C} 01$ & C0103 & Summer & Caudal & 64.0588 & 0.060536314 \\
\hline $1 / 3$ & $\mathrm{C} 01$ & C0107 & Summer & Caudolateral & 91.0314 & 0.072552736 \\
\hline $1 / 3$ & $\mathrm{C03}$ & C0303 & Summer & Craniomedial & 99.8502 & 0.076093259 \\
\hline $1 / 3$ & $\mathrm{CO3}$ & C0302 & Summer & Cranial & 170.3762 & 0.100212429 \\
\hline $1 / 3$ & $\mathrm{CO3}$ & C0309 & Summer & Craniolateral & 131.8323 & 0.08780642 \\
\hline $1 / 3$ & $\mathrm{CO3}$ & C0306 & Summer & Caudomedial & 50.7176 & 0.053673069 \\
\hline $1 / 3$ & $\mathrm{CO3}$ & C0315 & Summer & Caudal & 78.2818 & 0.067125481 \\
\hline $6 / 7$ & $\mathrm{CO3}$ & C0312 & Summer & Caudolateral & 87.8231 & 0.071223695 \\
\hline $6 / 7$ & $\mathrm{C} 06$ & $\mathrm{C} 0603$ & Summer & Craniomedial & 142.5787 & 0.125819464 \\
\hline $6 / 7$ & $\mathrm{C} 06$ & C0608 & Summer & Cranial & 143.5876 & 0.126188924 \\
\hline $6 / 7$ & $\mathrm{C} 06$ & $\mathrm{C} 0610$ & Summer & Craniolateral & 157.6414 & 0.131185169 \\
\hline $6 / 7$ & $\mathrm{C} 06$ & C0606 & Summer & Caudomedial & 130.6262 & 0.121320998 \\
\hline $6 / 7$ & C06 & C0615 & Summer & Caudal & 62.6464 & 0.089377626 \\
\hline
\end{tabular}




\begin{tabular}{|c|c|c|c|c|c|c|}
\hline $6 / 7$ & $\mathrm{C} 06$ & C0613 & Summer & Caudolateral & 119.2924 & 0.116827421 \\
\hline $6 / 7$ & $\mathrm{C} 07$ & $\mathrm{C} 0715$ & Summer & Craniomedial & 63.5545 & 0.089914112 \\
\hline $6 / 7$ & $\mathrm{C} 07$ & C0717 & Summer & Cranial & 56.085 & 0.085358779 \\
\hline $6 / 7$ & $\mathrm{C} 07$ & C0703 & Summer & Craniolateral & 105.1457 & 0.110853189 \\
\hline $6 / 7$ & $\mathrm{C} 07$ & $\mathrm{C} 0711$ & Summer & Caudomedial & 75.8497 & 0.096775881 \\
\hline $6 / 7$ & $\mathrm{C} 07$ & C0707 & Summer & Caudal & 81.918 & 0.099923265 \\
\hline $6 / 7$ & $\mathrm{C} 07$ & C0705 & Summer & Caudolateral & 57.6736 & 0.086355979 \\
\hline S11 & C11 & C1108 & Summer & Craniomedial & 151.2129 & 0.09411656 \\
\hline S11 & C11 & C1120 & Summer & Cranial & 108.0243 & 0.080612703 \\
\hline S11 & C11 & C1117 & Summer & Craniolateral & 136.6505 & 0.089828633 \\
\hline S11 & C11 & C1107 & Summer & Caudomedial & 161.1128 & 0.096905514 \\
\hline S11 & C11 & C1111 & Summer & Caudal & 116.6815 & 0.083525856 \\
\hline S11 & C11 & C1114 & Summer & Caudolateral & 84.4119 & 0.071957624 \\
\hline $\begin{array}{c}22 / 2 \\
6 \\
\end{array}$ & $\mathrm{C} 22$ & C2207 & Summer & Craniomedial & 128.4149 & 0.086523167 \\
\hline $\begin{array}{c}22 / 2 \\
6 \\
\end{array}$ & $\mathrm{C} 22$ & $\mathrm{C} 2215$ & Summer & Cranial & 145.6573 & 0.092276679 \\
\hline $\begin{array}{c}22 / 2 \\
6 \\
\end{array}$ & $\mathrm{C} 22$ & $\mathrm{C} 2217$ & Summer & Craniolateral & 122.7761 & 0.084560466 \\
\hline $\begin{array}{c}22 / 2 \\
6 \\
\end{array}$ & $\mathrm{C} 22$ & $\mathrm{C} 2211$ & Summer & Caudomedial & 159.8207 & 0.096757602 \\
\hline $\begin{array}{c}22 / 2 \\
6\end{array}$ & $\mathrm{C} 22$ & $\mathrm{C} 2222$ & Summer & Caudal & 170.8631 & 0.100117844 \\
\hline $\begin{array}{c}22 / 2 \\
6 \\
\end{array}$ & $\mathrm{C} 22$ & C2219 & Summer & Caudolateral & 59.1273 & 0.05821277 \\
\hline $\begin{array}{c}22 / 2 \\
6 \\
\end{array}$ & $\mathrm{C} 26$ & C2612 & Summer & Craniomedial & 103.6656 & 0.077556915 \\
\hline $\begin{array}{c}22 / 2 \\
6 \\
\end{array}$ & $\mathrm{C} 26$ & C2601 & Summer & Cranial & 55.8375 & 0.056534569 \\
\hline $\begin{array}{c}22 / 2 \\
6 \\
\end{array}$ & $\mathrm{C} 26$ & C2603 & Summer & Craniolateral & 94.8877 & 0.074128636 \\
\hline $\begin{array}{c}22 / 2 \\
6 \\
\end{array}$ & $\mathrm{C} 26$ & C2614 & Summer & Caudomedial & 46.2053 & 0.051320817 \\
\hline $\begin{array}{c}22 / 2 \\
6 \\
\end{array}$ & $\mathrm{C} 26$ & C2609 & Summer & Caudal & 57.0123 & 0.057139276 \\
\hline $\begin{array}{c}22 / 2 \\
6 \\
\end{array}$ & $\mathrm{C} 26$ & C2606 & Summer & Caudolateral & 81.5244 & 0.068596289 \\
\hline
\end{tabular}




\section{Appendix C Densitometry Aluminum Step Wedge Keys}

\begin{tabular}{|cc|ccccc|}
\hline \multicolumn{1}{|c|}{ Autumn } & \multicolumn{6}{|c|}{ KEYS Mean Pixel Intensity } \\
\hline \hline \multirow{2}{*}{ Step \# } & ETA & \multicolumn{5}{c|}{} \\
& {$[0.025 \mathrm{~mm} /$ Step $]$} & 10 & 11 & 12 & 13 & 25 \\
\hline \hline 1 & 0.025 & 7.1978 & 4.909 & 3.1097 & 2.6303 & 0.0071 \\
2 & 0.050 & 41.5899 & 24.1583 & 18.593 & 14.8564 & 2.0826 \\
3 & 0.075 & 118.4469 & 72.9365 & 64.1272 & 49.6613 & 11.2983 \\
4 & 0.100 & 220.5816 & 135.6588 & 134.1584 & 104.416 & 44.0515 \\
5 & 0.125 & 253.9084 & 222.2152 & 201.9778 & 176.6639 & 125.8284 \\
6 & 0.150 & & 253.2734 & 247.3346 & 228.566 & 211.8184 \\
7 & 0.175 & & & & & 253.998 \\
\hline
\end{tabular}
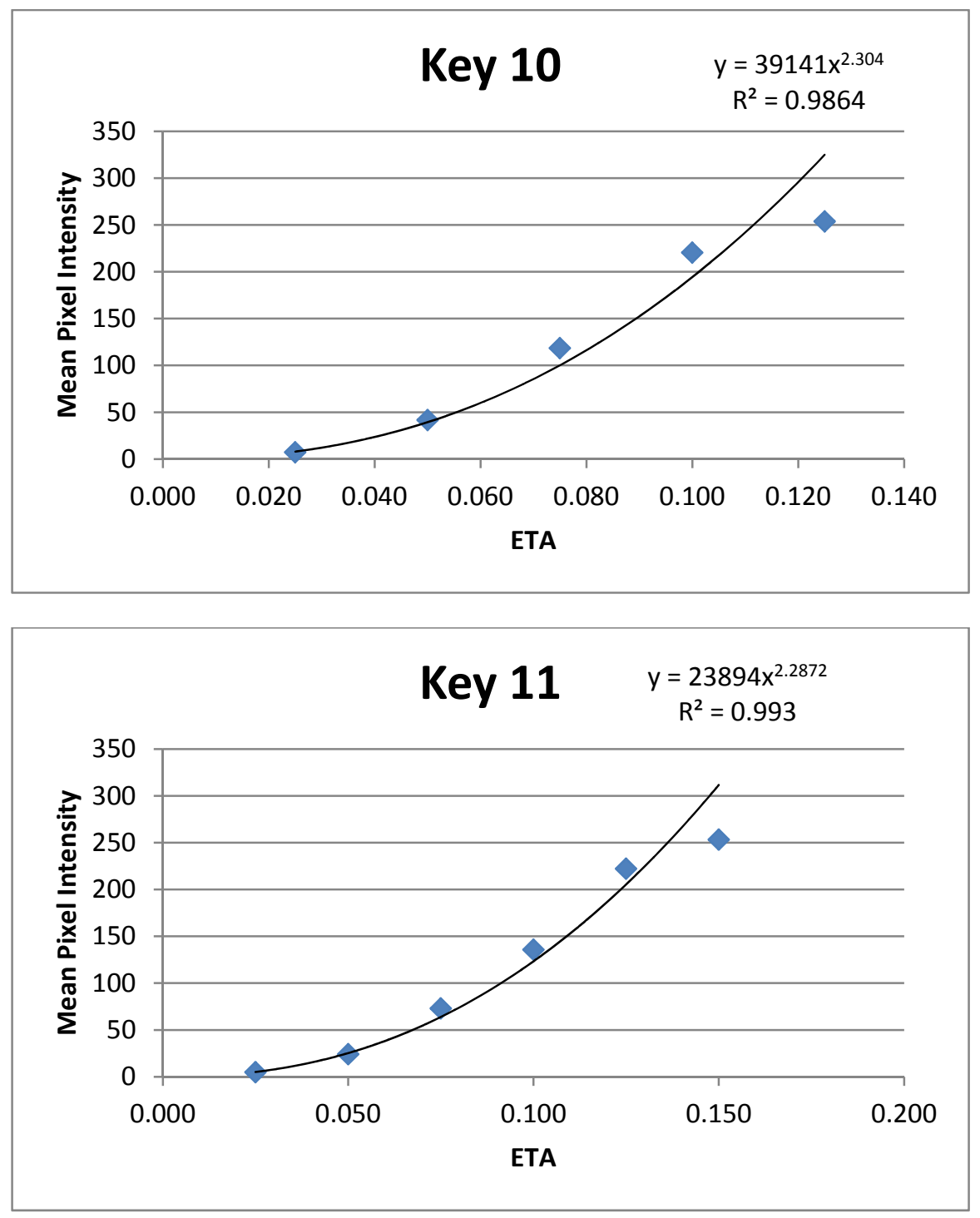

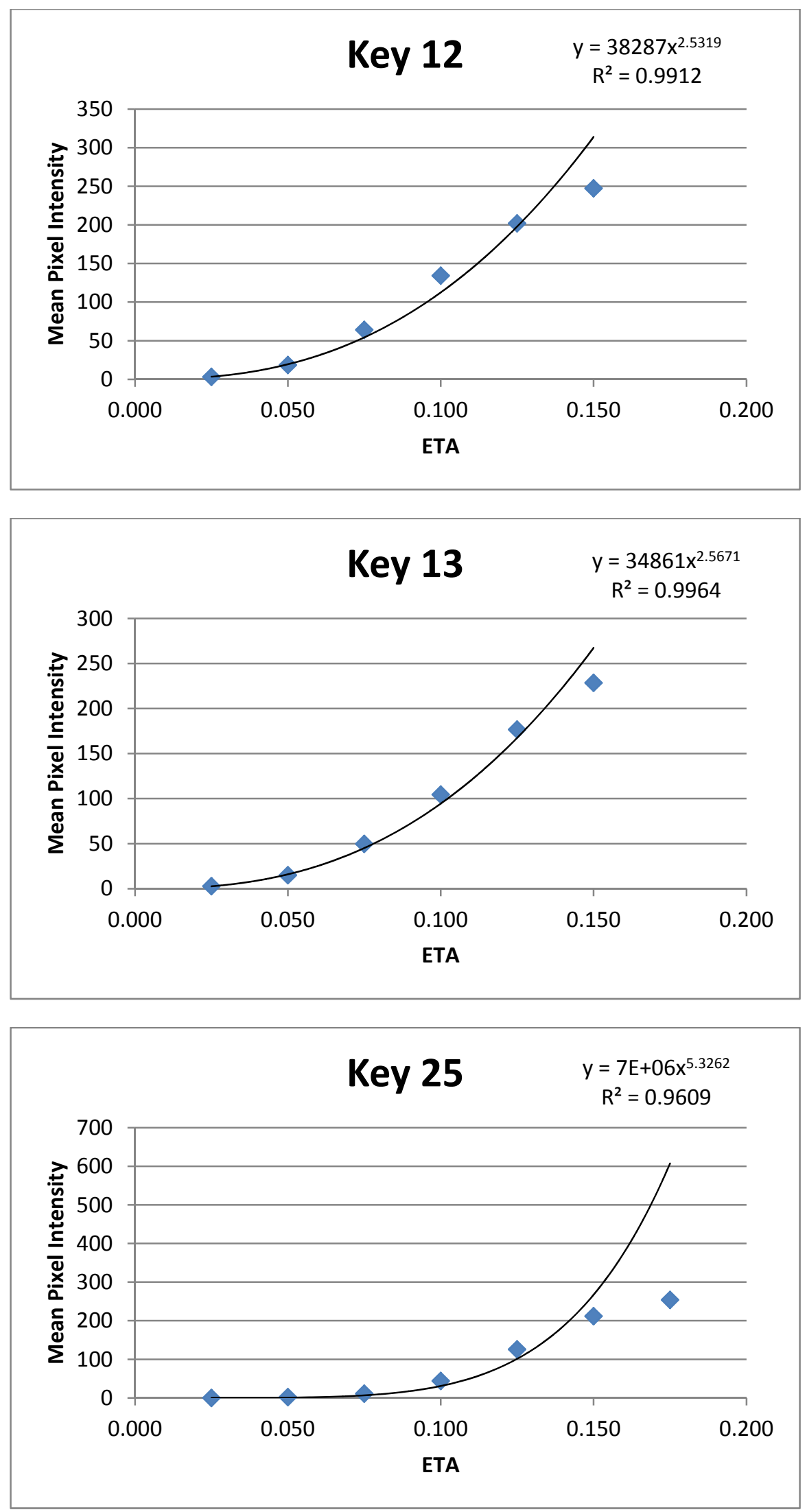


\begin{tabular}{|cc|cccc|}
\hline \multicolumn{1}{|c|}{ Winter } & \multicolumn{5}{|c|}{ KEYS Mean Pixel Intensity } \\
\hline \hline \multirow{2}{*}{ Step \# } & ETA & \multicolumn{5}{c|}{12} \\
& {$[0.025 \mathrm{~mm} /$ Step $]$} & 2 & 3 & 5 & 12 \\
\hline \hline 1 & 0.025 & 1.0002 & 0 & 0.9995 & 3.0798 \\
2 & 0.050 & 2.1526 & 0.263 & 1.848 & 19.1424 \\
3 & 0.075 & 7.2075 & 1.9993 & 5.5781 & 64.4665 \\
4 & 0.100 & 19.7897 & 7.9691 & 14.6054 & 134.7307 \\
5 & 0.125 & 51.9307 & 26.7677 & 37.5965 & 201.8678 \\
6 & 0.150 & 123.1663 & 75.1163 & 95.716 & 247.6778 \\
7 & 0.175 & 198.1668 & 164.7528 & 181.9852 & \\
8 & 0.200 & 248.8933 & 229.3546 & 247.9746 & \\
9 & 0.225 & & 253.9911 & & \\
\hline
\end{tabular}
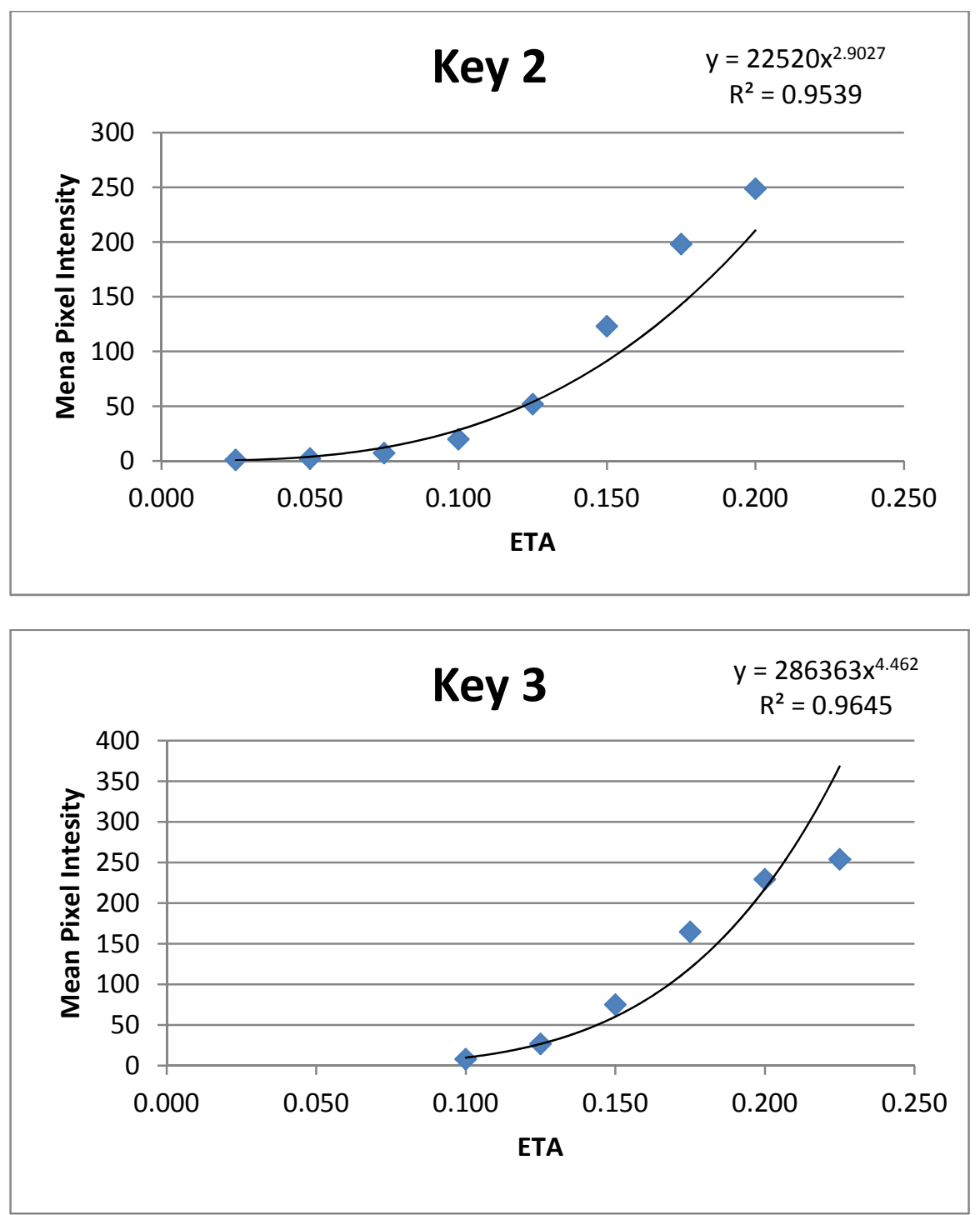

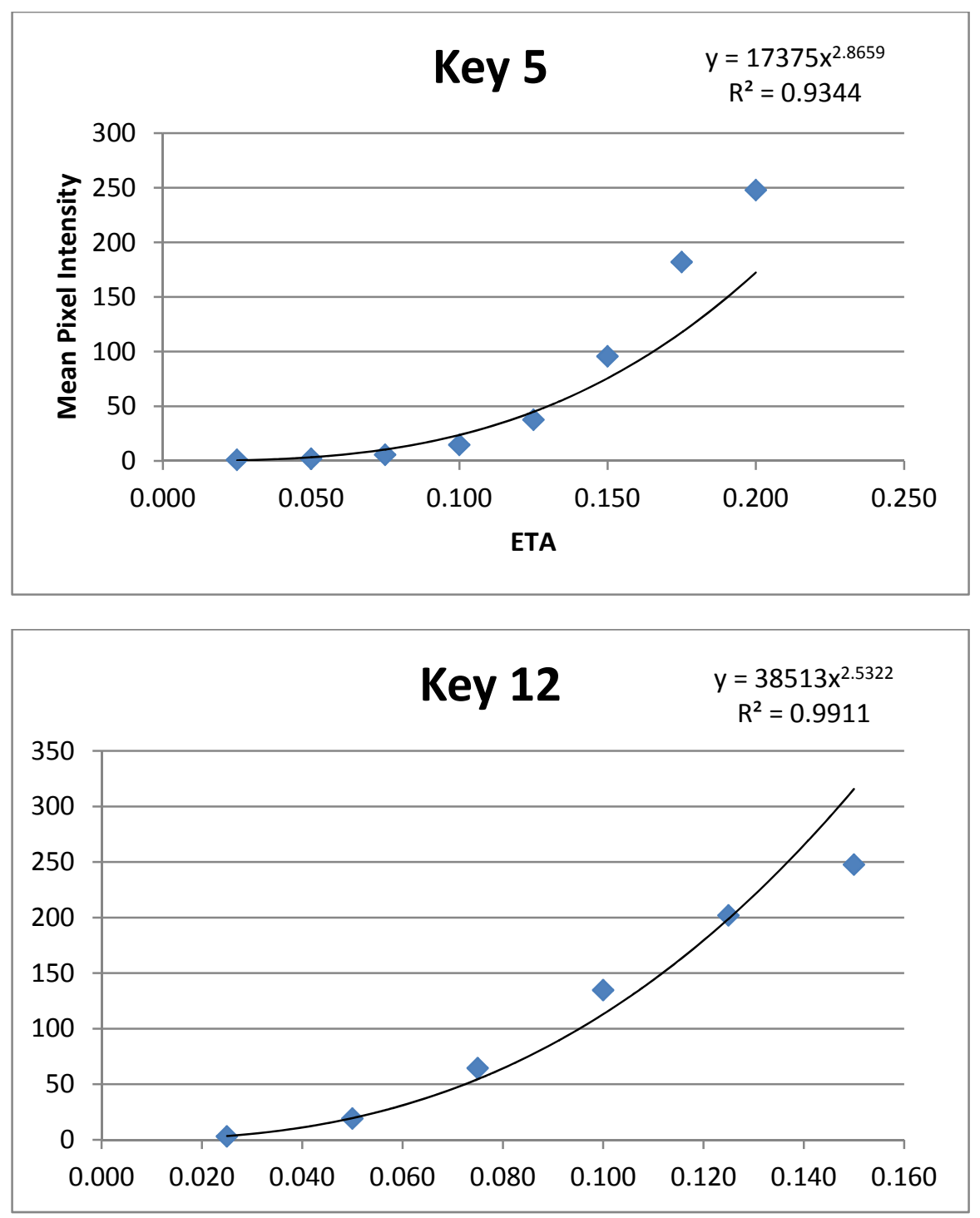

\begin{tabular}{|cc|ccccccc|}
\hline \multicolumn{10}{|c|}{ Spring } & \multicolumn{10}{|c|}{ KEYS Mean Pixel Intensity } \\
\hline \hline $\begin{array}{c}\text { Step } \\
\#\end{array}$ & $\begin{array}{c}\text { ETA } \\
{[0.025 \mathrm{~m}} \\
\mathrm{m} / \text { Step }]\end{array}$ & 14 & 18 & 19 & 20 & 22 & 23 & 25 \\
\hline \hline 1 & 0.025 & 1.942 & 0.9989 & 1.1982 & 1.0009 & 0.0006 & 1.0041 & 0.0187 \\
2 & 0.050 & 11.0109 & 2.5484 & 7.2852 & 4.3628 & 1.8553 & 5.4219 & 2.1678 \\
3 & 0.075 & 47.4988 & 15.4494 & 29.1147 & 19.4118 & 12.2434 & 23.5392 & 12.2799 \\
4 & 0.100 & 131.6477 & 53.1272 & 83.2881 & 61.9213 & 47.0203 & 79.2201 & 47.7626 \\
5 & 0.125 & 191.9769 & 160.116 & 182.3101 & 159.8455 & 129.1476 & 182.3045 & 131.0924 \\
6 & 0.150 & 248.4841 & 232.7273 & 252.8799 & 237.7506 & 205.5176 & 250.909 & 210.9074 \\
7 & 0.175 & & 253.9877 & & & 253.7837 & & 253.9978 \\
\hline
\end{tabular}



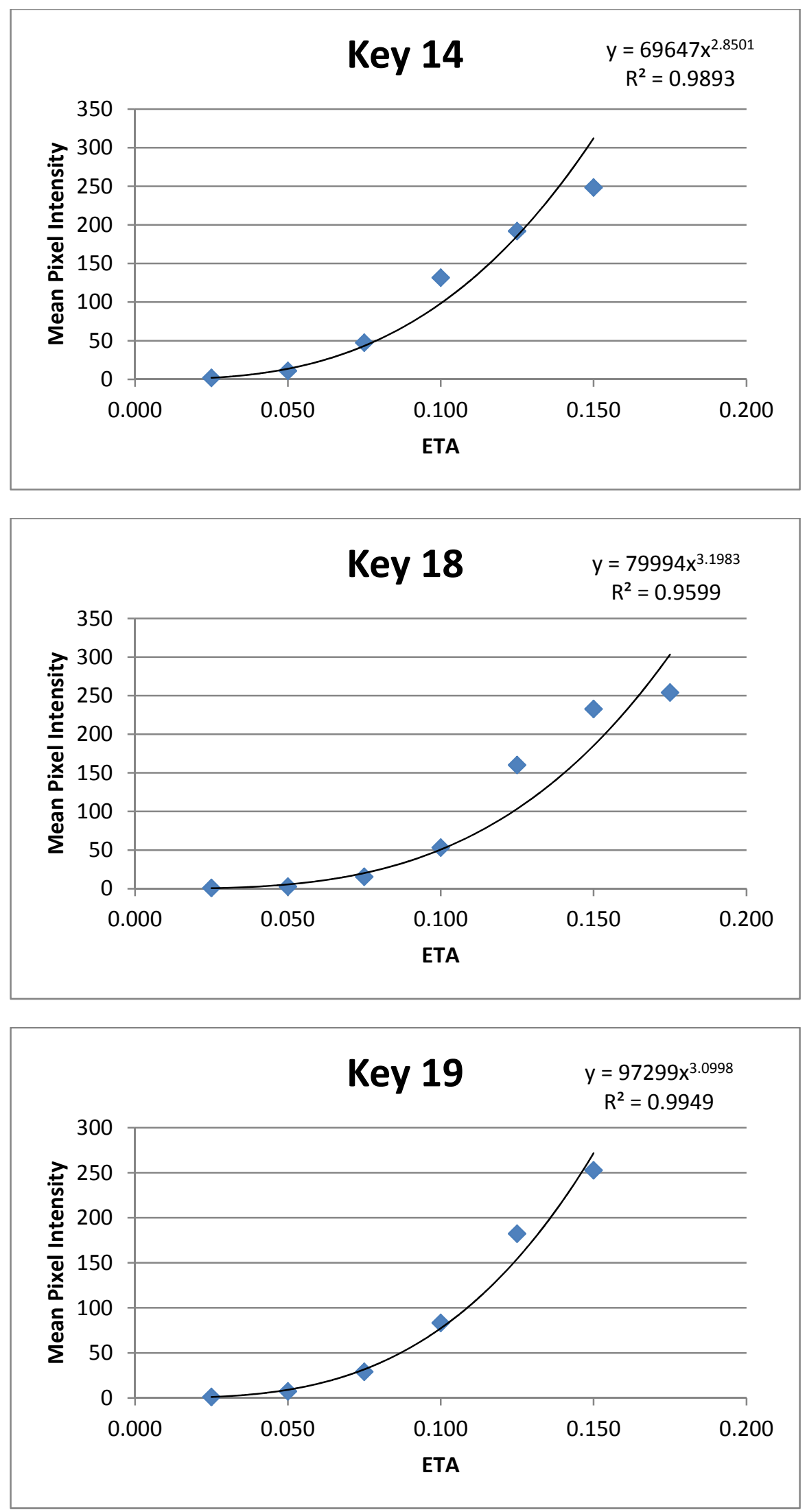

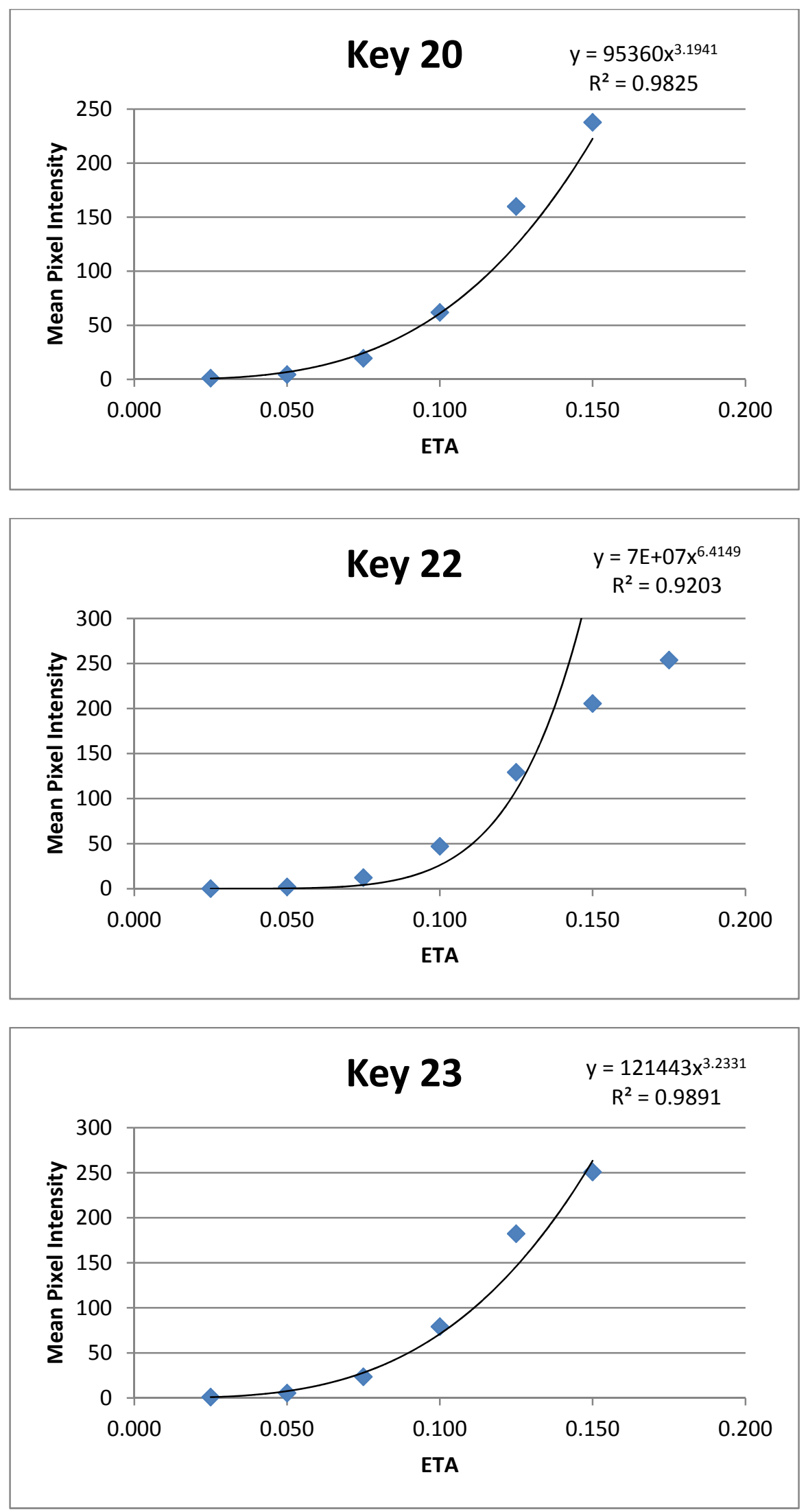


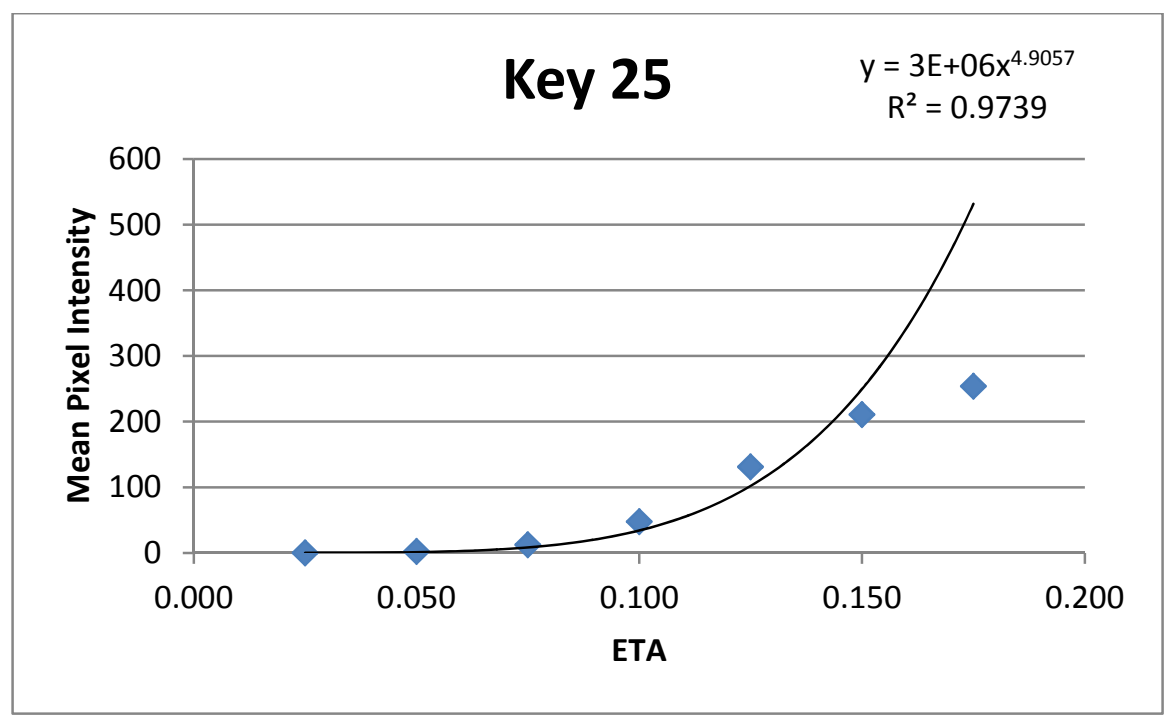

\begin{tabular}{|c|c|c|c|c|c|}
\hline \multicolumn{6}{|c|}{ Summer } \\
\hline \multirow{2}{*}{ Step \# } & \multirow{2}{*}{$\begin{array}{c}\text { ETA } \\
{[0.025 \mathrm{~mm} / \text { Step] }}\end{array}$} & \multicolumn{4}{|c|}{ KEYS Mean Pixel Intensity } \\
\hline & & $01 / 03$ & $06 / 07$ & S11 & $22 / 26$ \\
\hline 1 & 0.025 & 11.5987 & 3.1845 & 8.6335 & 12.5159 \\
\hline 2 & 0.050 & 40.484 & 11.4204 & 34.7321 & 34.681 \\
\hline 3 & 0.075 & 108.1602 & 41.4837 & 99.4100 & 101.5184 \\
\hline 4 & 0.100 & 180.0585 & 107.9134 & 194.4416 & 195.2673 \\
\hline 5 & 0.125 & 239.7927 & 166.5719 & 250.5824 & 252.0189 \\
\hline 6 & 0.150 & & 216.8735 & & \\
\hline 7 & 0.175 & & 250.4502 & & \\
\hline
\end{tabular}

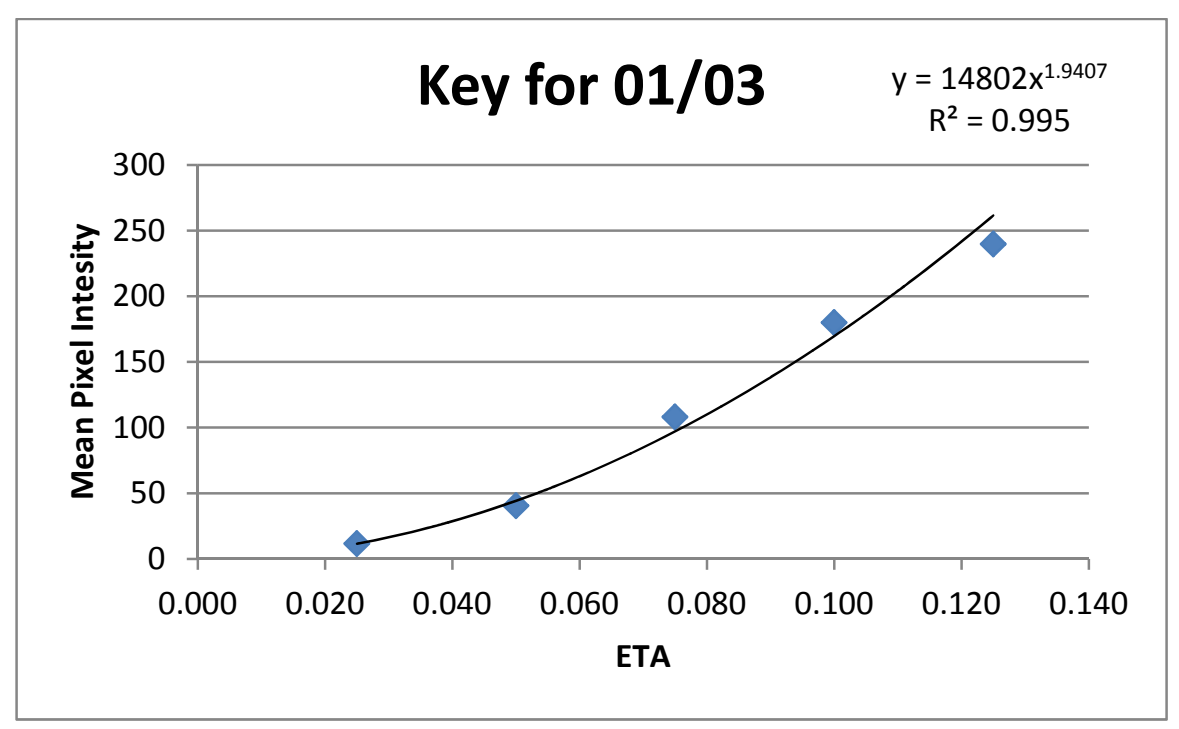



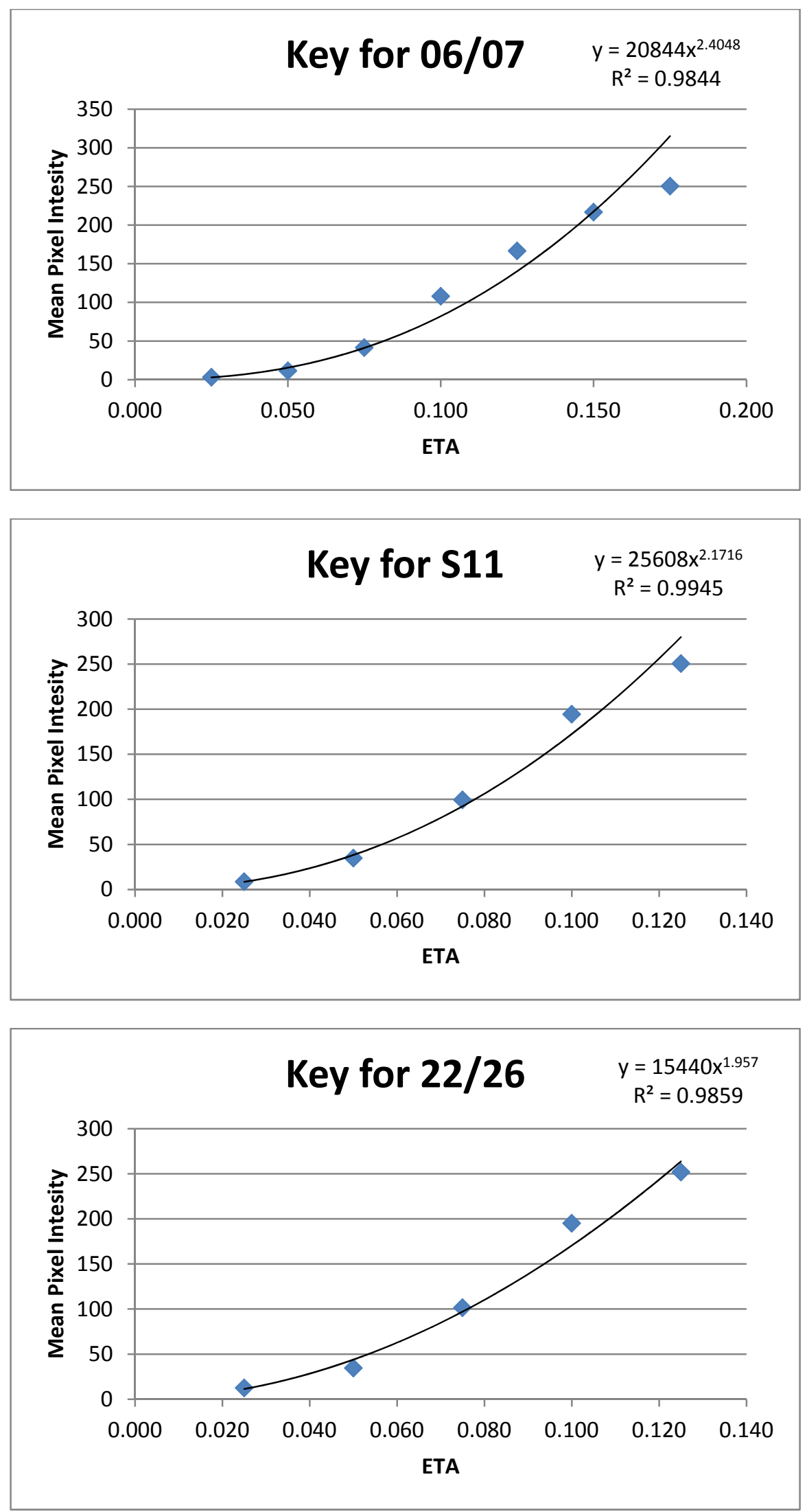


\section{Appendix D Densitometry Sector and Step Wedge Images}
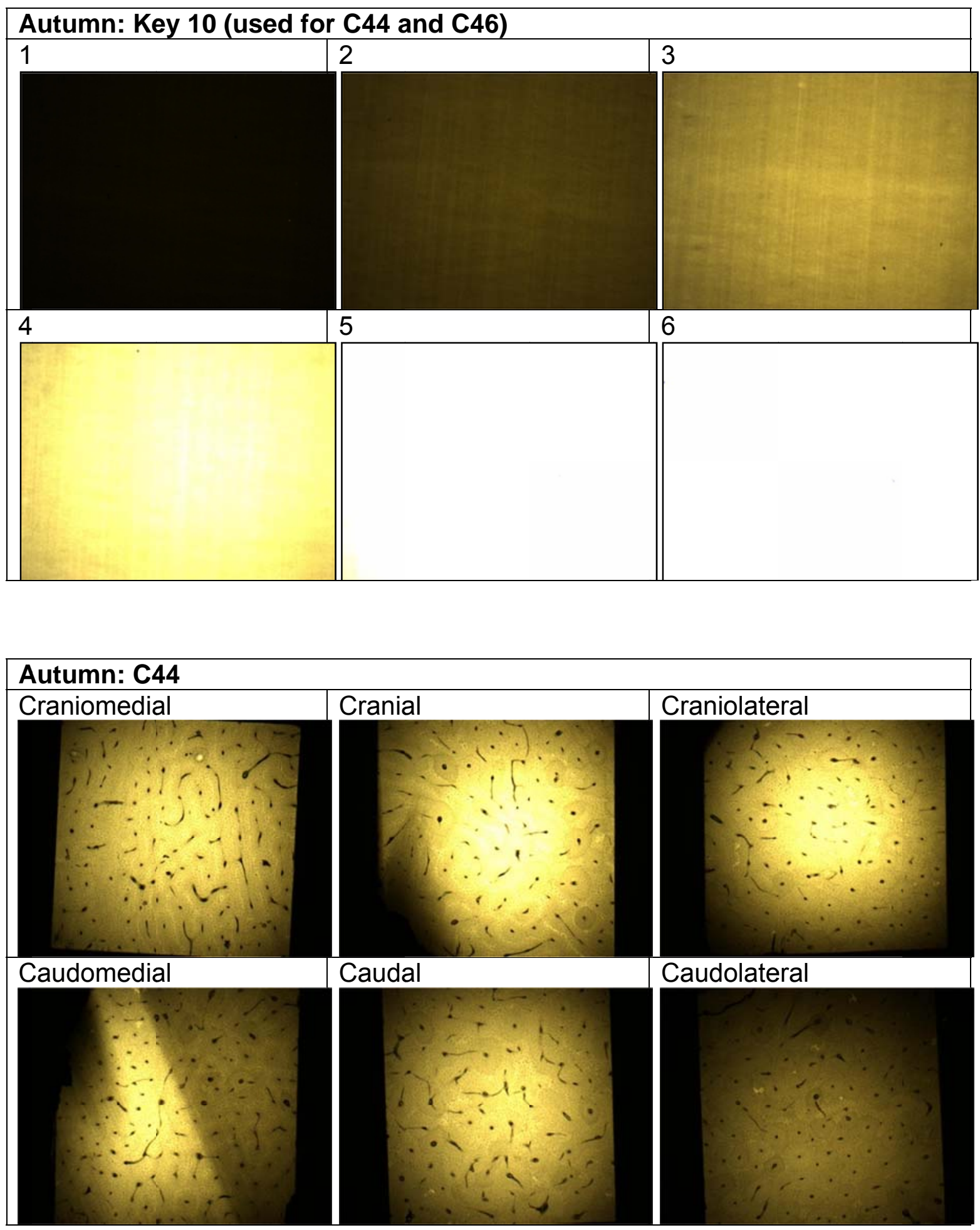

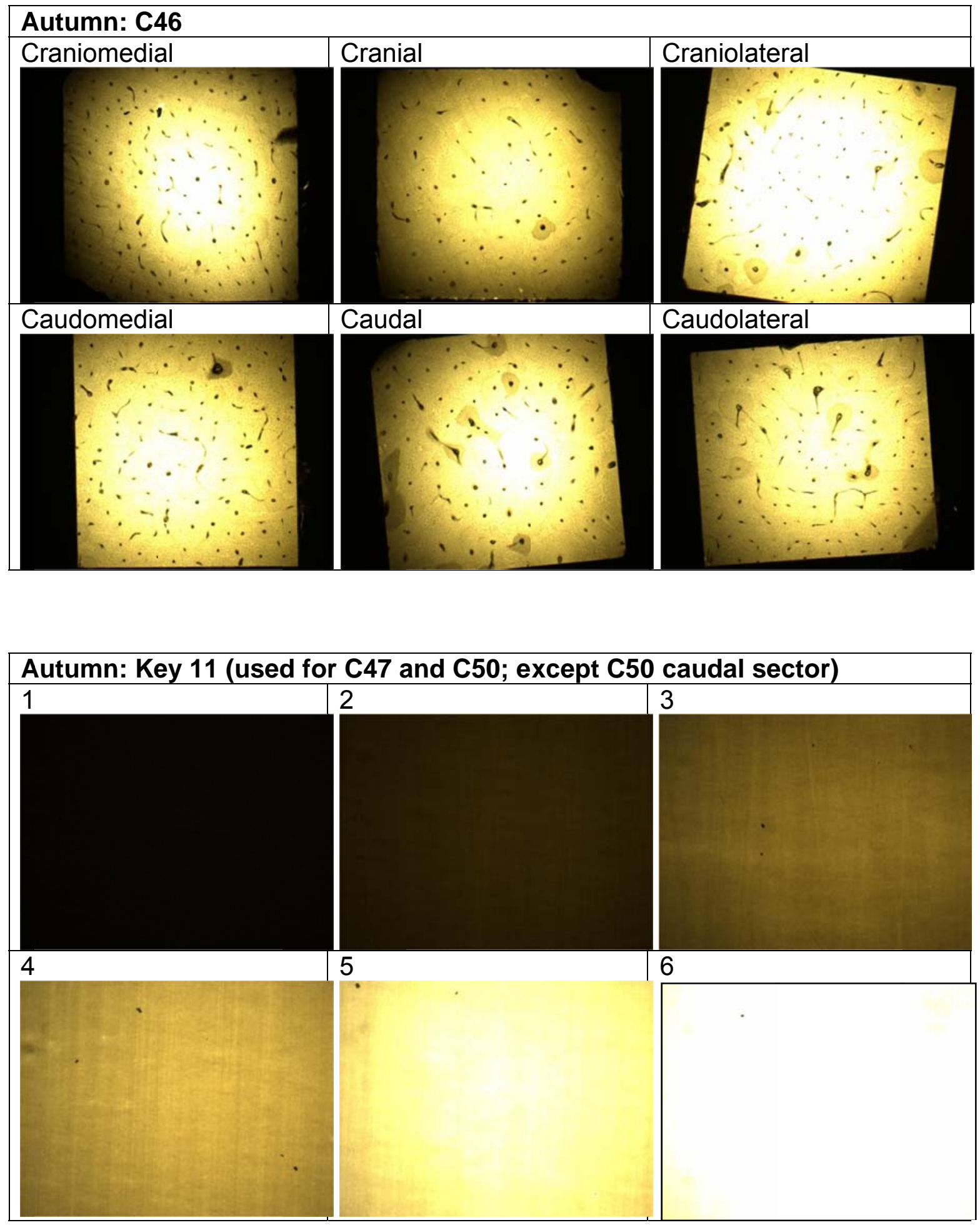

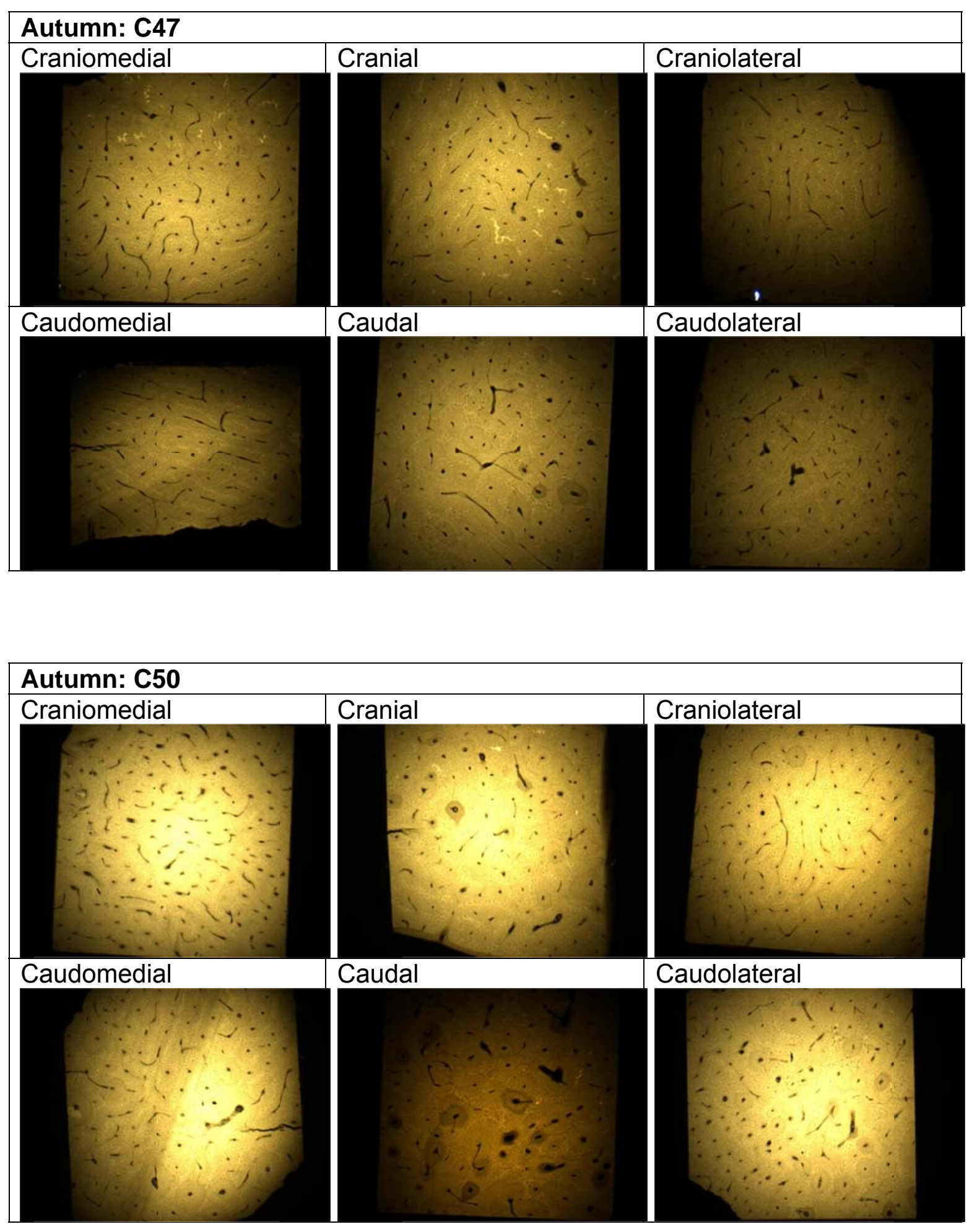

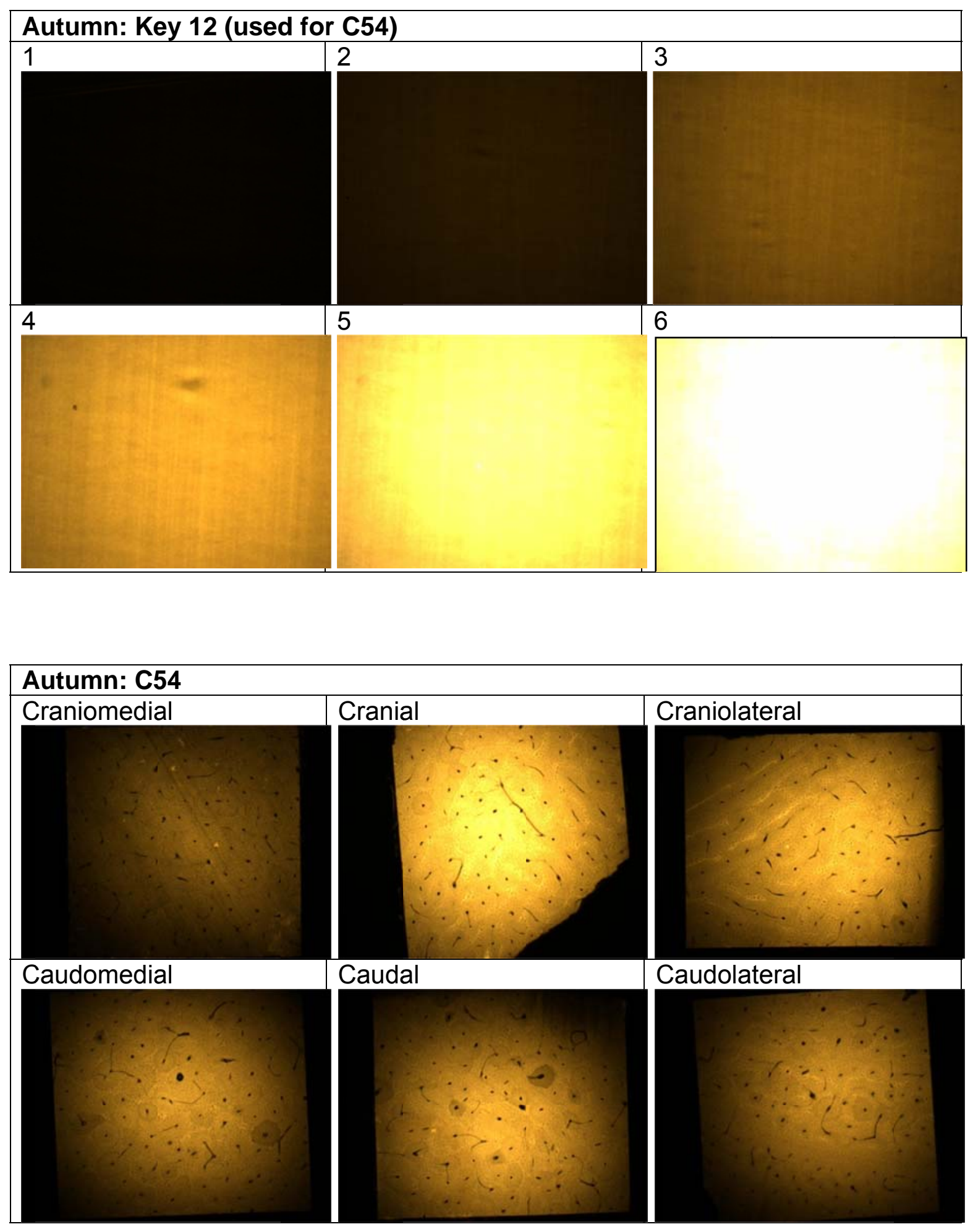

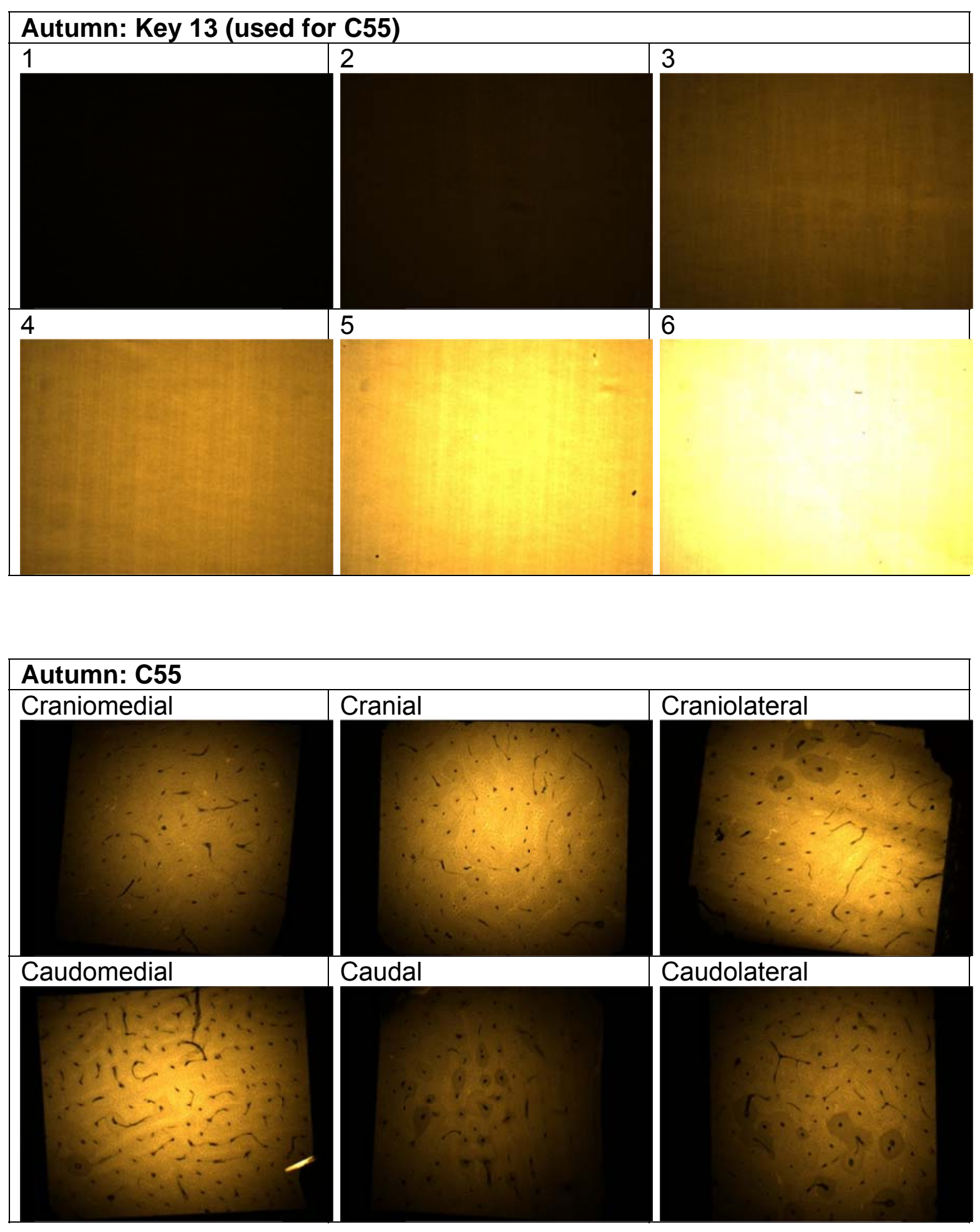


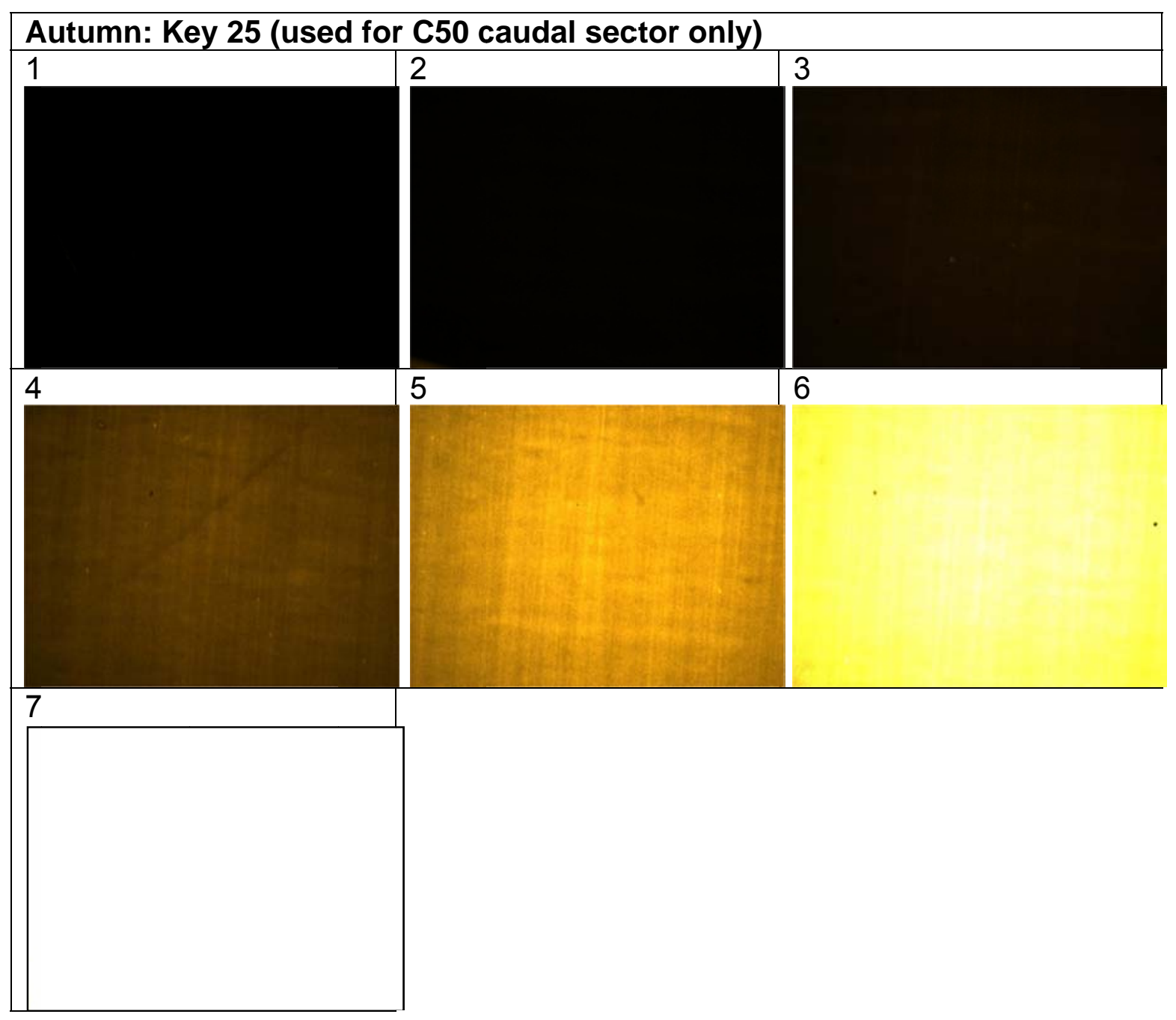




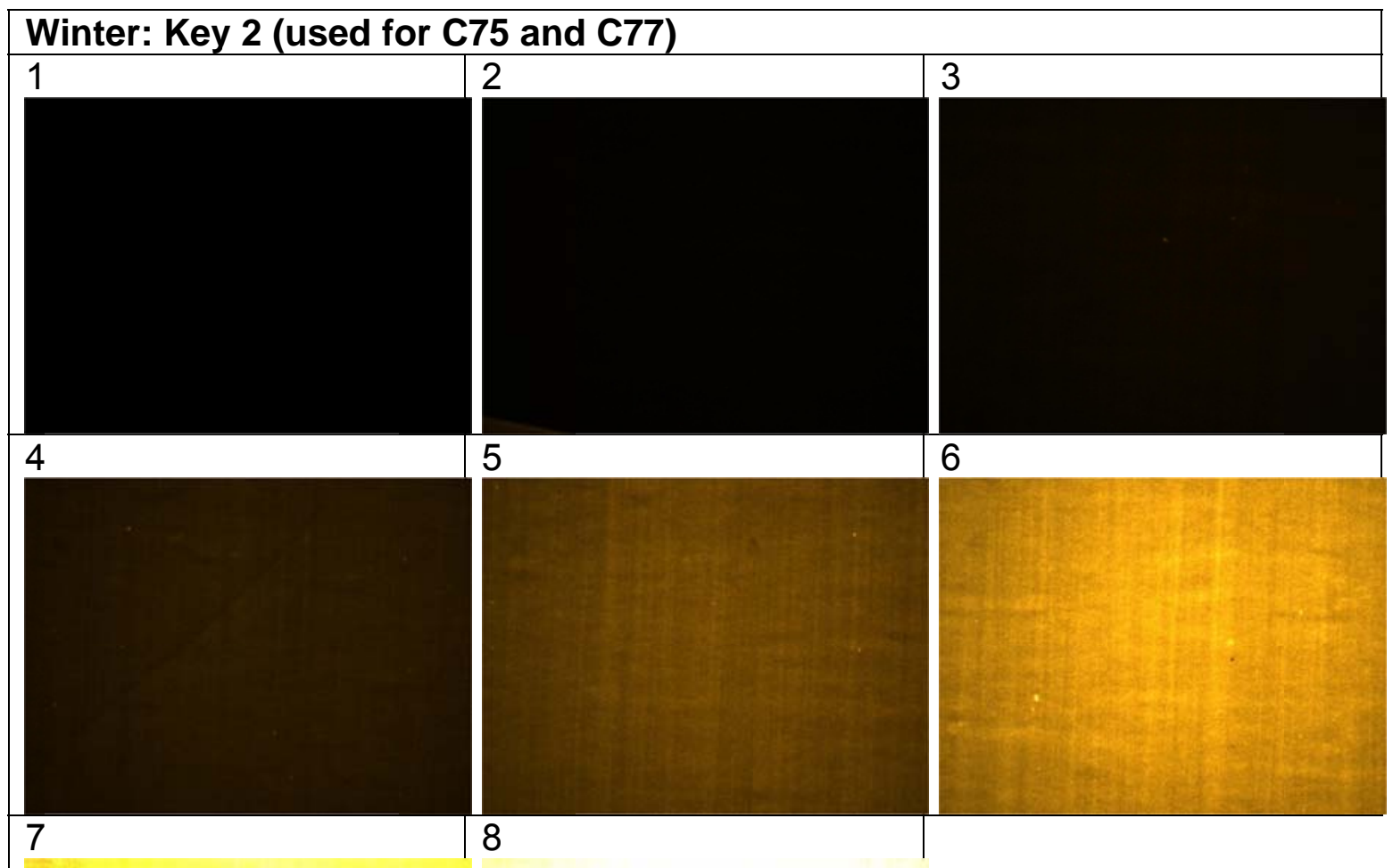



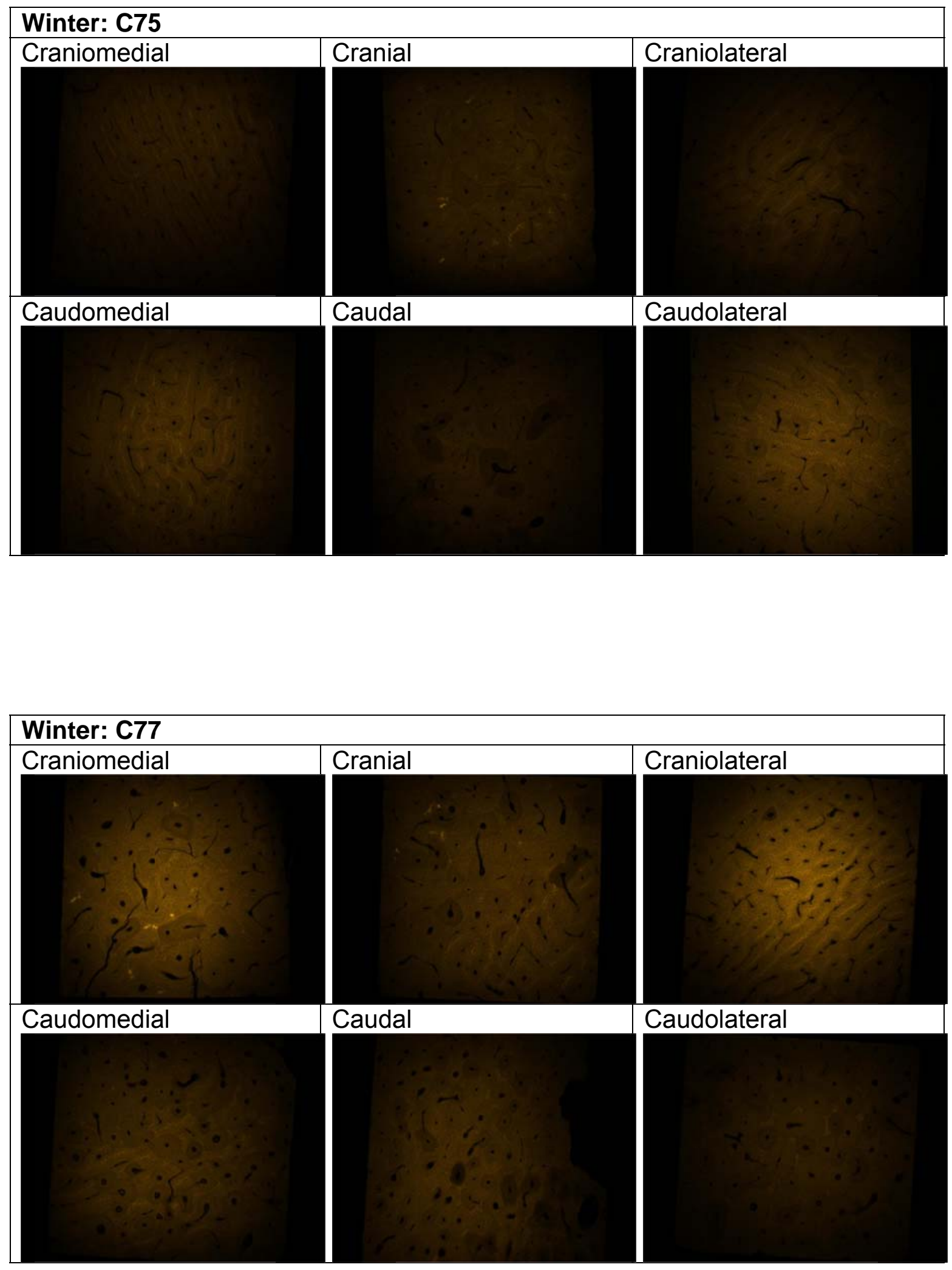


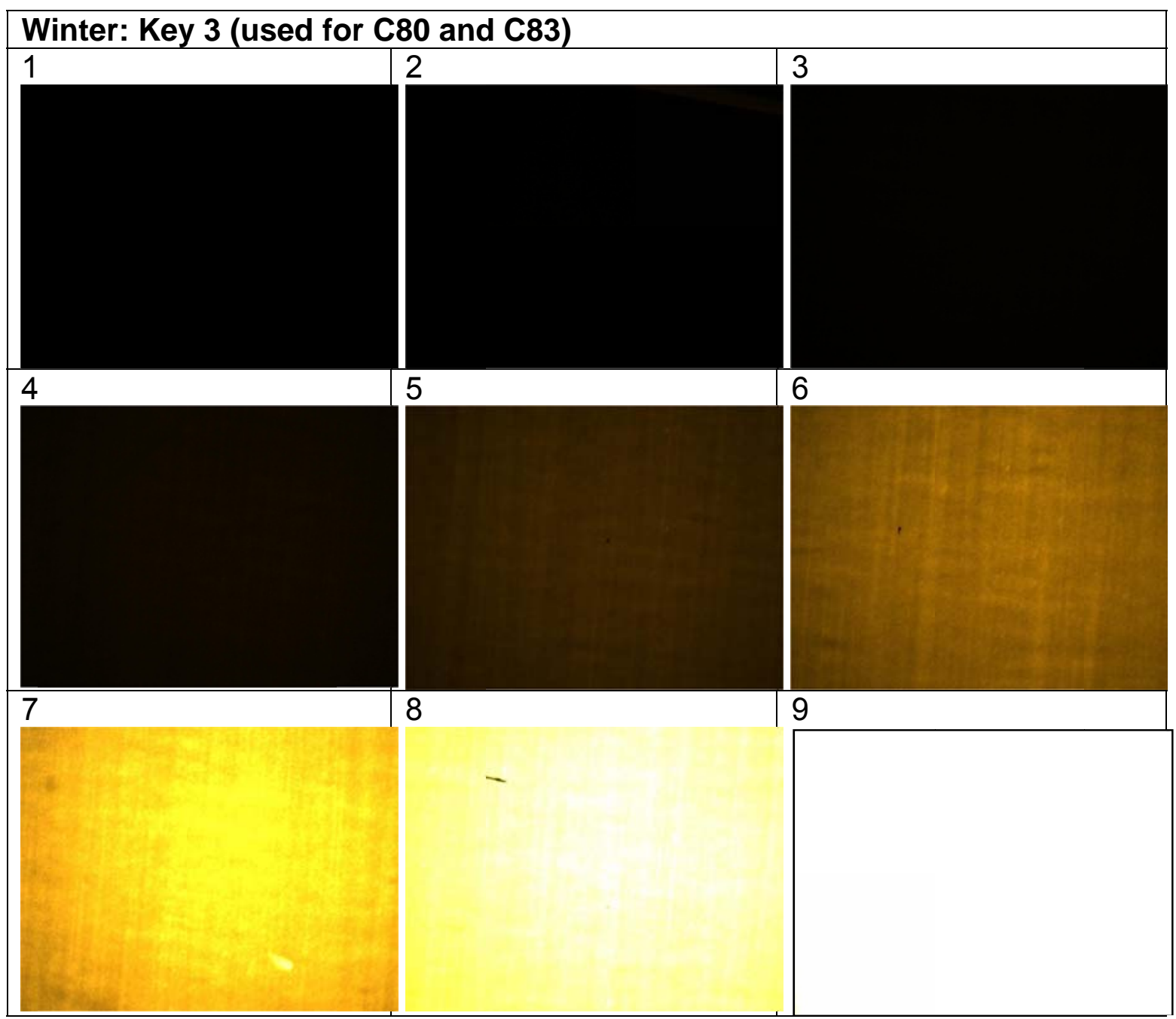



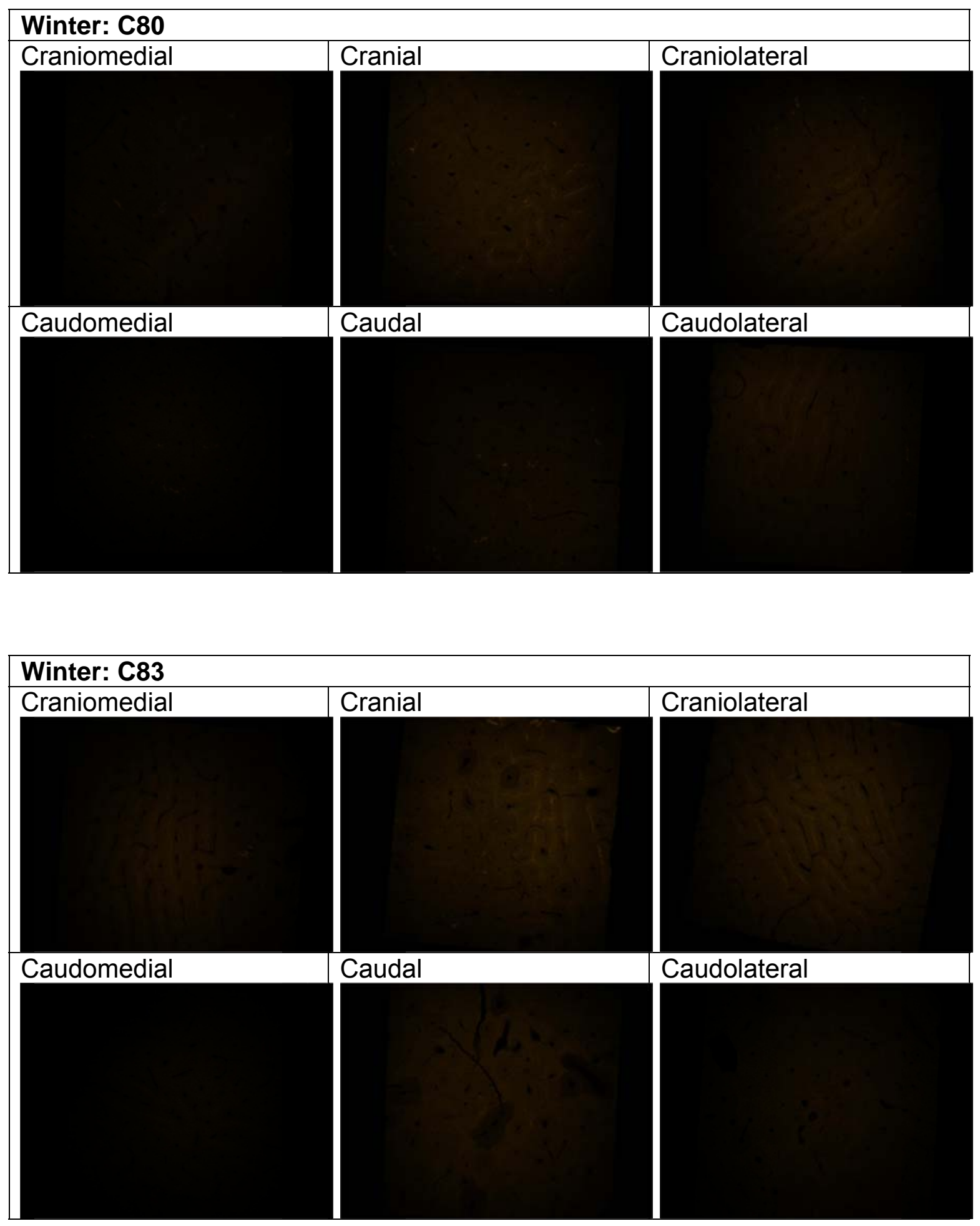


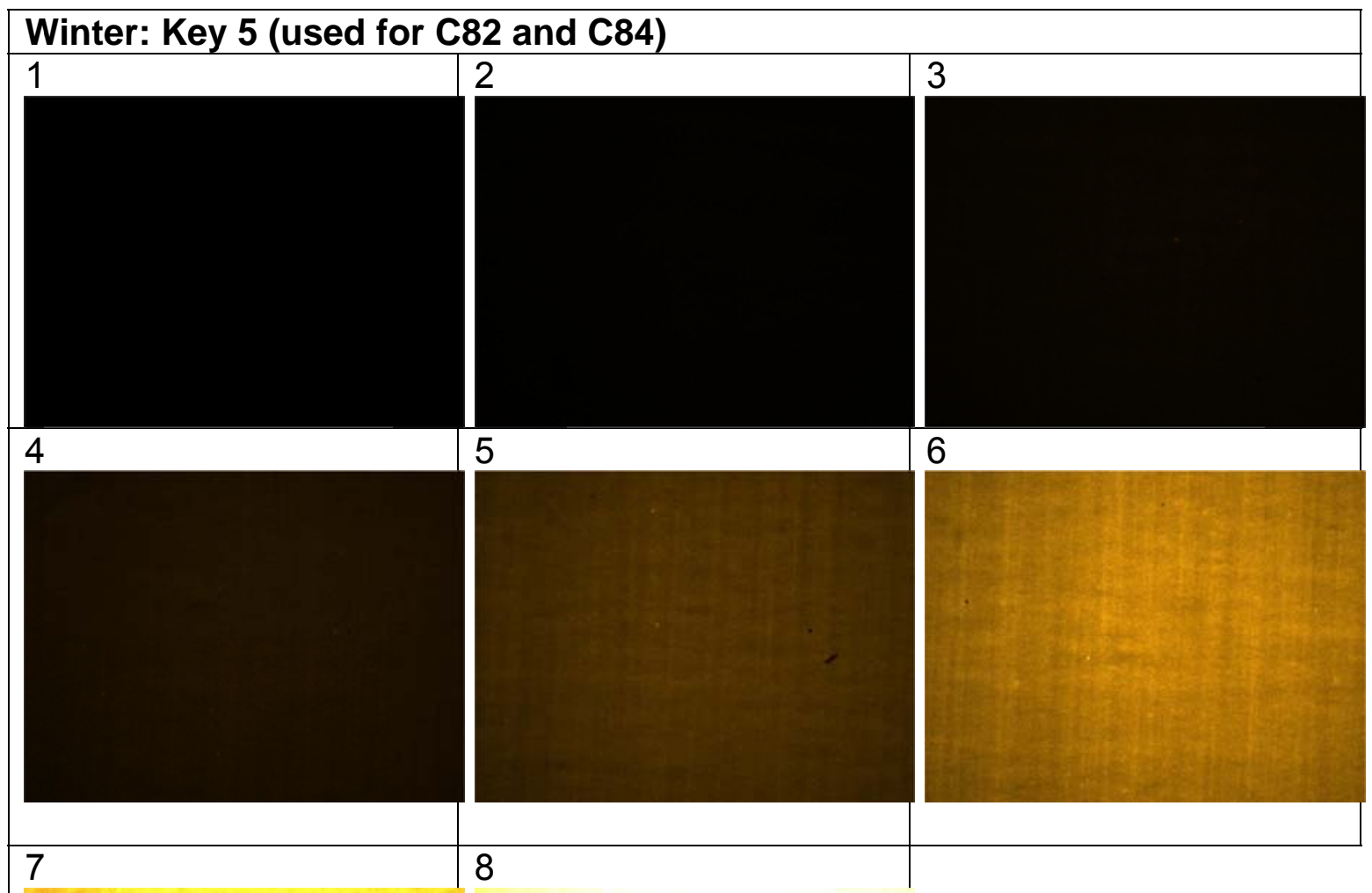



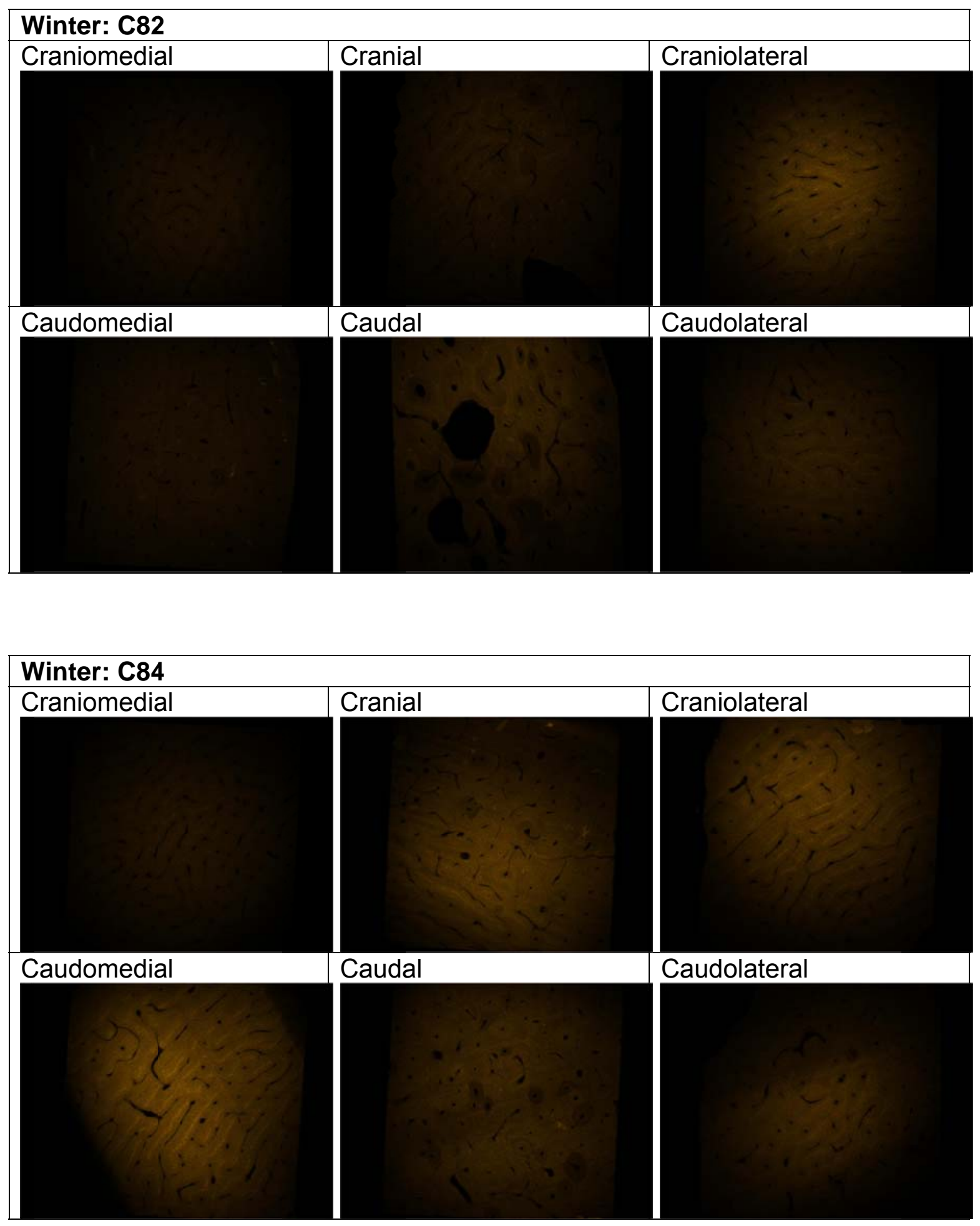

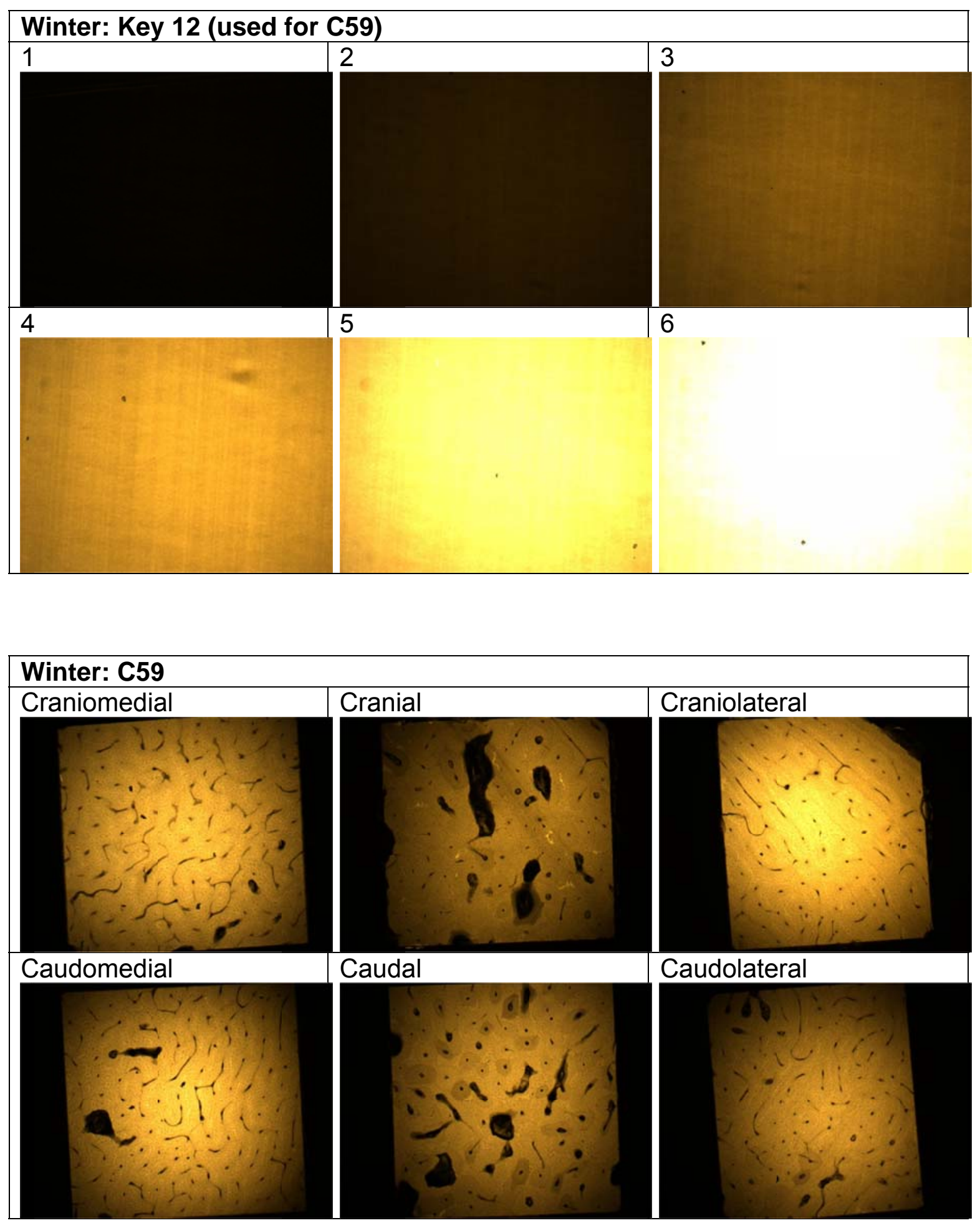

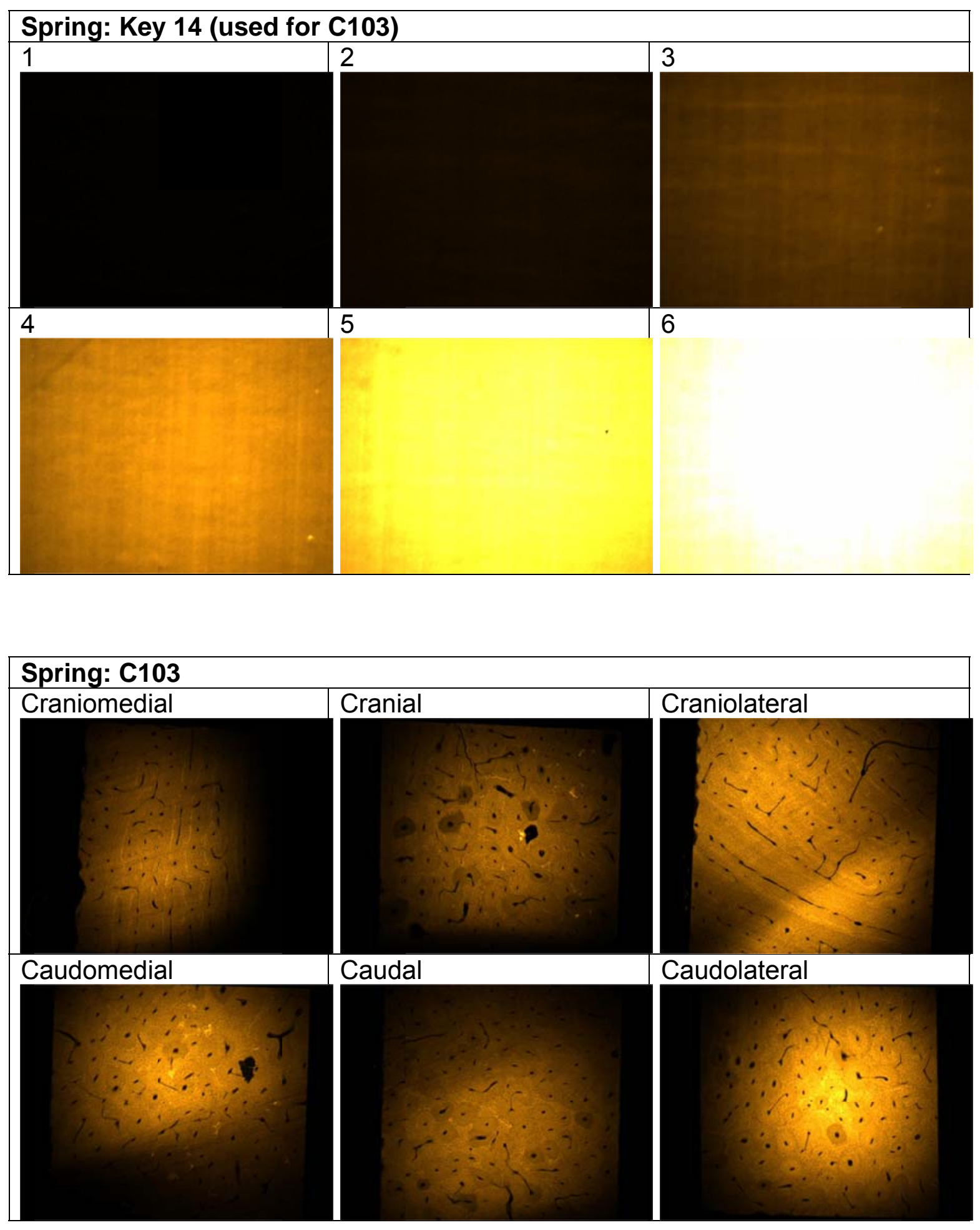


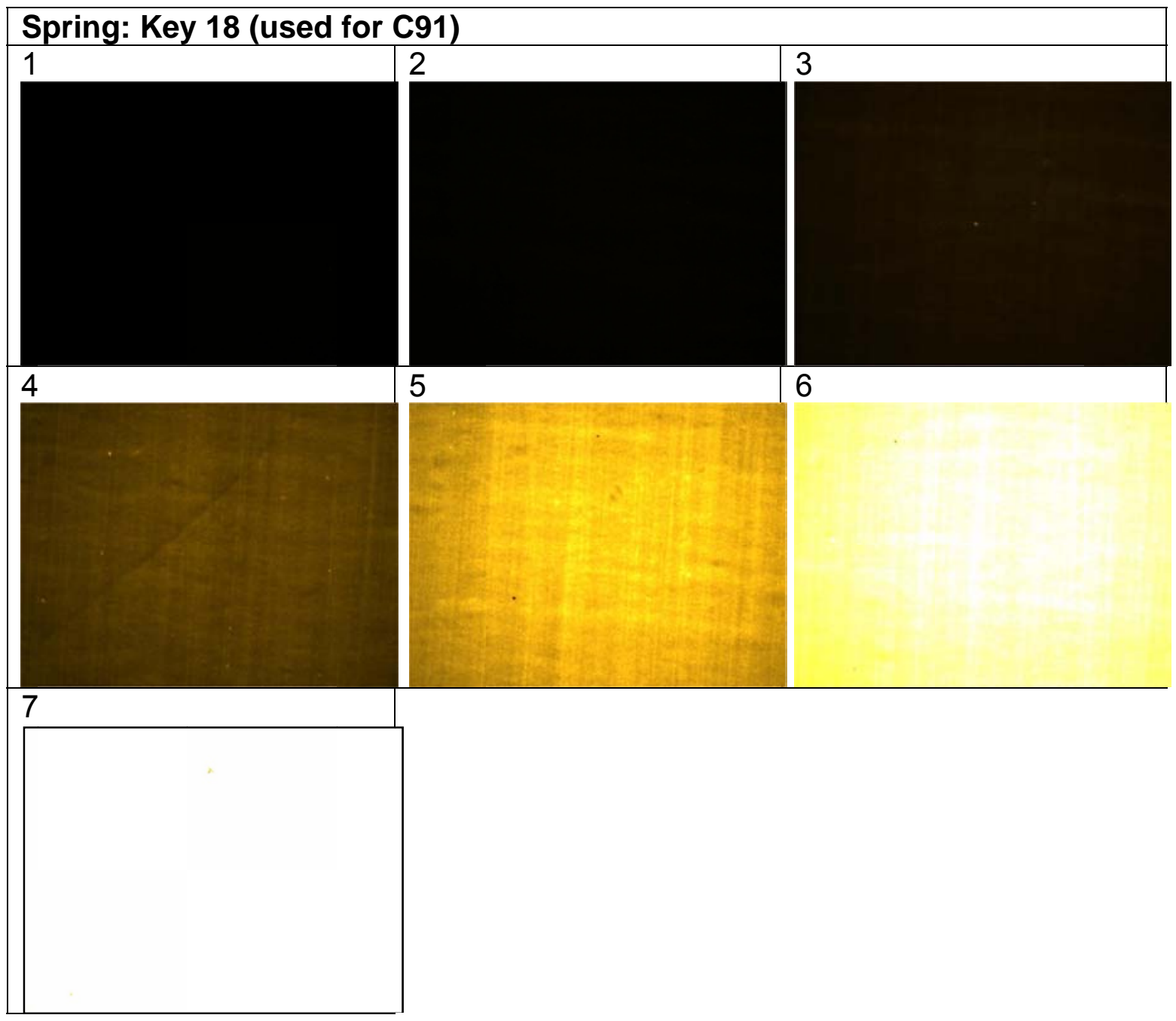



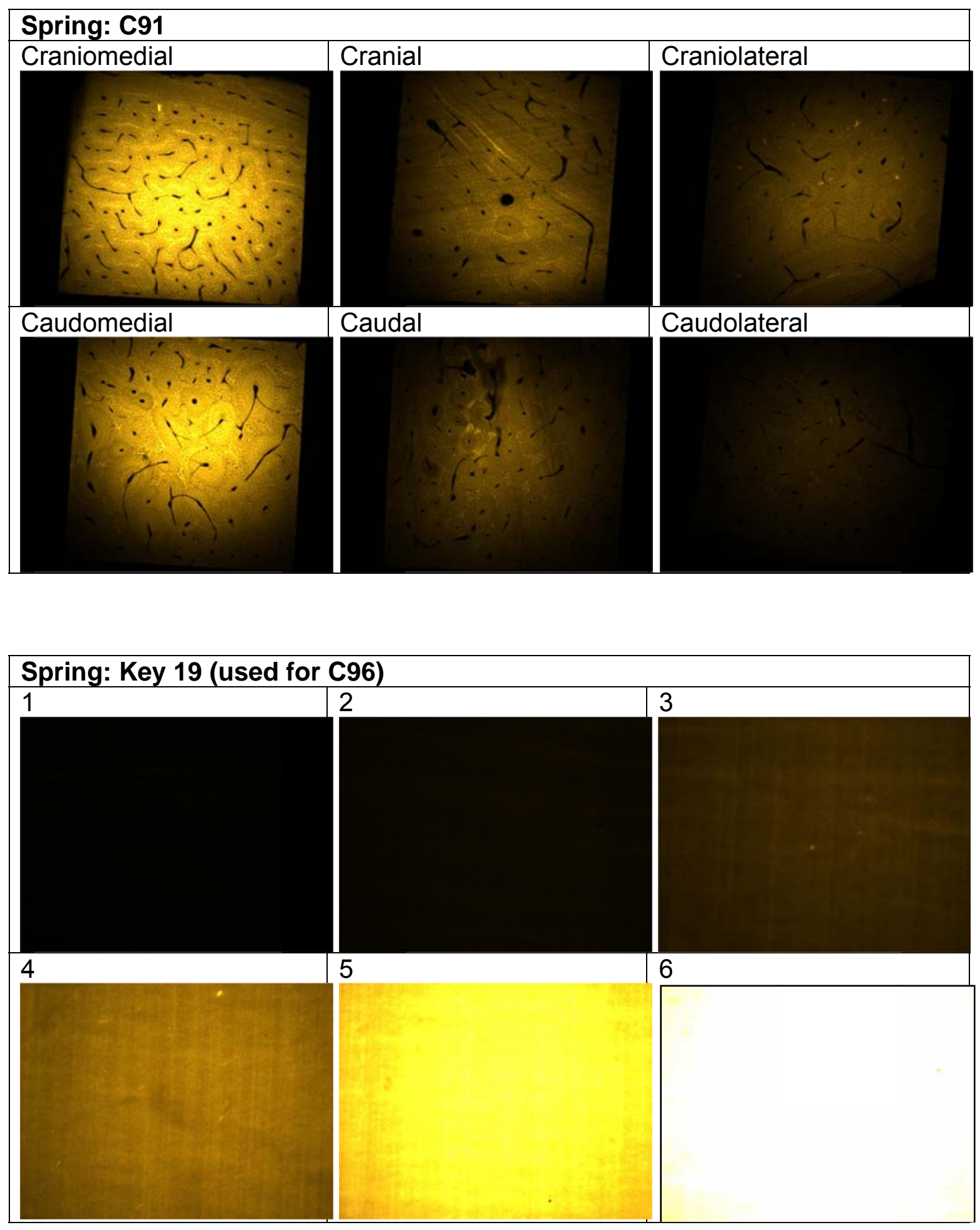

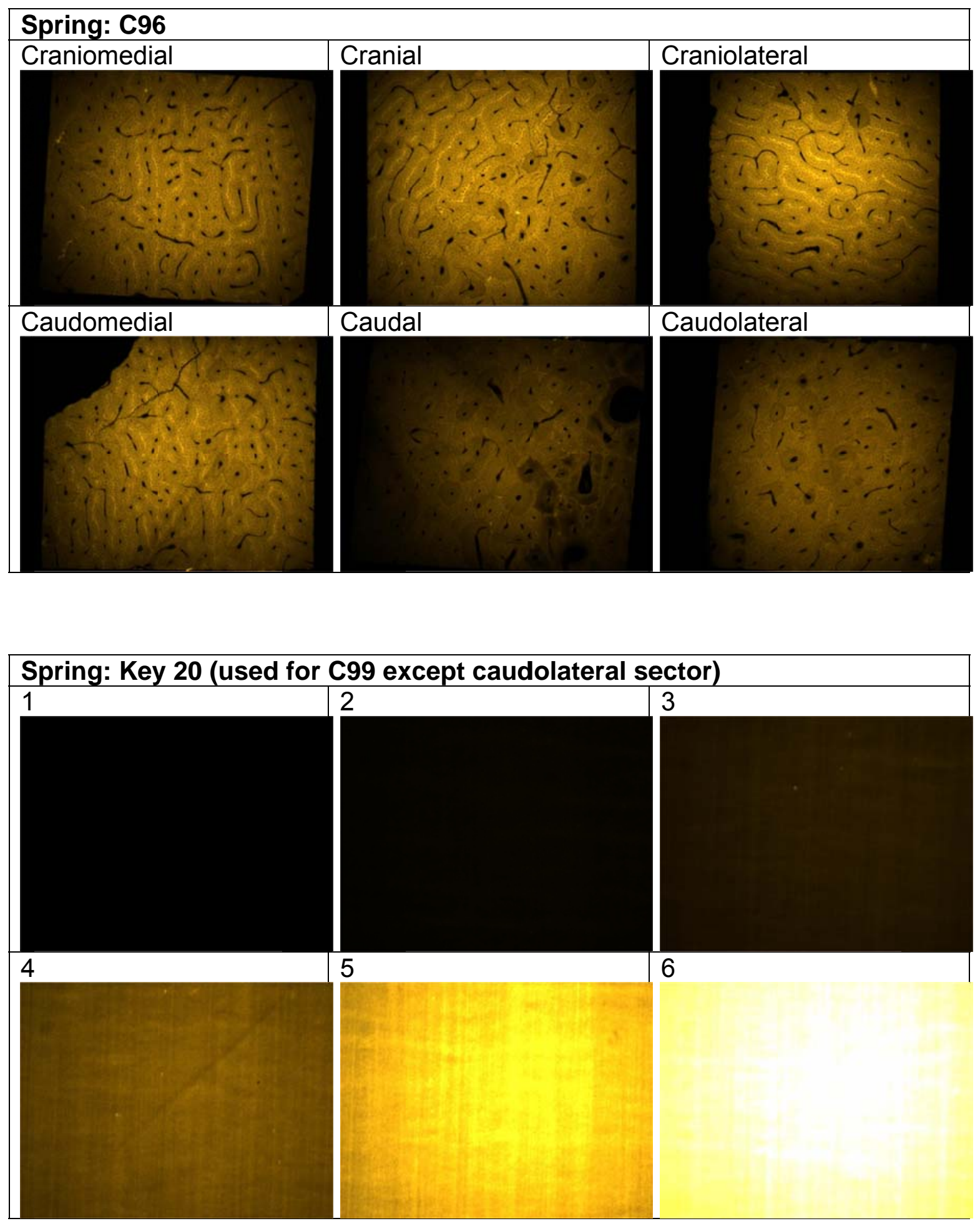


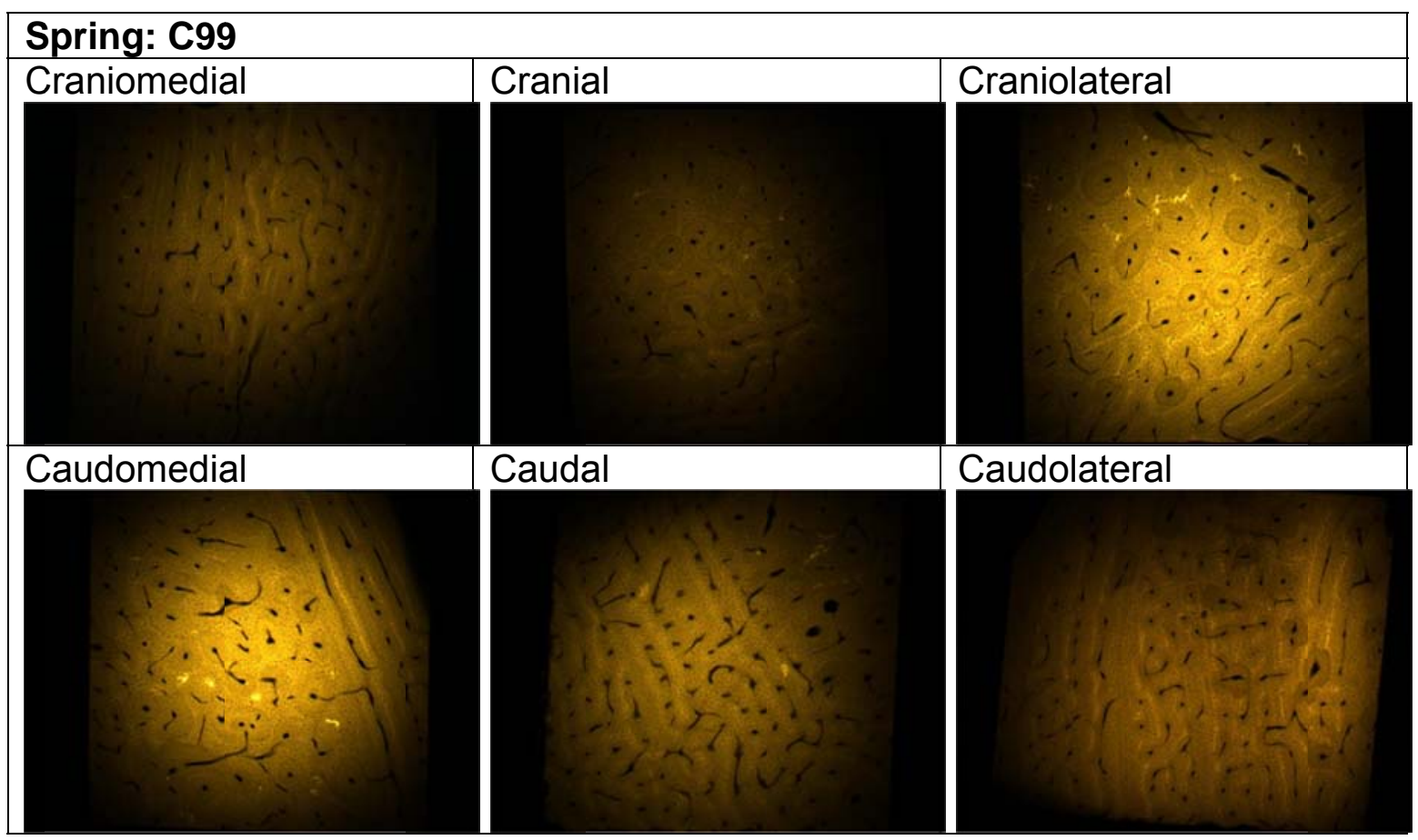




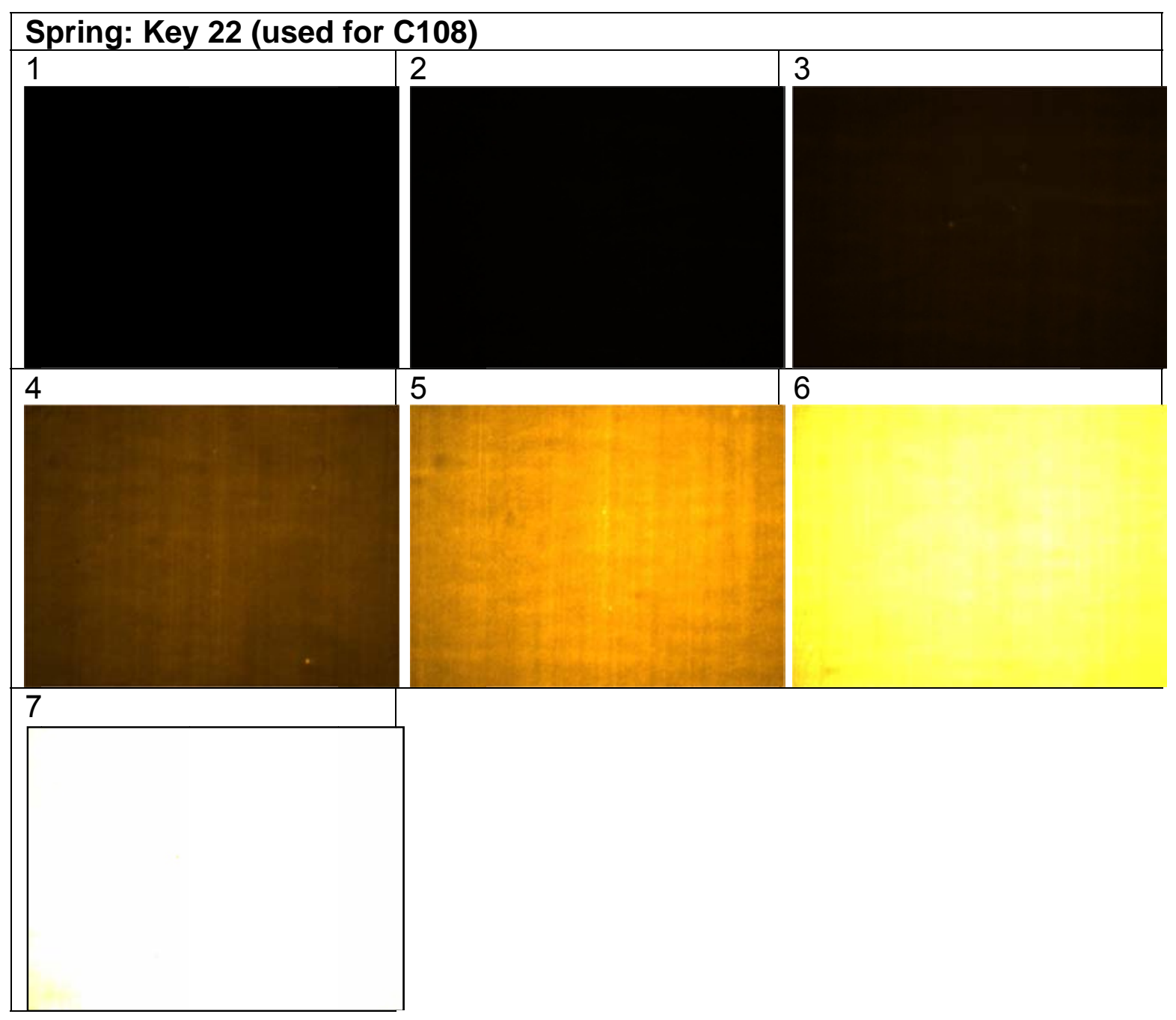



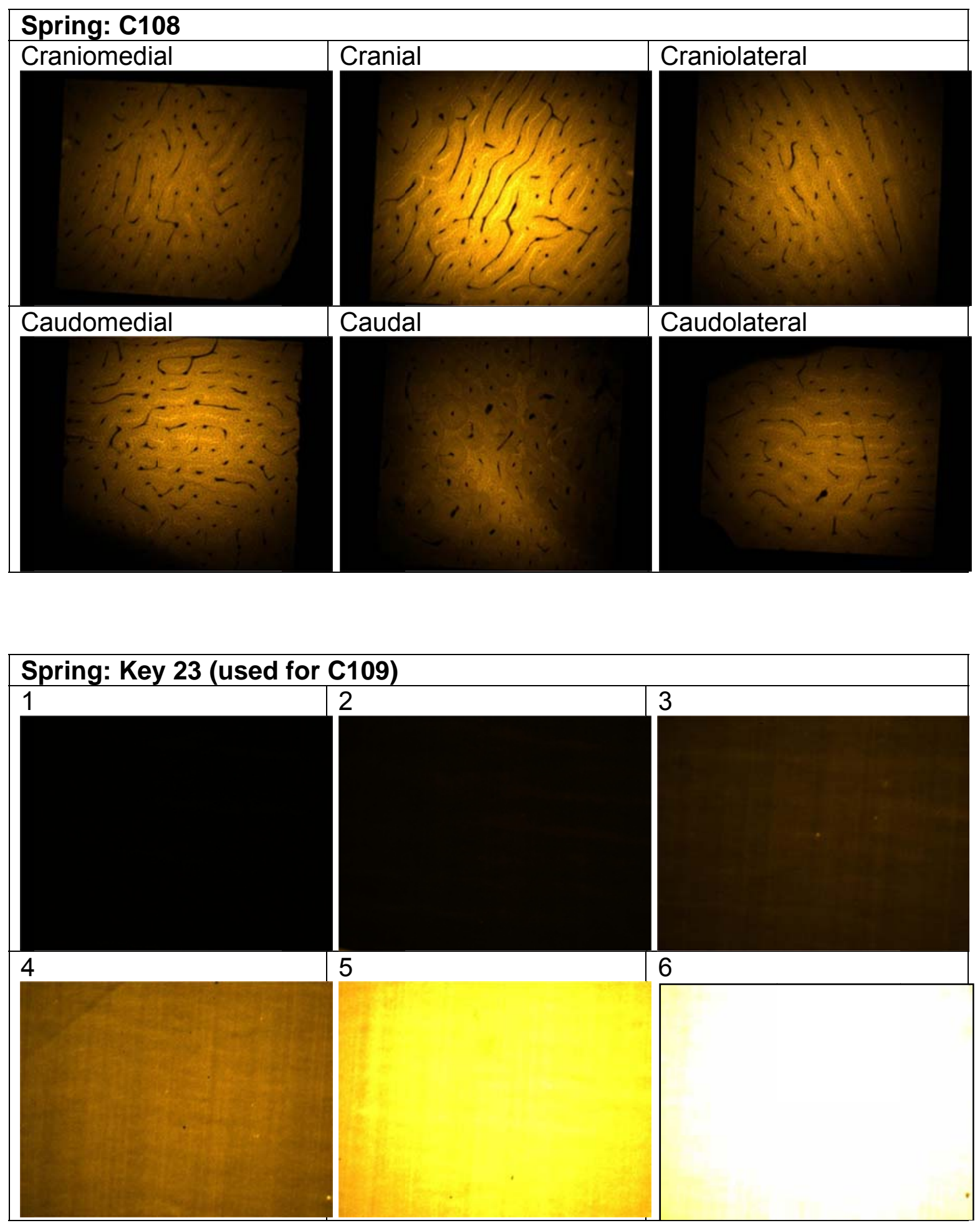


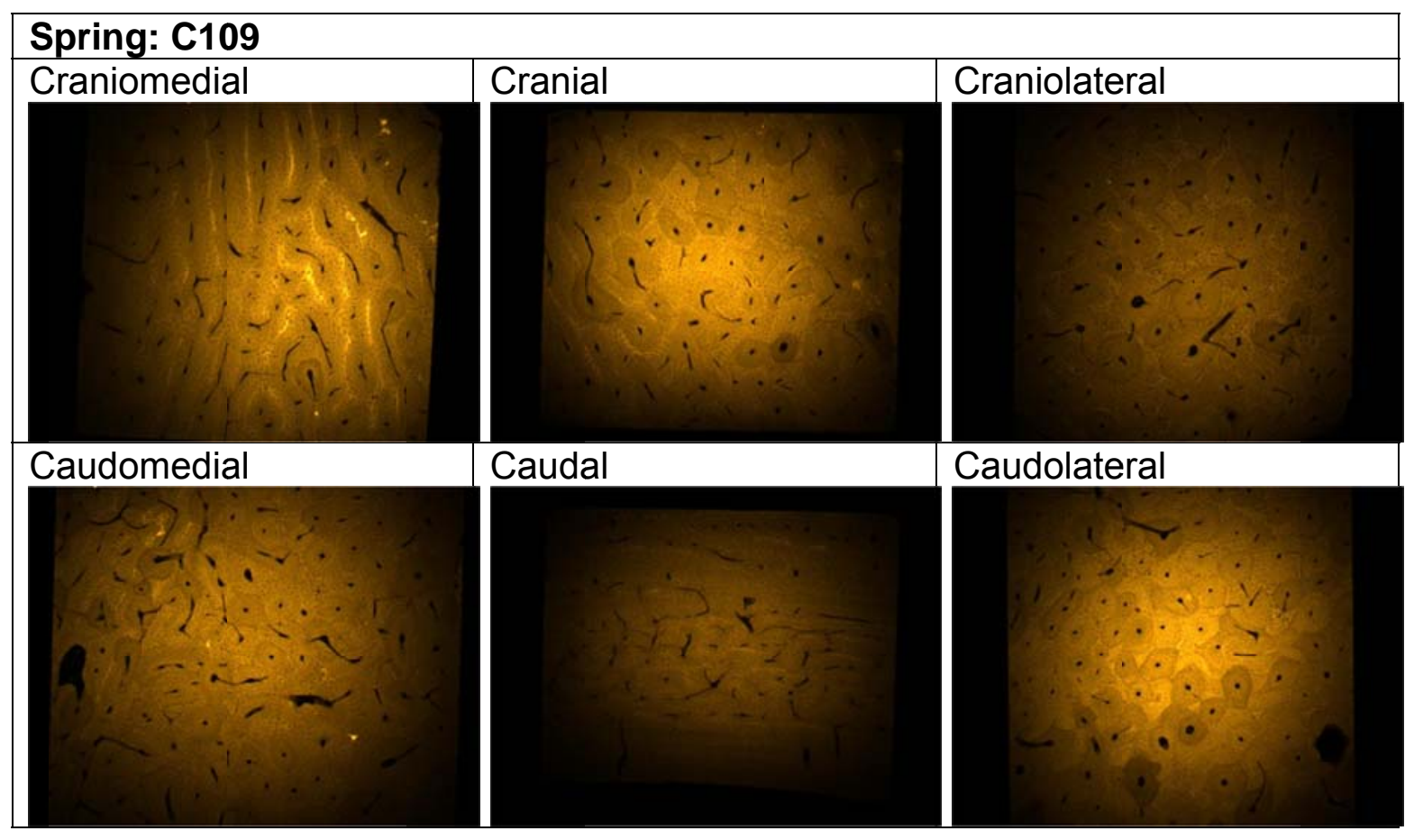




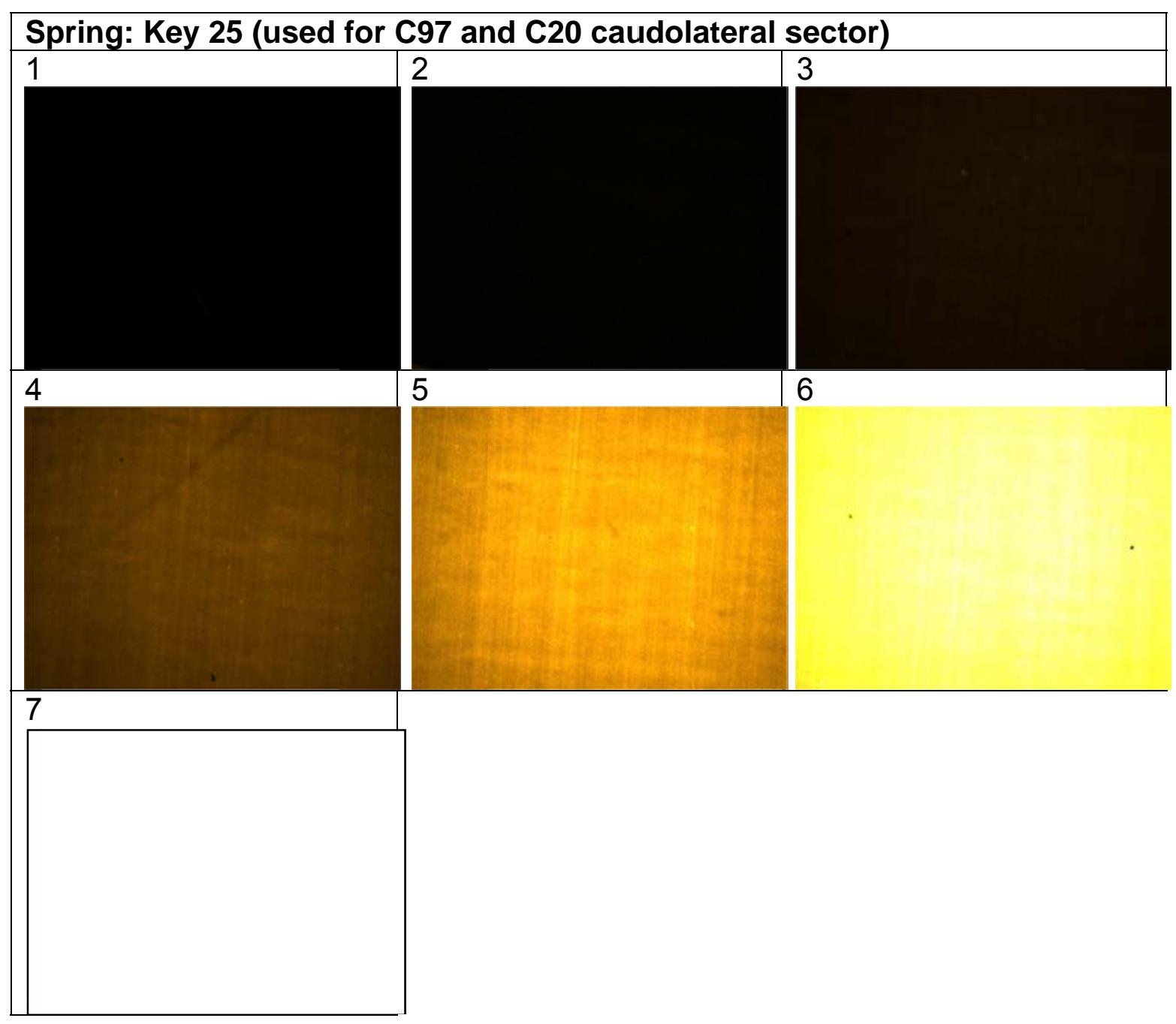



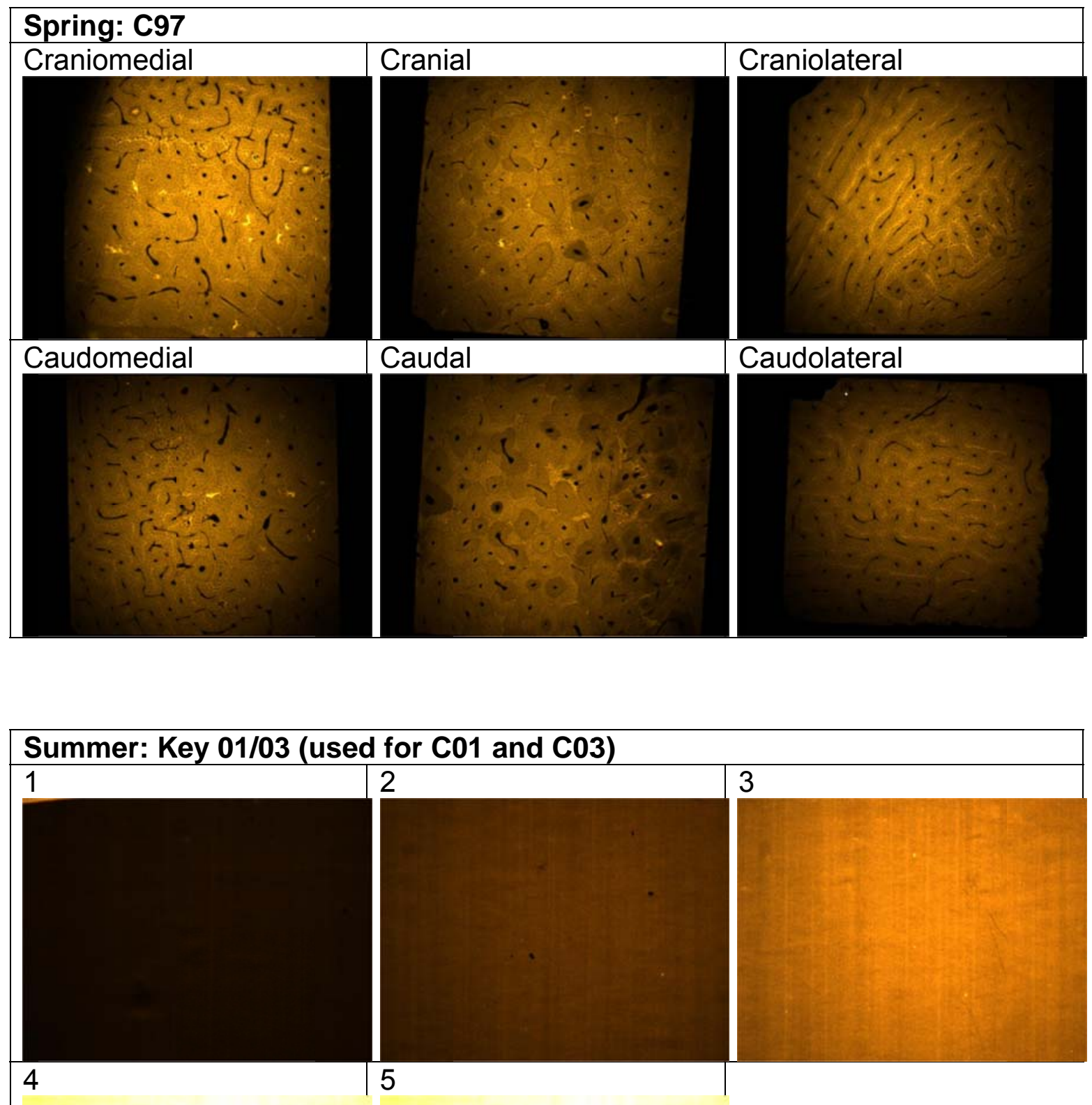

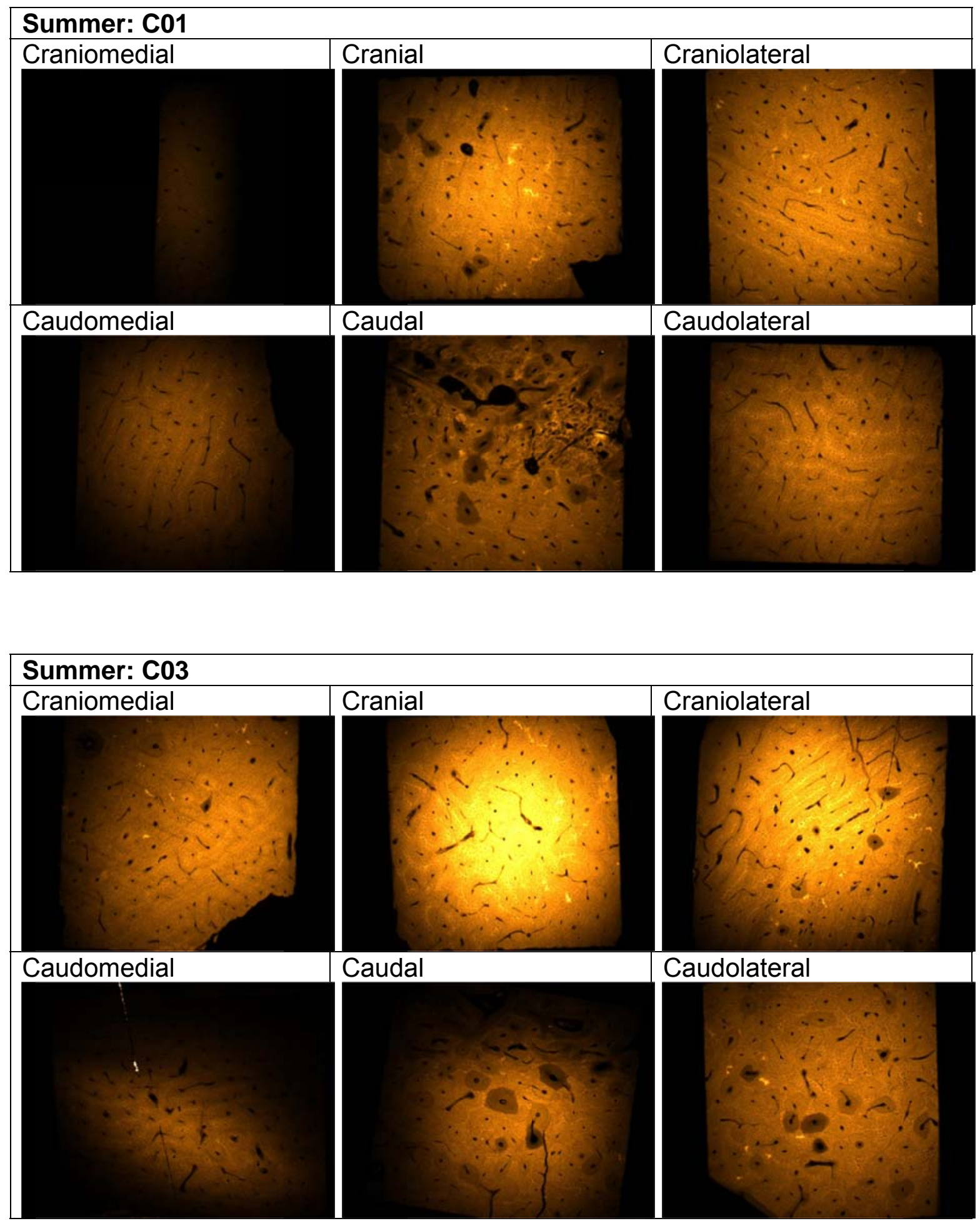


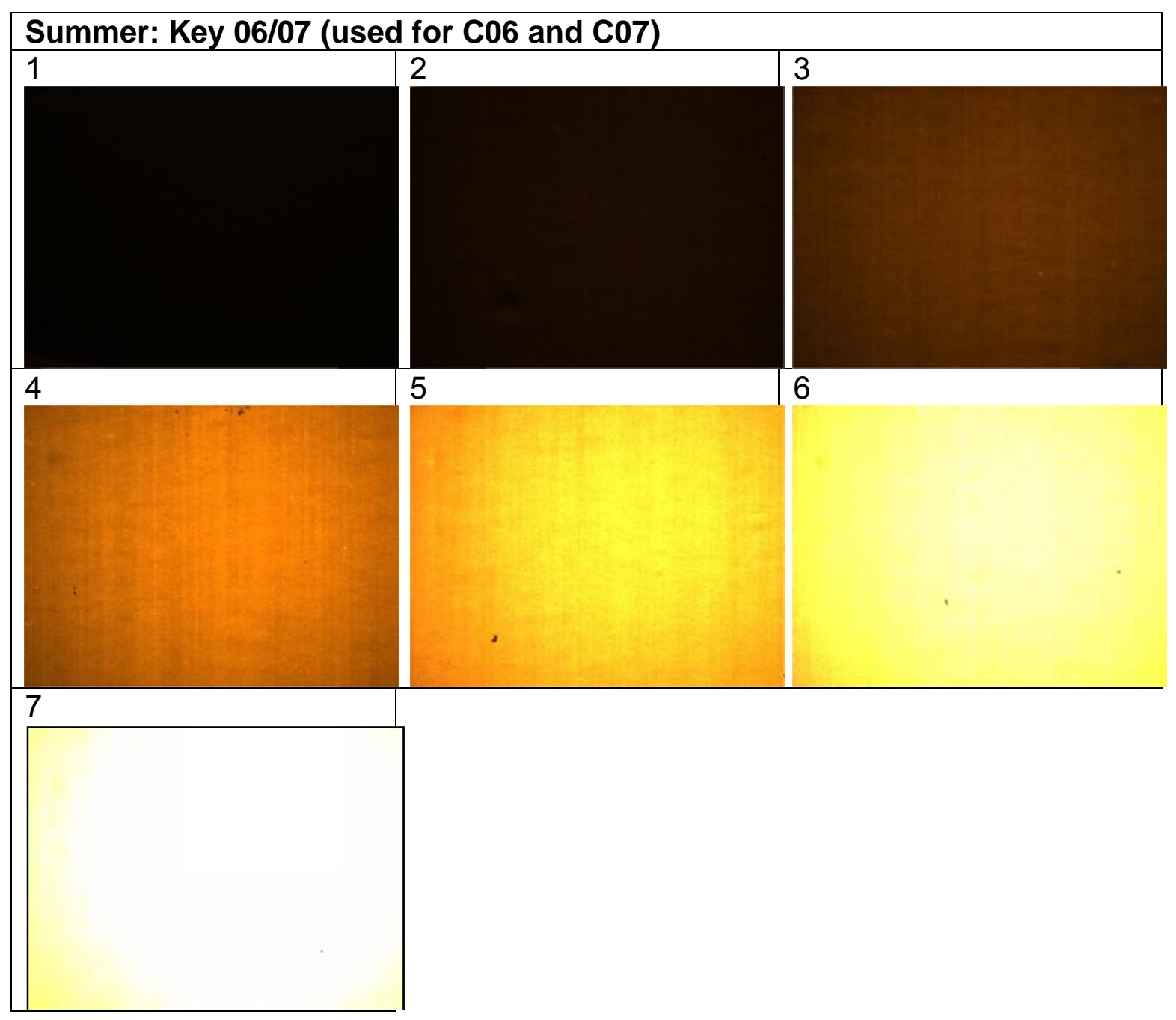



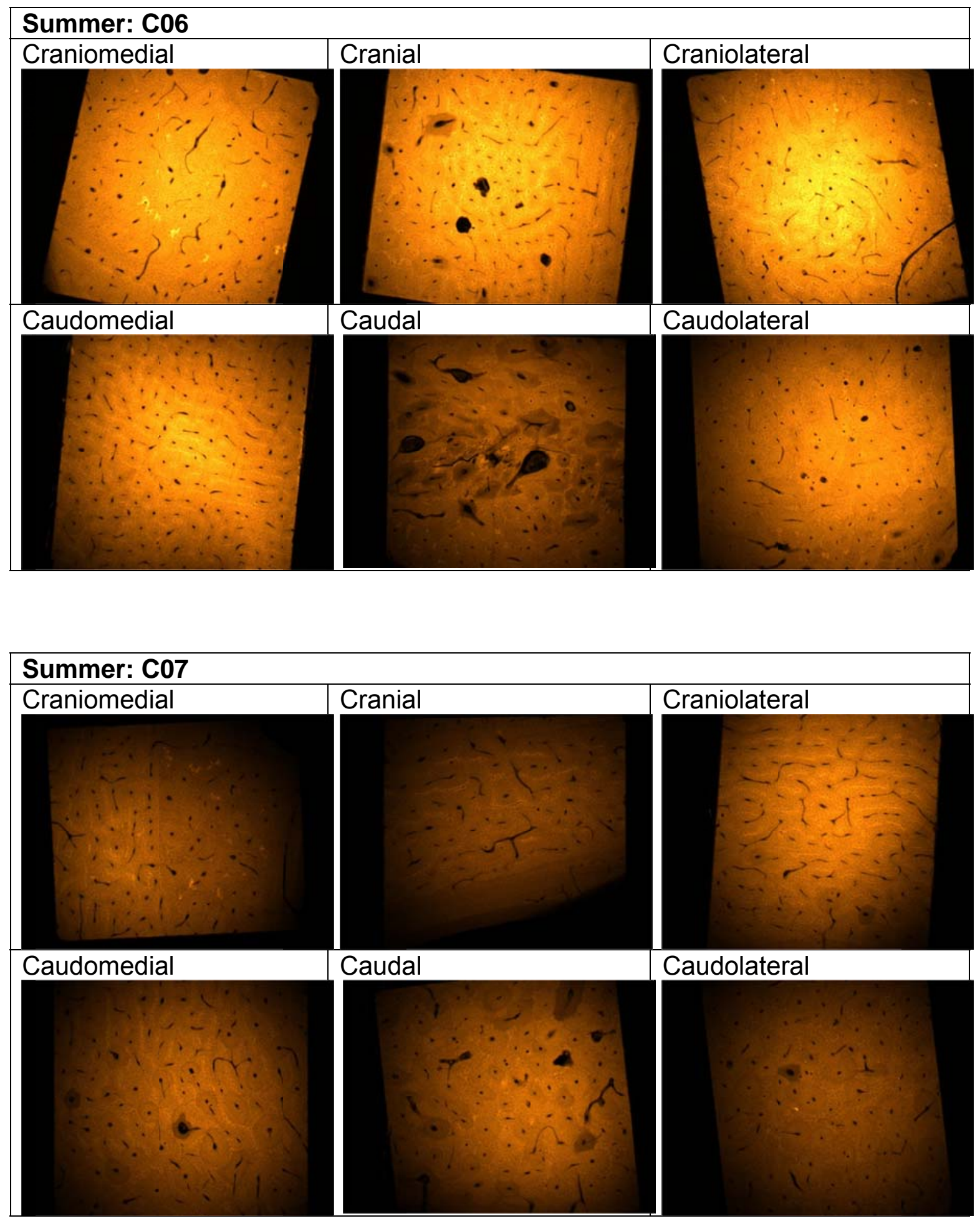

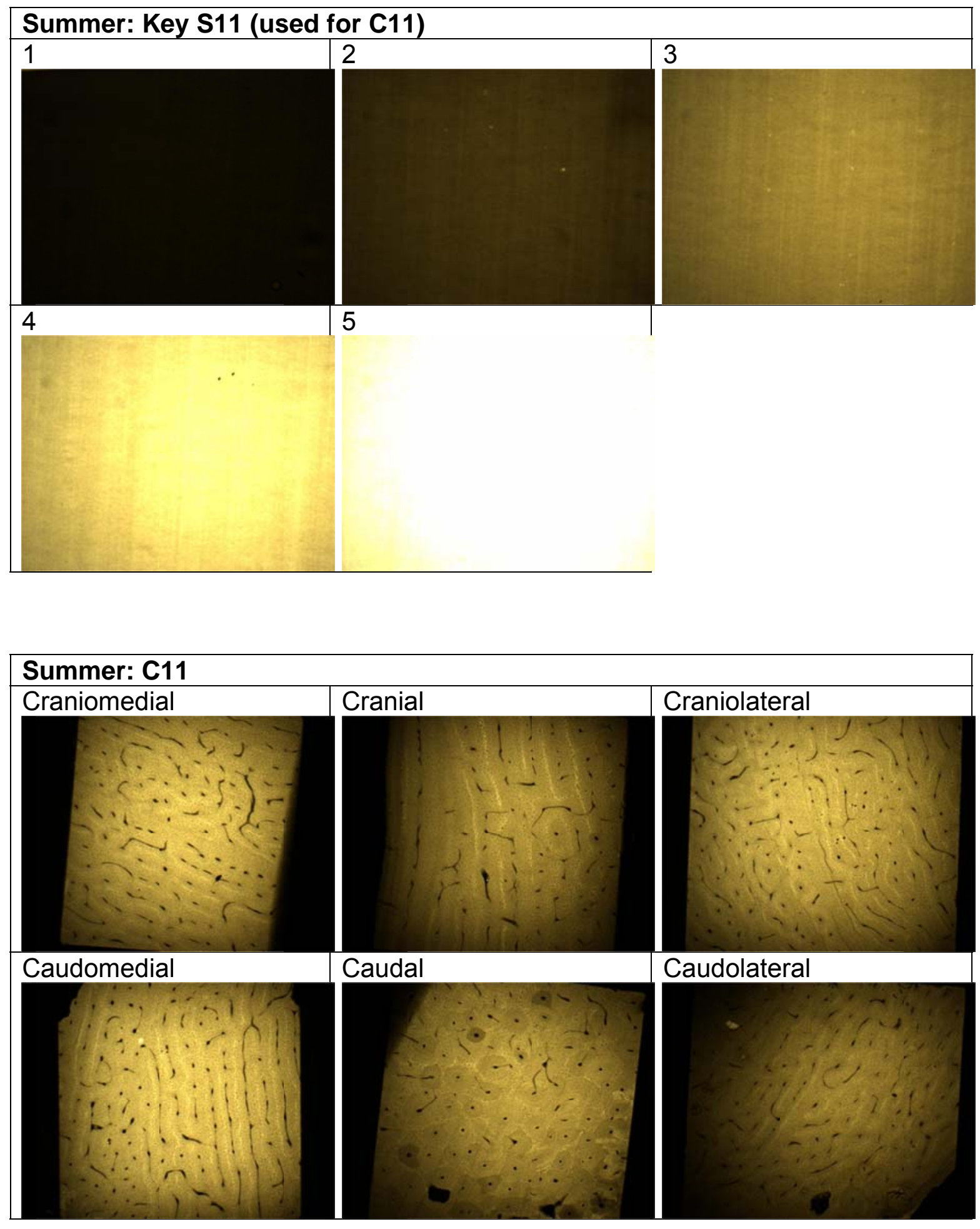

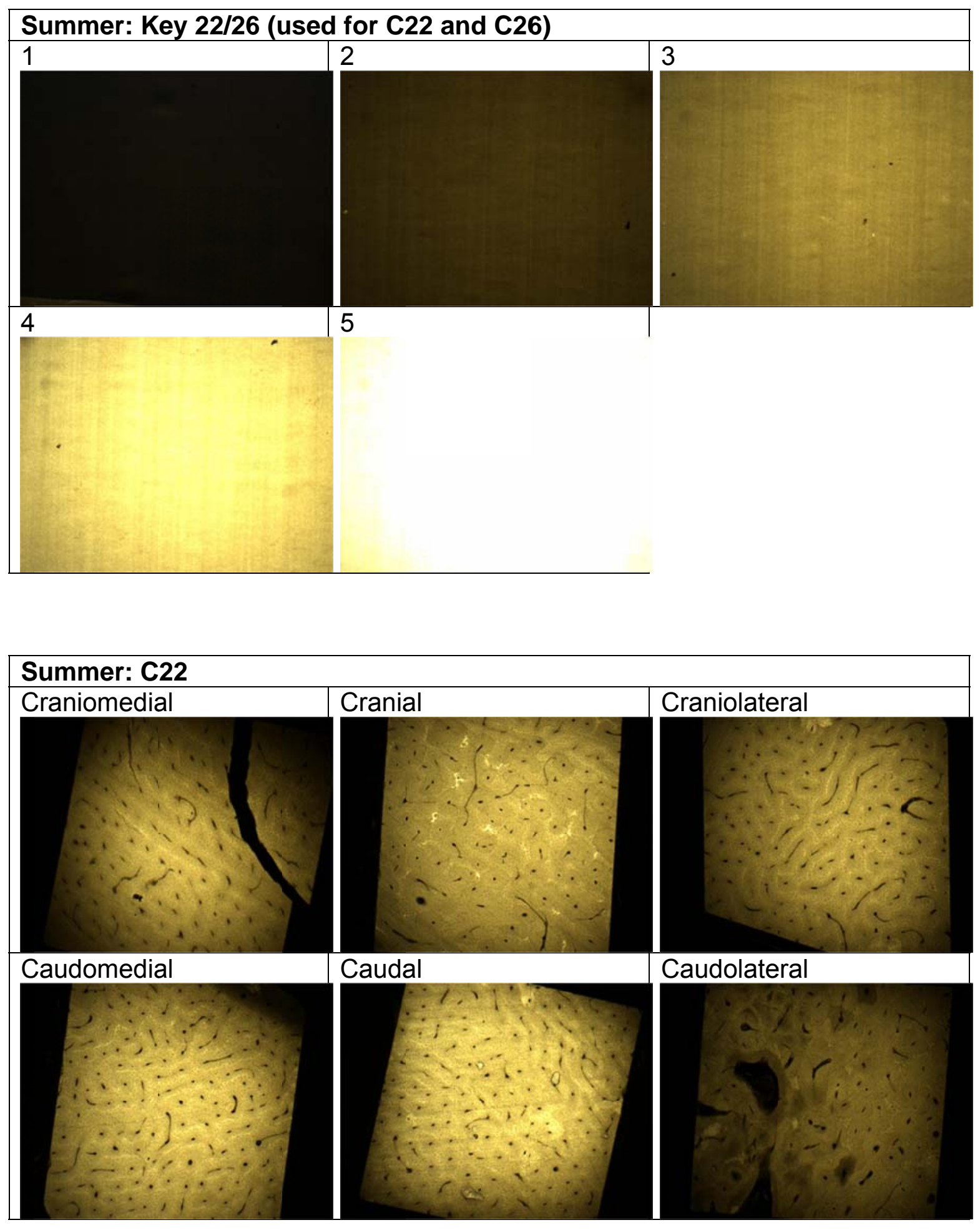


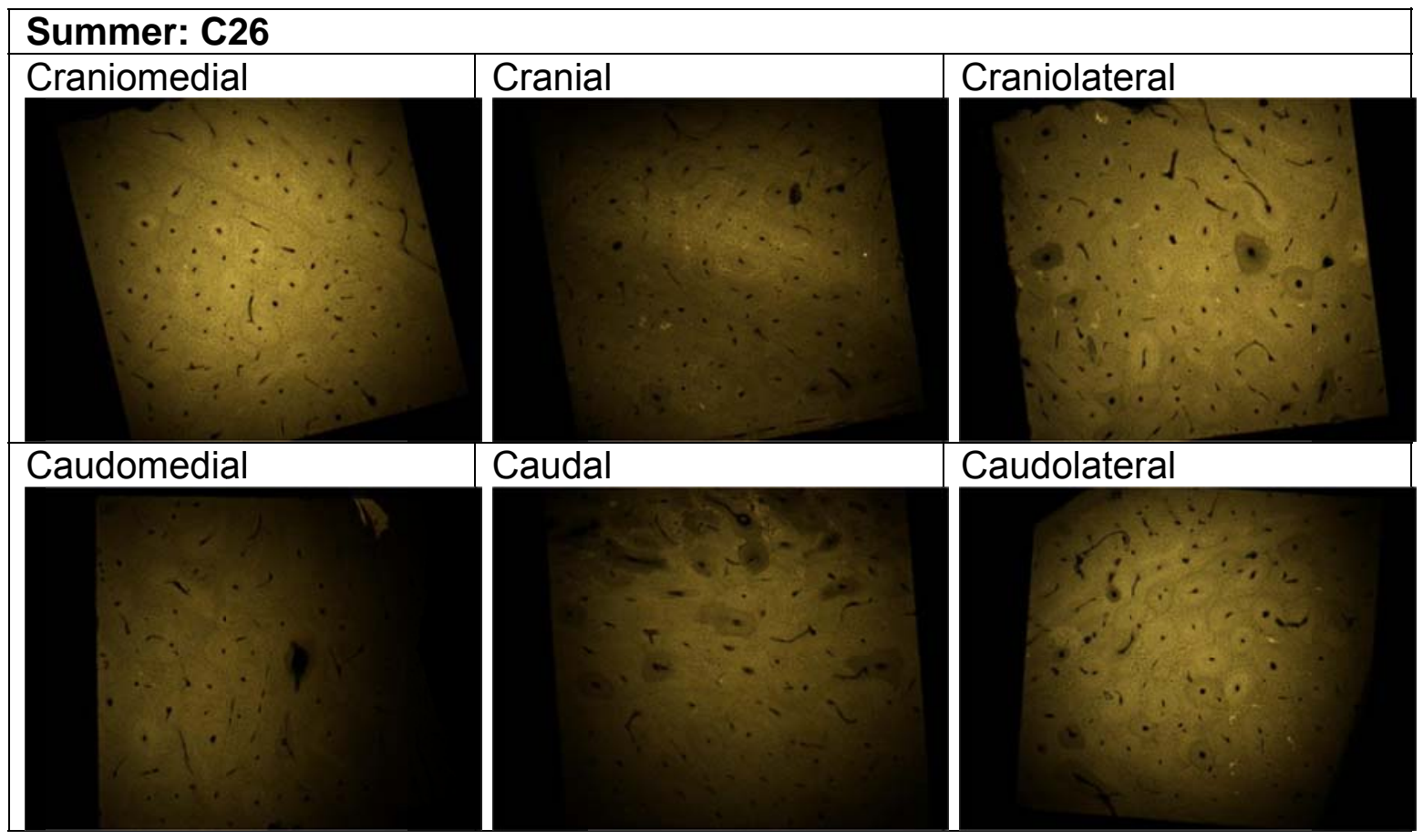

